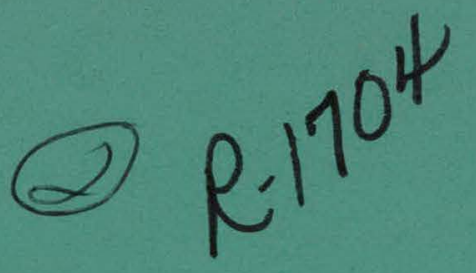

Dn 2263

\title{
Satellite Power Systems (SPS) Space \\ Transportation Cost Analysis and Evaluation
}

November 1980

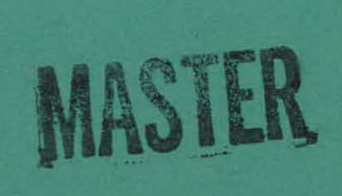

Prepared for:

U.S. Department of Energy

Office of Energy Research

Satellite Power System Project Division

Under Contract No. 31-109-38-5397

DOE/NASA

Satellite Power System

Concept Development

and

Evaluation Program

Evaluation Program 


\section{DISCLAIMER}

This report was prepared as an account of work sponsored by an agency of the United States Government. Neither the United States Government nor any agency Thereof, nor any of their employees, makes any warranty, express or implied, or assumes any legal liability or responsibility for the accuracy, completeness, or usefulness of any information, apparatus, product, or process disclosed, or represents that its use would not infringe privately owned rights. Reference herein to any specific commercial product, process, or service by trade name, trademark, manufacturer, or otherwise does not necessarily constitute or imply its endorsement, recommendation, or favoring by the United States Government or any agency thereof. The views and opinions of authors expressed herein do not necessarily state or reflect those of the United States Government or any agency thereof. 


\section{DISCLAIMER}

Portions of this document may be illegible in electronic image products. Images are produced from the best available original document. 


\section{NOTICE}

This report was prepared as an account of work sponsored by the United States Government. Neither the United States nor the United States Department of Energy, nor any of their employees, makes any warranty, express or implied, or assumes any legal liability or responsibility for the accuracy, completeness, or usefulness of any information, apparatus, product, or process disclosed, or represents that its use would not infringe privately owned rights. Reference herein to any specific commercial product, process, or service by trade name, mark, manufacturer, or otherwise, does not necessarily constitute or imply its endorsement, recommendation, or favoring by the United States Government or any agency thereof. The views and opinions of authors expressed herein do not necessarily state or reflect those of the United States Government or any agency thereof.

Avallable from:

National Technical Information Service (NTIS)

U.S. Department of Commerce

S285 Port Royl Road

Price:

$$
\begin{array}{lr}
\text { Printed Copy: } & \$ 10.00 \\
\text { Microfiche: } & \$ 4.00
\end{array}
$$




\section{Satellite Power Systems (SPS) Space Transportation Cost Analysis and Evaluation}

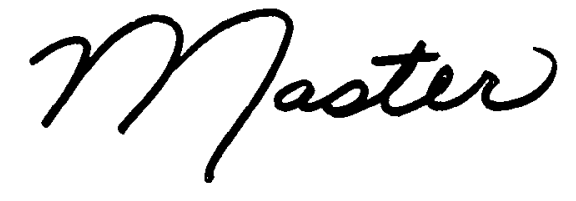

November 1980

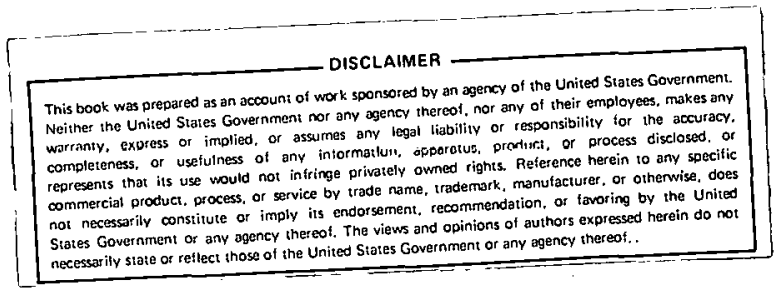

Prepared by:

Battelle Columbus Laboratories

Columbus, Ohio 43201

Under Contract No. 31-109-38-5397

Prepared for:

U.S. Department of Energy

Office of Energy Research

Satellite Power System Project Division

Washington, D.C. 20585

\section{DOE/NASA}

Satellite Power System

Concept Development

and

Evaluation Program 
TABLE OF CONTENTS

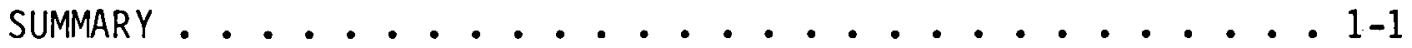

1.1 Background and Reasons for Study. ............ 1-1

1.2 Objective and Approach.................. 1-2

1.2 .1

1.2 .2

1.2 .3

1.2 .4

1.3

Theoretical and Historical Review. ........ 1-3

Performance Review ............. 1-7

Review of Overall Transportation Assumptions ..... 1-8

Review of Individual Cost Assumptions. . . . . . . 1-9

SPS Transportation Costs Review--Conclusions

and Recommendations ................. 1-10

1.3 .1

1.3 .2

1.3 .3

1.3 .4

1.3 .5

1.3 .6

1.3 .7

1.3 .8

General Conclusions about SPS Space Transportation Plans . 1-10 Conclusions About the Reference System ....... 1-12 Heavy Lift Launch Vehicle Conclusions. ....... . 1-14 Electric Orbit Transfer Vehicle Conclusions. . . . . . 1-17 Personnel Launch Vehicle Conclusions ......... . 1-22 Personnel Orbit Transfer Vehicle Conclusions ...... 1-23 Intra-Orbital Transfer Vehicle Conclusions . . . . . 1-24 Program and Vehicle Costs and Uncertainty--

Summary and Recommendations. ......... 1-25

2.0 REVIEW OF SPS TRANSPORT REQUIREMENTS, COSTING

METHODOLOGY, AND RESULTS. ............ 2-1

2.1 SPS Requirement and their Translation into Transportation

Requirements.................... 2-1

2.2 SPS Designs to Meet Transport Requirements. . . . . . 2-9

2.3 Costing Methodology Used in These Estimates, Its

. Appropriateness and Limitations .......... 2-18

2.4 Historical Experience . . . . . . . . . . 2-27

2.5 Conclustons and Recommendations ................... 2-34

3.0 REVIEW OF VEHICLE CONCEPTS AND PERFORMANCE. ........ 3-1

3.1 Heavy Lift Launch Vehicle Concepts and Cost Impacts . . . . 3-1

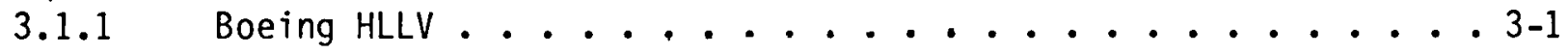

3.1 .2 , Rockwell HLLV ...................... 3-7 
3.2 Personnel Launch Vehicle (PLV) Concepts and Cost Impacts. . . : 3-11

3.2.1 PLV Technical Assessment. . . . . . . . . . . . . 3-11

3.3 Cargo Orbit Transfer Vehicle (EOTV) Concepts and Cost Impacts.................... 3-13

3.3.1 Boeing EOTV . . . . . . . . . . . . . 3-13

3.4 Personnel Orbit Transfer Vehicle Concept and Cost Impacts . . 3-18

3.4.1 POTV Weights. . . . . . . . . . . . . 3-18

3.4.2 POTV Level of Technology. . . . . . . . . . . . . . . . . . . . . .

3.4.3 POTV Performance. . . . . . . . . . . . . . . . . . . . . 20

3.5 Utility/Intraorbital Transfer Vehicles. . . . . . . . . 3-20

3.6 Launch, Recovery and Refurbishment Facilities . . . . . . 3-?1

3.7 . Staffing and Production Implications. . . . . . . . . . 3-22

3.8 Fleet Requirements, Production Implications and Space

Construction \& Servicing. ................. 3-24

APPENDIX A: SPS Concept and Current Reference System

Description. . ...............A-1

APPENDIX B: SPS Transportation Cost Estimate........ . B-1

RFFFRENCES. ....................... C-1

\section{LIST OF TABLES}

Table 1.3.1 Reference System Vehicle Cost Estimates. . . . . . . 1-20

Table 1.3.2 SPS Transportation Cost Estimates,

Adjustments and Uncertainties. .......... 1-26

Table 2.1.1 Payload Characteristics (Mass) . . . . . . . . 2-2

Table 2.1.4 Mass and Personnel Transport Plan for

Reference System ... . . . . . . . . 2-8 
Table 2.2.1 Cost Estimates with 85 Percent Learning. . . . . . 2-15 Table 2.4.1 NASA Expenditures by Categories (1959-76). . . . . 2-29

Table 2.4.2 Original Shuttle Estimates . . . . . . . 2-30 Table 3.1.2 Engine Out Performance Penalty (Boeing HLLV) . . . . 3-7

Table 3.1.4 Engine Out Performance Penalty (Rockwell HLLV) . . . 3-11 Table 3.4.2' POTV Mass Fraction Comparison with LOX/Liquid Hydrogen Stages................. 3-19

\section{LIST OF FIGURES}

Figure 2.1.2 SPS GEO Construction Concept ............ 2-3

Figure 2.1.3 Alternative SPS Program Scenarios. ........ 2-5

Figure 2.3.1 Hypothetical Cost Estimating Relationships

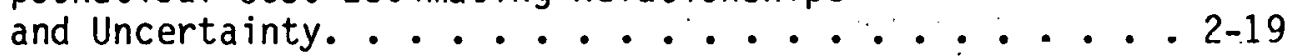

Figure 2.3.2 Learning Curves. . . . . . . . . . 2-24

Figure 2.4.3 Delta Launch Vehicle Growth. . . . . . . . . . 2-32

Figure 3.1.1 Boeing HLLV Drawing and Inert Mass Statement . . . . 3-2

Figure 3.1.3 Rockwell HLLV Drawing and Mass Statement ...... 3-8

Figure 3.2.1 PLV Drawing and Inert Mass Statement . . . . . . 3-12

Figure 3.3.1 EOTV Drawing and Mass Statement . . . . . . . . 3-14

Figure 3.4.1 POTV Drawing and Mass Statement. . . . . . . . . 3-18 


\subsection{SUMMARY}

\subsection{Background and Reasons for Study}

Background

The Satellite Power System (SPS) was originally proposed by Peter Glaser in 1968 and has been under increasingly intensive study by the National Aeronautics and Space Administration (NASA) since 1971 and by the Department of Energy (DOE) and its predecessor since 1976. The original design concepts have been largely preserved in the current Reference System(1) while the understanding of requirements and characteristics has increased significantly. Because of the promise of providing base-load power from the sun, and without major continuing fossil fuel needs, the SPS concept is being actively investigated to determine its technical, economic, environmental, and social requirements and their impacts to determine if commitment of substantial resources should be recommended.

One of the criteria which will be used to judge the SPS is its costs and certainty of those costs in relation to other methods of baseload power generation.

This study concentrates on the certainty and accuracy of the costs in one major sub-area of the SPS: those of the space transportation system necessarily associated with lifting the Space Power System components and assembly equipment to Low Earth Orbit (LEO) and to its ultimate location in Geosynchronous Equatorial Orbit (GEO). A description of the Reference SPS Concept and its associated transport requirements are located in Appendix $A$. The costs of these systems, their current status and level of certainty and their comparison with likely future energy alternatives have accordingly been planned as part of the Concept Development and Evaluation Program undertaken jointly by DOE and NASA. Through two aerospace contractors, Boeing and Rockwell, the concepts proposed by Glaser and expanded by others were investigated and reduced to specific design and implementation proposals. The engineering investigation for those designs enabled a variety of technology needs and environmental interactions or effects to be specified in sufficient 
detail to permit approximate descriptions of the progress needed in all areas to implement the SPS concept. These studies also permitted specification of the approximate costs associated with each major subsystem of the SPS to the extent that major cost drivers could be identified. While major cost concerns exist in all areas, the two major cost drivers identified are the solar cell production cost and the recurring cost of space transportation. This study reviews all space transportation costs to determine their accuracy and certainty.

The reason for this study is to provide an overview of the costs in one of the major SPS subsystems, as part of a series of similar studies to determine whether there have been any omissions in costs categories, whether reasonable procedures have been followed, and to estimate the uncertainties in the costs as given in the various estimates from the design contractors and assessments from NASA.

These estimates have been found, in general, to be reasonably based on assumptions made by the design contractors and NASA/Johnson Space Center. However, several of these are subject to challenge. Accordingly, cost uncertainties are investigated in the form of sensitivity analyses. That is, alternative cost calculations are made based on varying these assumptions over ranges believed to be reasonable.

\subsection{Objective and Approach}

The objective of this study is to provide a clear picture of SPS space transportation costs at the present time with respect to their accuracy as stated, the reasonableness of the methods used, the assumptions made, and the uncertainty associated with the estimates. The approach used consists of examining space transportation costs from several perspectives--to perform a variety of sensitivity analyses or reviews and examine the findings in terms of internal consistency and external comparison with analogous systems.

These approaches are summarized as a theoretical and historical review including a review of stated and unstated assumptions used to derive the costs, and a performance or technical review. These reviews cover the overall transportation program as well as the individual vehicles proposed. 
The review of overall cost assumptions is the principal means used for estimating the cost uncertainty derived as a conclusion in this report. The cost estimates used as the best current estimate are contained in Reference 2 , and reproduced as Appendix B.

\subsubsection{Theoretical and Historical Review}

Estimating Methods: There are two fundamental approaches in deriving cost estimates for complex systems such as the SPS: The bottom-up method in which every component is priced through catalogs and labor factors and the top-down method in which major systems are priced by comparison to analogous equipment with extrapolation to the requisite capability. The bottom-up method is typically applied to projects where experience in building similar equipment provides a base for selecting appropriate reserves and accordingly has typical uncertainty of \pm 5 percent in comparison with profit goals of 10 to 20 percent. The top-down method is usually applied in aerospace projects where new capabilities are sought and typically has an uncertainty in the range of \pm 10 percent to \pm 15 percent. This stated uncertainty implicitly applies to the next generation of equipment and where capabilities improvements are typically increased by a factor of two or less.

The SPS transport equipment cost estimates are fundamentally derived by analogy to historical cost and technical parameters and then extrapolated to the requirements of the SPS. These requirements are well beyond the range of current operating experience in size of structures, from the standpoint of reusing chemical propulsion launch vehicles, and any major experience with electric propulsion vehicles. The uncertainties in the costs to develop, produce and operate the space transport vehicles are accordingly large.

Historical analogy indicates, but does not prove, that the growth in payload capability needed by the SPS and the level of uncertainty can be significantly reduced by appropriate technology demonstrations. These technology demonstrations will provide the building blocks and engineering information which will permit capability growth. One of these, the Space Shuttle, is nearing early operational capability. Work on photovoltaic cells is being actively pursued by many organizations. Other activities such as 
developments in space structures and electrical propulsion are in early development stages with more activity planned. With anticipated technological progress in these areas over the next decade, the groundwork needed to develop the SPS vehicles should be in place to permit practical design and construction. Otherwise, uncertainty is not reduced and the uncertainty in costs will be at least that of the methodology. The likelihood of having additional expenditures to achieve needed capabilities in the design or development phase of the vehicles would be greatly increased.

Accordingly, the method used to estimate uncertainty in SPS vehicle development and initial production costs is to indicate the type and size if program needed to achieve the recurring cost goals if the initial development proves unsatisfactory in meeting goals of reusability or operating requirements. The existence of demonstrated basic technology at the time of commitment to system development effort is considered a prerequisite to our estimates. This method is chosen over a detailed review of the two aerospace contractors' estimating procedure for several reasons:

(1) The basic equipment costs were derived by two different aerospace contractors (Boeing and Rockwell) from two nominally separate data bases. The agreement between the two estimates is considered good when allowances are made for differences in equipment proposed and for the inherently imprecise results of this methodology.

(2) In the areas of the Electric Orbital Transfer Vehicle (EOTV), structures, engine reusability, reusable reentry thermal protection systems and refurbishment/maintenance of vehicles (both on the ground and in space), no operating experience exysts. Manly of the applicable space Shuttle estimates implicitly and explicity used are also being questioned although it is expected that reasonable extensions of current efforts will yield success.

(3) The detailed estimating relationships used by Boeing are based on company experience primarily in aircraft and secondly in spacecraft and launch vehicle stage construction and are highly proprietary. Our request for information in this area was 
denied. In view of the great extrapolation required to achieve SPS capabilities, it was not considered worthwhile to pursue a detailed investigation of the Rockwell estimating methods (which used a NASA data base) when the Boeing designs were selected as the Reference System vehicles. The Boeing designs are considered to be less technically ambitious than the Rockwell designs.

(4) The performance and programmatic assumptions made to derive SPS transportation costs have uncertainties affecting operating costs which are believed to be more significant at this time than projection errors from historical data.

The conclusions drawn from the examinations made in the program indicate, moreover, that if the proposed Reference Vehicles are used, and the requisite technologies for the SPS and SPS vehicles are pursued with the diligence needed to make the concept valid, the basic cost estimates for the vehicles are reasonable.

Historical Comparison: The historical comparisons we made indicate that the development and operating costs projected for the SPS are reasonable from the standpoint that they reflect the costs experienced in past major programs. Historically, real costs of conducting operations are reduced as technology progresses in a given area, but this progress does not continue indefinitely. Costs tend to level out as a specific technology matures and further cost redurtion requires new technology. Space transportation shows no sign of approaching theoretical physical limits on cost reduction for reusable vehicles while the expendable concepts appear to have reached a plateau. Because selecting analogies for quantitative projections is conjectural and subject to challenge, we do not use historical projection methods for purposes other than to confirm that the estimated unit costs represent reasonable projections for twenty years in the ruture. The central question is whether 15 or 25 years will be needed to achieve them, and the level of research and development required in the interim.

Optimization: The SPS space transportation system has not been subjected to a formal optimization analysis in the sense that each vehicle and , 
the entire system design is backed by explicit calculations showing that variations in capabilities would cost more than those of the current proposed designs. Most efforts in this direction are based on exclusion of designs that clearly cost more. One example is the selection of the Electric Orbit Transfer Vehicle for cargo transport. The requirement to lift fuels to orbit to propel chemical cargo transfer vehicles clearly make an electric propulsion vehicle desirable because of its mass efficiency. So little is known about the requirements for electric vehicles that considering minor variations on the payload and hence the overall size is inappropriate. In the case of the Heavy Lift Launch Vehicle, however, it is likely that optimization studies can produce conclusive results. A study by R. H. Miller(4) indicates that the HLLV design as proposed for the SPS program occupies a region in parameter space where costs do not vary significantly with vehicle size. This is consistent with our understanding that NASA and its contractors considered HLLVs with weights of twice and half that of the currently proposed HLLV with only modest overall changes in total program costs. On the basis that devel-' opment costs are approximately proportional to vehicle weight, it is likely that smaller HLLV designs can reduce front-end costs with increases in recurring use costs but only modest increases in total program costs. The advantages of extensive reuse of vehicles without significant refurbishment between flights are so great, however, that significant investments in reusability (as contrasted with refurbishability) would, if successful, provide a greater reduction in total program costs than any program which extends shuttleequivalent technology depending on refurbishment and expendable items such as external tanks. Since reusability via-a-v1s the airlines is not now available and represents an area of high uncertainty in any case, proposals in this area by Rockwell were not selected for the Reference Design. The Personnel Launch Vehicle presents another problem. While the concept of a light cargo and personnel vehicle is considered to have validity, no mission other than personnel transport has been identified. This mission could also be accomplished by a personnel module aboard the HLLV with a savings in both development and recurring cost. Thus, unless the HLLV is unacceptable for some reason, such as safety, the PLV does not have a strong justification at this time. Adaptation of the then-existing Shuttle capability without a major development chargeable to the SPS program appears to be a reasonable path. 
Since the major purpose of this study is to evaluate the cost estimates of the given Reference Design, the analyses do not undertake extensive assessments of designs whose costs are even more uncertain than those available. The question of optimization of the space transportation capabilities and costs is unresolved and this investigation is limited to commenting on available results and potential opportunities to achieve improvements.

\subsubsection{Performance Review}

The performance review undertaken in this investigation considers performance to reflect all technical aspects of the proposed Reference Design and some of the alternatives. The reviews reflect knowledge of the difficulties and problem areas for current operations and planned space activities within the next decade. The growth in vehicle size, capabilities, and reusability envisioned for the SPS has many unresolved and probably undetermined problems. We do not purport that our investigation has uncovered all of them.

The performance of the specific designs was checked using standard performance evaluation programs and the performance claims made were found to be accurate. The improvements in capabilities required to achieve the performance goals are considered to be reasonable given the time and funding projected for their development. Our major concern with the costs projected on the basis of the stated designs is that they assume 100 percent reliability. There are no reserves other than a very minor allowance for below-nominal performance of all engines. Furthermore, no provision has been made for such contingencies as engine trouble which can require the shut-down of one or more of the 30 engines on the HLLV.

We believe that any system will be required to have safety and nperating margins which anticipate all majur dnd must minor incidents or accidents. Accordingly we can infer potential cost changes from our perception of safety and operating margin requirements. These changes affect both development and operating costs and there are only limited opportunities to trade development and/or investment costs for operating savings. Our evaluation in the performance area consists of three main activities: 
(1) Comparison of transportation vehicle weights with present systems and designs to determine whether or not the projected, weights can reasonably be achieved

(2) Identification and assessment of the level of technology required for the major vehicle hardware elements (e.g. rocket engines)

(3) Analysis of vehicle mission performance to verify that the vehicles defined by the contractors would produce the results claimed.

These results, and consideration of deviations therefrom, are then used to determine cost impacts and uncertainties.

\subsubsection{Review of Overall Transportation Assumptions:}

The current SPS transportation $\mathrm{pl}$ an is based on a variety of assumptions which were made to permit a fixed and specific cost estimate for the SPS program. These assumptions range from 100 percent vehicle reliability and the use of the same launch vehicle technology over thirty years to the stated program goal of sixty SPS satellites with a production rate of exactly two per year over thirty years. These assumptions are considered to be the major cause of cost uncertainty in both the overall SPS program and the space transport costs. The cost estimates for specitic developments have beefil ilide using an accepted methodology and are large in comparison to most other human activities. We have also examined the overall SPS program development and implementation scenarios to determine their reasonableness. The approach used is to examine both the overall plan and its specific assumptions, both stated and unstated; to determine elements in the scenario which are, in our opinion, unduly optimistic. The reference designs are themselves moderately conservative estimates of technical capability 20 years in the future and are thus the major component of pessimism found. Specific areas of optimism are then assessed to determine what alternative assumptions are considered more realistic. The cost impact of these new assumptions is then estfmated using uncomplicated techniques and, as necessary, our own simplifying assumptions. We did not select unduly pessimistic or worst case assumptions for two reasons: 
(1) Significant development is required for SPS and the cost estimates reflect this. We expect that most of the presently perceived problems will be resolved by the year 2000. (2) It is all too easy to make assumptions based on current knowledge which show that a future system will not work or will have enormous costs. These pessimistic assumptions frequently have little more basis than optimistic assumptions and frequently fail to recognize the potential magnitude of technical progress that is likely over a period of two decades or more.

One assumption has been found, however, which we feel is overly optimistic. This is the assumption that vehicle development requirements will end by the time of the first SPS. Vehicle developments and improvements are a continuing process and can be expected to take place throughout the SPS program. These will be a source of improvements leading to progressively more cost-efficient vehicles during the proposed thirty-year SPS construction cycle. The cost implications of this type of vehicle improvement have not been addressed in the SPS plans to date because of the difficulty in projecting these types of costs (and their benefits) into the distant future. Because the costs (and benefits) are diffuse and these improvements will also benefit other programs, no penalty has been assessed to the SPS program cost estimates.

\subsubsection{Review of Individual Vehicle Cost Assumptions}

The cost estimates for individual vehicles were al so investigated and assessed for real1sm in lerms of self-consistency, relation to current and historical experience and technological development requirements. This assessment is then related to cost uncertainties, especially for recurring costs. The vehicle cost and performance estimates were point estimates and did not contain any significant allowances for less than 100 percent of stated capabilities. Our approach for assessing cost uncertainty is acknowledged to be somewhat simplistic in that uncertainties in the individual vehicles are not independent and, hence, are not strictly additive or cumulative. Thus, the comments on individual vehicles should be used as an indication that further work is required to determine capabilities, requirements, and costs, rather than an assumption that a specific design element or its implication has a direct and unavoidable impact on costs. 


\subsection{SPS Transportation Costs Review}

\section{Conclusions and Recommendations}

\subsubsection{General Conclusions About SPS Space Transportation Plans}

The costs determined by NASA and its contractors for the SPS space transportation requirements are believed to be reasonable early program estimates if some adjustments for optimistic development and operations scenarios are made. The uncertainty in these estimates is high and not easily quantifiable because there are technology development areas (e.g. large space structures) where no experience exists.

The cost estimates NASA directly associates with space transportation (Reference 2) do not explicitly include items such as the launch facilities and intra-orbital transfer vehicles (IOTV's) as the Work Breakdown Structure (WBS) (Reference 4) used assigns these items to other categories than to space transport. The launch facilities, for example, support the SPS platforms and the IOTV's are also used for space construction. Cost estimates for these items have been made and are included in the overall program. These estimates appear adequate under the assumptions made for the SPS deployment scenario and are briefly reviewed as part. of this study. The major assumption with a cost impact on space transportation is that the Kennedy. Space Center (KSC) will be adequate for launching the Reference Design's 5-Gigawatt SPS platforms and associated equipment at a rate of two per year. Existing international airports such as Los Angeles transfer approximately this mass (or more) at the present time so it is likely that KSC, will be adequatc. If nut, dlluther launch site will be required with an additional cost of $\$ 2$ billion to $\$ 6$ billiun depending upon where and how the center is located. An equatorial land stte, if available, would tend toward the lower estimate (for construction only) and a sea-floor site would tend toward the higher estimate. Specialized SPS facilities are not included in these estimates.

The cost estimates and initial designs used to make these estimates reflect early program information and are usually considered not to be the type of information upon which a firm commitment to a go/no go decision can be 
made unless additional information confirms this judgement. - Rather, these estimates and designs may indicate, from the standpoint of space transportation, whether the SPS concept may be cost competitive with other sources of power; but the uncertainties may be too large to make this judgement based on the stated program costs. Similarly these stated costs do not permit rejection of the current SPS concept.

There is a tradeoff between recurring cost per flight, development expenditure and the certainty of estimates in capabilities and costs. If the goal is low and certain capabilities and costs for recurring space transportation operations, the development costs to achieve those capabilities cannot be subjected to rigid limitations or single-line development programs. The possibility of development failures must be anticipated and some alternative subsystem concepts must be carried along, until success is demonstrated. This type of effort requires a higher and more uncertain level of program costs at a time when the program is not producing direct economic benefits. The development and deployment scenarios used in deriving the transportation cost estimates basically assume that the program does not carry any unresolved development problems forward to the time of initial deployment. Because research results are not deterministic, the development cost uncertainty is. high even for the current designs which are based, with some significant exceptions, on currently available technology. Paying the price to assure reliable and reusable vehicles must be done at some time as the space transportation costs themselves are a major cost driver of the SPS program. We also have a related concern that a program defined for thirty years is based on use of the same vehicle designs to haul equipment of the same design over the entire period. If the concepts prove viable, it is expected that the designs will be modified to take advantage of improvements in technology. The use of a personnel vehicle directly related to the current shuttle design (PLV) twenty to fifty years in the future is also considered questionable on the same basis. This aspect of the program has already been recognized and alternatives such as a personnel module aboard the HLLV will receive future consideration if only because the quoted recurring cost per flight is the same while the payloads have a mass ratio of almost 5 to 1 . This concern does not, however, reflect directly upon the question of accuracy 
and certainty of the cost estimates for space transport for the given Reference Design which do not contain any allowance for development problems discovered during SPS operations. Advances in vehicle technology leading to later efficiencies similarly have not been proposed.

The fact that the space transportation costs are a major cost driver of the SPS program is leading to a significant program of technology development and possible reexamination of alternatives. These alternative designs, such as Rockwell's aerospace plane, were not selected for the SPS Reference Design because of their additional technology requirements. If these concepts are admitted, the tcchnology, developmont and test rnsts sian lead to an expenditure level significantly higher than currently estimated ( $\$ 17$ billion) through the first operational SPS. This level can easily be a factor of two ( $\$ 34$ billion) but, like the current estimate, it would be spread out over 15 to 20 years. From this level of effort, recurring costs for transportation can be expected to be at and probably significantly below the current recurring estimates. The recurring cost reduction would come from the improved ability to reuse vehicles as contrasted with the Shuttle where significant refurbishment and replacement is associated with each flight. This approach will, however, require an early national policy commitment to increase the level of launch vehicle and related development effort. We do not, therefore, direct our examination of the transportation cost estimates toward areas requiring major expenditure increases.

\subsubsection{Conclusions About the Reference System.}

The SPS transportation costs have been derlved using an apprupriate methodology, specifically the top-down or extrapolation technique which typically has an uncertainty of \pm 15 percert when applied to programs undertaken in the immediate future. The SPS program will be using technology to be developed over the next ten years and the uncertainty in specific areas is thercfore higher. Specific areas of uncertainty are discussed in sections covering each vehicle.

If the technology and development programs are funded at a reasonable level and problems resolved as uncovered over the next 15 to 20 years it is 
considered likely that the goals for recurring costs can be met with the development and investment expenditures at or only moderately above current estimates. For the vehicles specified, the potential increases are considered to be in the range of 15 to 50 percent resulting in a potential increase of the current estimate of $\$ 17$ billion for DDT\&E to $\$ 20$ billion to $\$ 26$ billion. The 15 percent figure reflects a limit based on the uncertainty of the methodology and the upper limit of 50 percent reflects cost growth experience in some large, technologically ambitious military programs. 'A formal calculation estimates the uncertainty at -15 percent to +25 percent.

The recurring transportation costs are based on an ambitious scenario with an early initial operating capability and an assumption of 100 percent vehicle reliability. While adequate allowances have been made for cargo breakage ( 2 percent) and for payload packaging and palleting (15 percent), no provision was made for either partial failures, such as an engine-out condition or for complete failures resulting in loss of a vehicle. The cost uncertainty associated with the estimating methodology is typically a \pm 15 percent band around the stated estimate. Further, a minimum of 10 percent reserve in transportation requirements is recommended at this time to permit adequate safety margins. Accordingly a growth of up to 25 percent is possible for recurring HLLV transportation costs. This growth, if fully realized, would result in an increase in the current estimate of HLLV costs, for example, of $\$ 2.8$ billion per SPS to $\$ 3.5$ billion. For the current program of 2 SPS satellites per year this is a growth from $\$ 5.6$ billion per year to $\$ 7.0$ billion per year. Major areas identified for efforts to control costs are the entire Electric Orbit Transfer Vehicle (EOTV) and the refurbishment/ reusability efforts for the Heavy Lift Launch Vehicle.' The uncertainty in costs is especially high in these areas because no operating experience exists. An especially sensitive case is the EOTV and this is discussed in section 1.3.4. Because of this uncertainty, it is not possible to state that cost growth is inevitable and, accordingly, the potential range of growth in costs should be used only as a guide in determining SPS program sensitivity to transportation costs in comparison with alternate power sources.

Associated with the transportation vehicles are facilities and personnel who will build and operate the vehicles and SPS platforms. These 
will be located on the ground and at two locations in space. There is significant ground experience in operating a spaceport, but most of this applies only to operations with expendable vehicles. The Skylab experience is the only effort where equipment was extensively planned for reuse. Considering that the initial launch had a partial failure, the experience of recovering from that failure strongly suggests that the SPS can succeed in handling most contingencies. The uncertainties in costs for operations with orders of magnitude increase in complexity are, however, very great. The uncertainty used in judging the orbital facilities and operations costs can only be that assigned to the SPS platforms and thoir opcrations. The available information on ground staffing plans for transport, however, appears adequate under the reusability assumptions made explicitly and the implicit assumption that the SPS space activities are imbedded in an active NASA space program and do not have to carry the additional burden of being the only space program. They are tight, but credible.

The conclusions about uncertainty in SPS Transporation costs is summarized in a quantitative table covering both the vehicles and the transportation plan in Section 1.3.8 after the individual vehicles are reviewed.

\subsubsection{Heavy Lift Launch Vehicle(HLLV) Conclusions}

The HLLV design and use scenario have reserves for cargo packaging and breakage totaling 17 percent, and these appear reasonable. However, no provision has been made for less than 100 percent reliability in planned launches, whether for minor incidents which could require the shut-down of one or two of the HLLV's thirty engines or total loss of a vehiclc. Based un assurned reliabilities of 0.99 to 0.9999 for individual engines, at least one engine would not perform adequately for 26 percent to 0.3 percent of the trips. With a payload reduction of approximately 10 percent, the desired orbit can be achieved if one engine on each stage fails. Further, the excess propellants for the successful trips can be transferred to orbital storage for use with POTV and intra-orbital vehicles, and for breathing and electrical power usage. Space propellant storage and refrigerators will be required but 
0

are not discussed from the standpoint of costs, as storage is viewed as part of the orbital construction facilities.

Since there is a rough mass balance between a 10 percent payload mass reserve for safety and propellant and oxygen consumption for orbital transfer and consumables requirements this specific safety factor may not result in any significant cost growth. This balance has not been investigated in detail and will require additional technical effort to understand all the implications.

Other factors such as supply requirements not forseeable at this time and weight growth in SPS satellites or orbital maintenance equipment suggest, but do not demonstrate, a need for a payload growth allowance of at least 10 percent. The technology development requirements for the HLLV are not so stringent that a major performance deficit is to be expected, but this 10 percent allowance can al so be viewed as a hedge that would permit slight growth in vehicle weight or slight reduction in engine performance if development does not proceed exactly as planned. An alternative lower limit on unforseen needs, equally valid, is that additional consumables can be accommodated by one additional HLLV Launch per year.

A major cost driver is the labor and time needed for replenishing the HLLV for each flight and for replacement or refurbishment of components upon wear-out or damage. There is no operational experience with reusable vehicles and estimates made for the shuttle have not been confirmed. Thus, these costs estimates are not subject to either confirmation or refutation on the basis of current knowledge. For the HLLV, the costs per flight can be categorized as:

$\begin{array}{lrl}\text { Vehicle Wear out (over } 300 \mathrm{flights}) & 19.6 \% & \text { [Calculated from } \\ \text { Other capital costs (Tooling) } & 2.3 \% & \begin{array}{l}\text { Reference 2 which } \\ \text { is reproduced as }\end{array} \\ \begin{array}{l}\text { Fuel } \\ \text { Replenishment/Refurbishment and } \\ \text { other Manpower }\end{array} & 15.2 \% & \begin{array}{l}\text { Appendix B] } \\ \text { (100.0\% }\end{array}\end{array}$

Thus uncertainties in replenishment/refurbishment, almost all of which are manpower costs, are the major source of uncertainty in the average cost per flight. Deviations from expected costs would change the average cost per 
flight proportionally. The cost risk to the program is, however, subject to a great degree of control through a development program which concentrates on the costs to fly the vehicle. The learning associated with the shuttle will al so reduce the lack of knowledge in this area. Accordingly, an adjustment to the estimates is not recommended at this time.

The HLLV fleet size, initially 6 , is considered to be too small when factors such as potential delays and the possibility of an accident are considered. The average launch rate is 1.2 per day and the stated turnaround t1me is $51 / 2$ days. The average life is $300 \mathrm{flights}$ and the equivalent production rate (including refurbishment) is 3 per year based on an equivalont of 94 vehicles over the 30-year program. The program will enter an initial build-up phase where learning can take place and the delay in availability of one of the six vehicles is unlikely to be critical to program progress. When actual construction of a power satellite is underway, any delay must be recovered as soon as possible. If a vehicle is out of service for any reason, whether by a serious accident, a launch hold, or by a weather delay, multiple 1 aunches will be required each day until the payloads for the scheduled EOTV are delivered. This will require the availability of reserve vehicles and payloads. These may, in fact, be vehicles which would be launched in the next few days. Based on a 300-flight life and 94 equivalent vehicles, there is a reserve in equivalent vehicles when refurbishment is considered, but we are concerned that sufficient physical vehicles may not be available for these multiple flight situations because of the 5-1/2-day turnaround time. The averlage unit cost for additional reserve HLLVs is $\$ 595 \mathrm{million}$ and the addition of each reserve HLLV is a 1.8 percent increment to the nominal DDT \& $E$ and Investment (front-end transportation cost) of $\$ 33$ billion. The addition of reserve vehicles is recommended as they can al so be used for other space programs and when the time value of delays in schedule of the SPS satellites is considered, it probably can be shown that that they will pay for themselves in this manner. The number of reserve vehicles can be projected based on risk acceptance assumptions and turnaround times. If a weather delay such as a week for a hurricane is to be compensated for by doubling of the launch rate, the fleet size must be doubled. This is expensive and may not be justified. If an airline analogy is used, the appropriate reserve factor is 10 to 15 
percent or 1 or 2 HLLVs. By analogy, this would lead to a 1 percent cancellation rate due to significant mechanical problems or a 5 percent delay rate due to minor mechanical problems. Recovery under these rates appears reasonable. The airline analogy also suggests that approximately 2 percent of the vehicles will, be lost in fatal accidents every 10 years and that 5 percent of the vehicles will be lost due to both fatal and non-fatal accidents every 10 years. For the 94 vehicle equivalent HLLV's over the 30-year program, it is likely, then, that two fatal and three non-fatal accidents will occur. One additional vehicle in reserve at any given time is considered adequate protection for this contingency.

Because many factors influence reserve requirements, including explicit statements of willingness to accept or spend to avoid risk for many differing contingencies, it is difficult to firmly recommend a specific estimate for reserve HLLV's. The airline analogy of a reserve of one-tenth or one-fifteenth of the vehicles, but at least one, is recommended for planning purposes.

The initial fleet size of six also causes a problem in cost certainty under the methodology used to forecast costs. This initial procurement barely gets to the knee of the learning curve and thus the costs for this procurement are subjected to the additional uncertainty of whether the actual learning experience will meet the 85 percent learning curve expectation by that time or some later time, since the assumption of learning at 85 percent can be accurate but realized later. If 90 percent learning is achieved on the first six vehicles, the cumulative difference is about ten percent of the expenditure on HLLV's to that point. This is also about 3.5 percent of the initial investment expenditure of $\$ 17$ Billion. This level of uncertainty is within the error band associated with the cost extrapolation methodology.

\section{1:3.4 Electric Orbit Transfer Vehicle (EOTV) Conclusions}

The Electric Orbit Transfer Vehicle is the most technically ambitious of those proposed for the Reference Design. There is no experience with large structures in space and the estimates of costs for both the SPS power satellites and EOTV's rest largely on unconfirmed calculations. The ion 
engines, however, have a development history. The major concern with these engines is achievement of acceptable lifetime in components subject to erosion by the ions. We conclude that if SPS structure goals can be met, so can those of the EOTV. The EOTV development cost estimates also reflect this close association for both structures, power conversion (solar cells), and power management through cost estimates lower than would otherwise be justified. The recurring costs also reflect co-production with the SPS of many componenls. The EOTV flect is projected at 23 to 28 vehicles with a production rate in orbit. of 6 or 8 per year as needed. The flight time to GEO is 180 days and the return ifme is 40 days. The 23 [OTV's will make 31 tilights per year with approximately 60 days al lowed for loading, unloading and refurbishment. This appears tight but probably adequate, except for the possibility of accidents requiring unscheduled repairs. On the basis of considerations discussed subsequently, we recommend at least two additional EOTV's be provided in space with contingency planning for additional ground storage of EOTV's so that prompt recovery from a severely damaged EOTV can be achieved. The cost of additional EOTV's is estimated at $\$ 284$ million, but is highly uncertain. Achieving this cost goal depends upon meeting production goals for structures, electrical distribution equipment and solar cells on the basis of a highly mature and productive industry over a relatively short period. This is possible, but not subject to proof or disproof in the near future. The use of silicon photovoltaic cells on the Reference EOTV also implies rapid degradation of power conversion capacity, up to 40 percent on a round trip, due to radiation damage. If continuous laser annealing of this damage, or some other form of rapid annealing, cannot be achieved, significant cost growth for both investment and recurring costs appears likely. The importance of annealing the solar cells is so great that we recommend that Gallium Aluminum Arsentde (GaAlAs) cells, which are expected to be selfannealing when used with concentrators, should be considered even if silicon cells are used on the SPS power satellites. Gallium availability in sufficient quantities and at economic cost is not certain at this time, but gallium in EOTV's would be available for reprocessing and reuse. The apparent advantages of GaAlAs cells vs. Silicon cells in terms of decreasing maintenance and refurbishment costs are not calculable at this time, and accordingly should be reexamined later in the SPS program. 
Calculations based on previous work with another large area spacecraft, the solar sail(6) indicate that the EOTV will experience a significant collision with a satellite (dead or active) with a probability of about 0.1 to 0.3 per round trip. The planned life of an EOTV is ten round trips and 30 to 40 trips are planned each year. Thus, between 3 and 12 significant collisions can be expected each year. It is expected that collisions with active satellites can be avoided, but collisions should be a planned contingency. A collision may in fact result in only a slight performance degradation if power distribution and control functions are redundant. If critical power elements or major structural members are struck, it is more likely that a rescue mission will have to be undertaken. This would require an additional EOTV and/or a special POTV flight with special equipment to repair the EOTV or to transfer the payload to the new EOTV. Since the Reference SPS Program does not assume the removal of space debris, the probability of collision for EOTVs is now higher in LEO than at higher altitudes. It is most likely, therefore, that collisions will occur below the Van Allen Radiation Belts. These Belts will probably prevent human participation in vehicle repairs should a collision occur there. EOTVs not needed for loading should be parked above the region where collisions are most likely.

All these considerations discussed indicate that the EOTV costs for development, capital investment and recurring use are uncertain for reasons which do not, at the present time, permit neat analytical measures of either uncertainty or cost growth. The costs will likely be higher because early program estimates tend to be optimistic. Breakthroughs either in technology or our understanding of reasonable requirements are also possible in the 10 to 20 years before commitment to specific designs. These can possibly lead to reductions which more than make up for underestimation in other areas. The appropriate direction of effort to reduce costs and their uncertainty can be determined from the current estimates of costs, given in Table 1.3.1. 
TABLE 1.3.1 REFERENCE SYSTEM VEHICLE COST ESTIMATES(2) (\$, MILLIONS)

\begin{tabular}{lrrrrrrr}
\hline .. Vehicle & DDT \& E & $\%$ & $\begin{array}{c}\text { Theoretical } \\
\text { First } \\
\text { Unit }\end{array}$ & $\begin{array}{l}\text { Avg. } \\
\text { Unit }\end{array}$ & $\begin{array}{r}\text { Avg. } \\
\text { Flight }\end{array}$ & $\begin{array}{r}\text { Per } \\
\text { SPS }\end{array}$ & $\%$ \\
\hline HLLV & 11,202 & 66 & 1,748 & 595 & 10.1 & 1,954 & 70 \\
EOTV & 2,247 & 13 & 2,126 & 284 & 40.7 & 575 & 20 \\
PLV & 2,616 & 15 & 190 & 673 & 10.7 & 260 & 9 \\
POTV & 1.012 & 6 & 100 & 44 & 1.3 & 13 & 1 \\
& 17,077 & 100 & & & & 2,802 & 100 \\
\hline
\end{tabular}

Clearly, direction of efforts toward cost reduction and control must be directed toward the HLLV first and the EOTV second. The estimated leverage of the HLLV on total transport cost over that for EOTV is three to five times as great. Inversely, the uncertainty in EOTV costs is on the order of three to five times that of the HLLV. The EOTV development cost is also strongly dependent on the success of developments for the SPS satellite and thus not subject to great reduction. Thus the goals for the presentit sliould be to reduce costs for the HLLV and reduce uncertainty for the EOTV.

The cost per flight for the EOTV is given by Reference 2 as;

$$
\text { Average Hardware }=\frac{\text { Average Vehicle Cost }}{\text { Flights per Vehicle }}=\frac{\$ 283.6 \mathrm{M}}{10}=\$ 28.4 \mathrm{M}(70 \%)
$$

Propellants

Refurbishment (including materials and labor and.

HLLV Launch costs)

Program Support

Total Cost Per Flight
$=0.5 \mathrm{M}(1 \%)$

$=11.3 \mathrm{M}(28 \%)$

$=\frac{0.5 M}{40.7 M}(1 \%)$

The major potential for cost control for the EOTV then comes from the capital cost of the vehicle, with a secondary potential from the refurbishment effort. The ability to reuse and repair the vehicle when damaged is the most significant area to concentrate effort to control or reduce costs. Based on the estimates of $\$ 10.1 \mathrm{M}$ per flight for the HLLV, the recurring effort to reuse and refurbish and load the EOTV which carries ten HLLV payloads is probably not subject to significant reduction from the estimate of $\$ 11.3 \mathrm{M}$, even if a longer 
lived design proves feasible. The likelihood of replenishment/reloading cost growth is high and can easily grow by $\$ 1$ million or more per flight. We recommend a 10 percent cost al lowance $(\$ 44.7 \mathrm{M}$ cost per flight) to cover orbital facilities requirements.

There is al so concern that learning projected in Reference 2 may not be achieved on the initial EOTVs. This rate of learning should be thoroughly investigated and documented in future studies.

The costs for other vehicles have been projected on the basis of a theoretical first unit (TFU) and a learning (experience) curve of 85 percent. The EOTV recurring cost for manufacture and assembly, however, has been projected on the basis of a mature industry approach for many of the components including photovoltaic cells, space structure and electrical conditioning and distribution equipment. The existence at an early stage of the SPS deployment program of such a mature capability in these areas is essential to the economic attractiveness of the SPS platforms as well as that of the EOTV. As an example, if the silicon cells are selected for the $5.2 \mathrm{~km} \times$ $10.4 \mathrm{~km}$ platform at a production rate of 2 per year, this implies a production rate of 72 acres per day, 365 days per year for the SPS platforms alone, in addition to other space and terrestrial uses. Analogous production capability is also needed for space structures on an areal basis.

If this capacity is not fully available at the time EOTV are to be constructed, the rapid progression from the TFU of $\$ 2.126$ billion to an average cost of $\$ 283.6$ million would not be possible. A possible consequences would be to place the FOTV on a learning curve in the manner of the other vehicles. If 70 percent learning is experienced, and this is believed to be better than is achieved in most aerospace production efforts, the 25th EOTV, for example, would cost $\$ 405$ million rather than the $\$ 283$ million average unit cost used in many of the Reference System calculations. The initial production of 23 EOTVs would then have an initial investment requirement of $\$ 16.880$ billion (23 vehicles, 70 percent learning, $\$ 2.126$ billion TFU) rather than the $\$ 8.649$ billion determined from the calculation of the TFU plus 22 average units.

The justification of the use of the average unit cost for the EOTV then clearly requires more than can be convincingly demnstrated at this early 
stage of investigation. Because this study is expected to provide explicit estimates of program costs and their uncertainties in a quantitative manner, we state an explicit uncertainty in a subjective manner for the EOTV. This is done by noting that if the technology demonstrations supporting the SPS have been completed before commitment to production, and the techriology and its economics are promising, the manufacturing, production and assembly of the EOTV components are expected to be a straight-forward set of tasks. Under these circumstances, the effort to correct production problems is likely to be accomplished by a relatively low number of billions of dollars than a relatively high number of billions of dollars. Accordingly, we believe, but cannot prove, that DDT \& $E$ and investment requirements w111 be closer lo lhe Reference System estimates than to the total of $\$ 19$ billion indicated by application of the methodology used for the chemical propulsion vehicles. Pending further study, we recommend using an estimate of $\$ 10$ billion for the initial EOTV investment and increasing the fleet size by three to five vehicles to account for the possibility of vehicle losses. Uncertainty in this estimate is not reduced by this change and remains very $h i g h$.

\subsubsection{Personnel Launch Vehicle (PLV) Conclusions}

The Personnel Launch Vehicle design is an extension of the present Shuttle design with the addition of a reusable booster as a lower stage. The development cost for this booster is reasonable in comparison with the development cost of the HLLV only if the development is concurrent. The recurring cost per flight is estimated at $\$ 10.7$ million in comparison with an estimate of $\$ 10.1$ million for the HLLV. The cargo capacity in tons, however, is 89 tons for the PLV while that for the HLLV is 425 tons (gross). The recurring cost is considered reasonable, even if it is slynlficanlly less than current estimates for the Shuttle. The reason for this judgement is that the current Shuttle charge includes program costs which are estimated separately for the SPS vehicles. These include facility use and general support at the launch site. This estimate of $\$ 10.7$ million for the PLV implicitiy assumes that the PLV is part of an ongoing space program for which it is only a small part. The payload ratio of 4.7 to 1 at approximately the same cost suggests that 
using the HLLV for personnel transport is more cost-effective, if the safety of personnel can be assured. No other specific mission than personnel transport is envisioned at the present time, but the concept of a general purpose/ emergency carrier is probably valid. The adaptation of the then existing Shuttle at whatever payload capacity it has at that time is a reasonable option for the purpose, but the specific development of the PLV is not recommended for the SPS program unless at least one major and cost-effective use can be found in addition to personnel transport. The HLLV, to be cost effective, must have at least the reliability associated with the Shuttle, and should therefore be strongly considered for the personnel transport role as well as that of a cargo transport.

Because the PLV can also be envisioned as NASA's general purpose vehicle for other missions, the SPS program should probably not bear the full burden of developing the PLV. Specifically, PLV's are estimated to have an average cost of $\$ 673$ million, of which $\$ 550$ million is for the Shuttle Orbiter and $\$ 123$ million for the booster. Since 15 boosters are recommended for the entire 60 Satellite SPS program, more would be spent on the booster development ( $\$ 2.6$ billion) than on the boosters themselves ( $\$ 1.962$ billion), and almost as much as our rough estimate of the total recurring costs of the booster ( $\$ 4.9$ billion) over thirty years.

\subsubsection{Personnel Orbit Transfer Vehicle (POTV) Conclusions}

The major source of uncertainty for the POTV comes from the requirement for reusable engines and propellant insulation. The DDT \& $E$ estimate of $\$ 1$ billion is roughly consistent with past estimates of $\$ 1$ billion for the reusable Tug to be used on the Shuttle and is reasonable under the assumption of ongoing technology programs for engines and avionics. The average unit ( $\$ 44$ million) and recurring cost per flight ( $\$ 1.3$ million) are reasonable under the assumptions made for the program, specifically, technology inheritance and co-development, and that the life estimate of 50 flights can be achieved. The recurring cost per flight estimate in Reference 2 does not include downtrip propellants (185 metric tons), about $\$ 50,000$. The HLLV and 
EOTV costs for transport of the total of 385 MT of propellants are also not included in this estimate, but have been included in the overall transport cost scenario and the average transport cost for each SPS platform.

The personnel module and its associated life support equipment were not included in this estimate because they represent reusable construction support equipment. Both POTV's and personnel modules need to be avallable for emergency use and are not included in the current estimates. Two (one at LEO and one at GEO) are viewed as the minimum for emergency use and will require $\$ 8 R$ million in capital investment. If the capability to evacuate the GEO station is required, five vehicles will be required as initial spares ( $\$ 176$ million) and this will slowly grow to twelve spares ( $\$ 528$ million) for POTV's alone with additional expenses for personnel modules. These vehicles could be used in normal operations so that they would not deteriorate with lack of use. The twelve reserve POTV's calculated would raise the currently planned production from 33 to 45 , a 36 percent increase. An alternative emergency vehicle which could evacuate the GEO station in one flight is considered likely to cost as much, but the personnel shelter could al so serve as the radiation shelter. This concept would also "put all the eggs in one basket".

\subsubsection{Intra-Orbital Transfer Vehicle (IOTV) Conclusions}

The IOTV is not included in the NASA definition of space transportation because it supports orbital operations as well as space transport. The area of orbital operations has not been investigated in the same level of detail as has the area of transport and no firm definition is available at this time. The contractors have identified several tasks which cannot be satisfied by the same vehicle and, accordingly, there is no single IOTV concept.

The POTV has been proposed as the large maintenance supply/work station transport vehicle and was appropriately costed as such. A smaller vehicle will be required for less demanding tasks in both LEO and GEO and we have an unoptimized, preliminary design proposal for a small hydrogen/oxygen stage which appears appropriate for tasks such as HLLV payload transfer to the EOTV. It would also be used to maneuver payloads at GEO. 
Because the orbital operations plans have not progressed to the same level of detail as the space transportation plans, no major conclusions can be drawn. The concern remains that this is an area where significant dollar growth can occur, but the potential percentage growth in transport and/or a transport-related costs is not considered high under the current division of the program. The cost uncertainties are viewed as coming from the human accommodations and their requirements rather than from the propulsion, tankage and vehicle control avionics.

1.3.8 Program and Vehicle Costs and Uncertainty

Summary and Recommendations

The following Table 1.3.2 represents a summary of our conclusions about the SPS transportation program, its costs and the uncertainty in those costs. The cost estimates are repeated from those References $(2,3)$. Our recommended adjustments are also stated together with our estimates of uncertainty in both estimates. The recommendations are based on very elementary calculations which should be reconsidered in the future.

A large number of footnotes are given which briefly indicate the source of the adjustment and other qualifications of the estimates. The uncertainty estimates for the chemical vehicles are based on the uncertainty typically associated with the CER methodology, \pm 15 percent. For the EOTV, however, the uncertainty is rated very high and the value of -15 percent to +100 percent is assigned. This is then related to the total SPS transportation uncertainty by dollar weighted averaging.

The \pm 15 percent cost uncertainty estimated for the chemical vehicles is a one-sigma estimate of the error. Because the error for the EOTV can only be rated as very high and the numeric value of -15 percent to +100 percent is assigned by us to this statement, dollar weighted averaging has been used for the overall cost uncertainty estimate. A sum of the variances estimate is not believed to be appropriate to the overall estimate because it would include the EOTV's assigned error estimate. 
TABLE 1.3.? SPS TRANSPORTATION COST ESTIMATES, ADJUSTMENTS AND UNCERTAINTIES

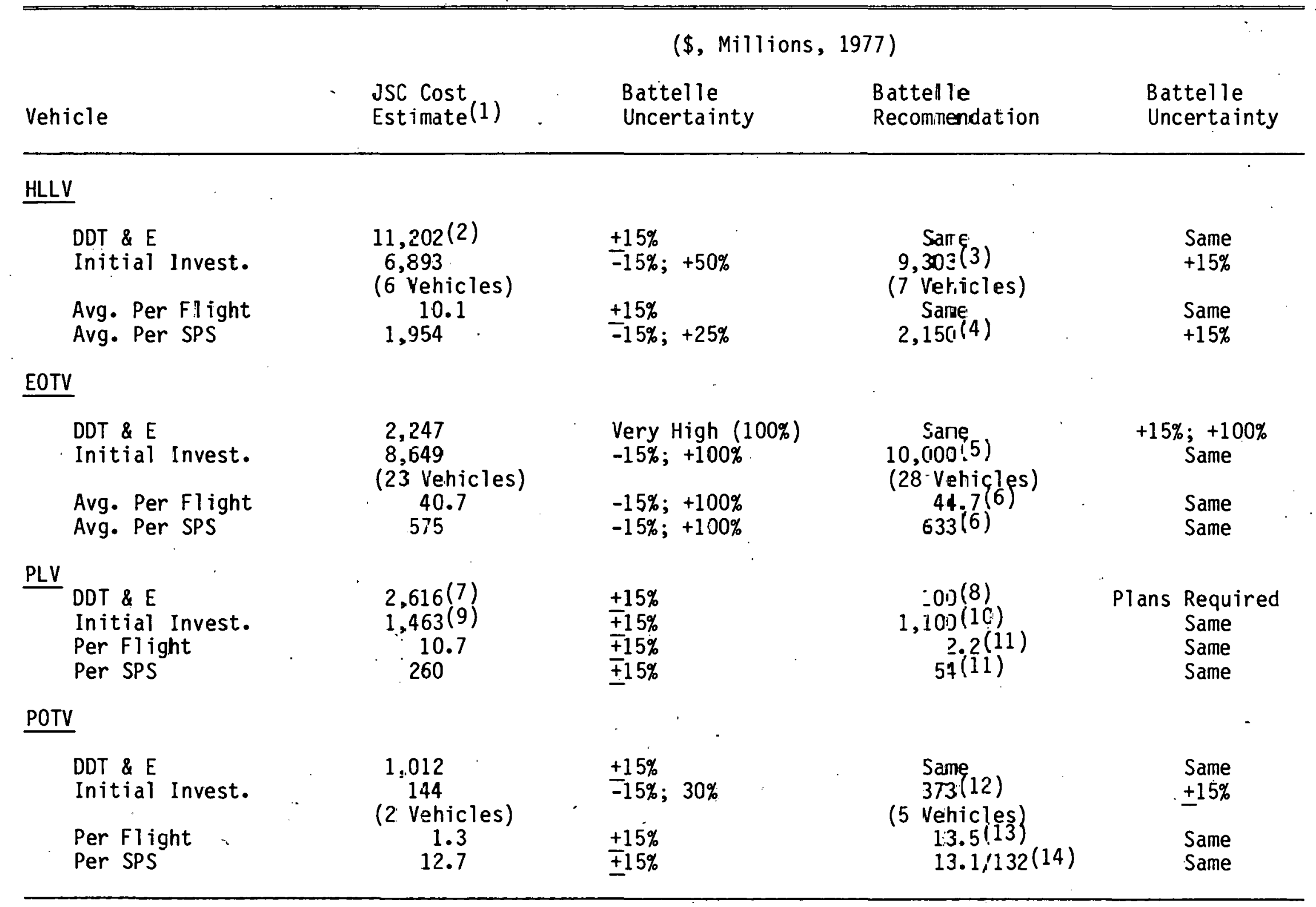


TABLE 1.3.2 (Continued)

\begin{tabular}{|c|c|c|c|c|}
\hline \multirow[b]{2}{*}{ Vehicle } & \multicolumn{4}{|c|}{ (\$, Millions, 1977) } \\
\hline & $\begin{array}{l}\text { JSC Cost } \\
\text { Estimate }(1)\end{array}$ & $\begin{array}{l}\text { Battelle } \\
\text { Uncertainty }\end{array}$ & $\begin{array}{l}\text { Battelle } \\
\text { Recommendation }\end{array}$ & $\begin{array}{l}\text { Battelle } \\
\text { Uncertainty }\end{array}$ \\
\hline \multicolumn{5}{|c|}{ 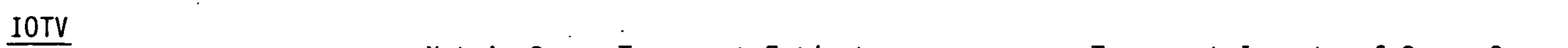 } \\
\hline & \multicolumn{2}{|c|}{ Not in Space Transport Estimates } & \multicolumn{2}{|c|}{$\begin{array}{l}\text { Transport Impacts of Space 0ps. } \\
\text { Needed for Full Picture }\end{array}$} \\
\hline $\begin{array}{l}\text { Ground Support } \\
\text { Per Year } \\
\underline{\text { Per SPS }}\end{array}$ & $\begin{array}{l}513(15) \\
263\end{array}$ & $\begin{array}{c}\text { High } \\
( \pm 25 \%)\end{array}$ & $\begin{array}{l}\text { Same } \\
\text { Same }\end{array}$ & $\begin{array}{l}\text { Same } \\
\text { Same }\end{array}$ \\
\hline \multicolumn{5}{|l|}{ SPS Transport } \\
\hline $\begin{array}{l}\text { CDT \& E } \\
\text { Initial Invest. } \\
\text { Fer SPS }\end{array}$ & $\begin{array}{r}17,077 \\
17,149 \\
2,802\end{array}$ & $\begin{array}{l}-15 \% ;+25 \% \\
-15 \% ;+70 \% \\
-15 \% ;+35 \%\end{array}$ & $\begin{array}{c}\text { Same } \\
20,776(17) \\
3,113(18)\end{array}$ & $\begin{array}{l}\text { Same }(16) \\
\text { Same }(16) \\
\text { Same (16) }\end{array}$ \\
\hline
\end{tabular}


TABLE 1.3.2. SPS TRANSPORTATION COST ESTIMATES

ADJUSTMENTS AND UNCERTAINTIES

$$
\text { (\$, Millions, 1977) }
$$

\section{Footnotes}

(1) Reference 2 (Appendix B)

(2) Does not include research; a strong precursor technology program is assumed.

(3) Addition of one reserve HLLV and strict application of 85 percent learning curve.

(4) 10 percent Payload Reserve for Growth in SPS and Miscellaneous Requirements

(5) Addition of five reserve vehicles to fleet; mature industry assumption. If learning at 70 percent is applien to TFI, initial investment is $\$ 19$ billion.

(6) 10 percent Cost reserve for operation of orbital maintenance facilities.

(7) PLV booster co-developed with HLLV.

(8) Battelle estimate of development cost of personnel module for HLLV.

(9) Purchase of 2 PLVs without personnel module.

(10) Purchase of one additional HLLV in addition to reserve vehicle.

(11) 22 percent of HLLV cost per flight

(12) Purchase of 5 POTVs with strict application of 85 percent learning curve.

(13) Adjustment reflects direct charge of 1 HLLV flight pl us 5 percent. of EOTV flight costs plus $\$ 50 \mathrm{~K}$ downtrip propellants to POTV. Personnel Module Excluded.

(14) Reference 2 corectly accounts for POTV costs in overall transport scenario.

(15) 6425 man-years at KSC at $\$ 40$ /hour.

(16) Dollar weighted average of uncertainties.

(17) Includes reserve vehicles and mature industry assumption for EOTV.

(18.) Includes Ground Support at KSC. 


\subsection{REVIEW OF SPS TRANSPORT REQUIREMENTS, COSTING METHODOLOGY AND RESULTS}

\subsection{SPS Requirements and their Translation into Transportation Requirements}

The payload characteristics associated with construction and maintenance of a system of geostationary-orbit solar power satellites (SPS's) have been detailed, and include not only' the SPS materials, but al so the facilities, supplies, and orbital transfer vehicles (OTV's) to support manned construction and maintenance in space. (Reference 2). The translation of these payload characteristics, shown in Table 2.1, into transportation requirements was made on the basis of:. (1) The SPS reference program and the underlying construction assumptions; (2) the implementation scenario, including construction and maintenance schedules and crew requirements.

The following discussion first focuses on the reference program. The implementation scenario and underlying assumptions are then examined, and the impact on the payload delivery schedules determined. Cost impacts are inferred in this discussion.

\subsubsection{SPS Reference Program}

The reference SPS program is based on construction of two 5 GW SPS's per year, for a total of 60 satellites. To accomplish this, two space bases are constructed in the initial phase of the program. The Low Earth Orbit (LEO) base functions as a staging depot and orbital transfer vehicle construction facility. Payloads from earth arriving on recoverable, heavy lift launch vehicles (HLLV's) are accummulated, and those destined for the Geosynchronous Equitorial Orbit (GEO) base are transferred to orbital transfer vehicles. Crew transfers between personnel launch vehicles (PLV's) and personnel orbital transfer vehicles (POTV's) are al so accomplished at the LEO base.

Actual satellite construction and maintenance operations are accomplished in geosynchronous orbit, with the GEO base providing work and crew facilities in addition to the four-bay end-builder which constructs the base1 ine $8 \times 16$ bay SPS in two successive passes. Figure 2.1.2 displays the GEO Construction Concept (D 180-2503/6 Boeing). 
TABLE 2.1.1 PAYLOAD CHARACTERISTICS (MASS)

(ALL WEIGHTS IN METRIC TONS)

\section{SPS}

Satellite (1)

Allowance for Breakage (2\%)

Total per Satellite

LEO BASE

Base

Crew Facilities Supplies/ $/ \mathrm{r}_{r}$

Work Facilities Supplies/ $/ \mathrm{r}$

GEO BASE

Base

Crew Facilities Supplies/ $/ \mathrm{r}$

Work Facilities Supplies/Yr

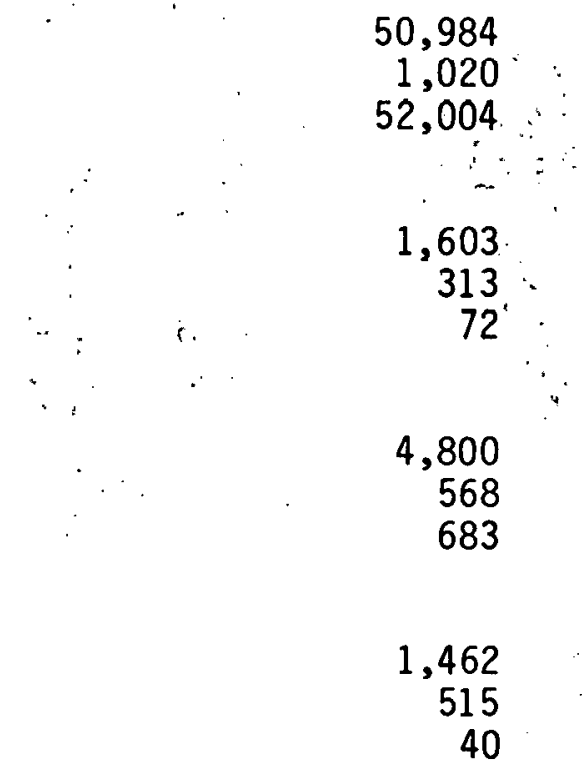

POTV - CREW ROTATION/SUPPLY

Stage

Propellant/Flight (Up/Dn)

Refurbishment/Flight

Personnel Module

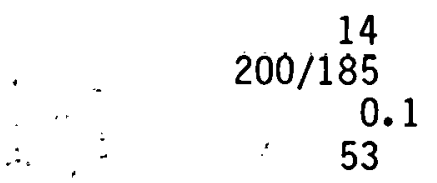

SPS MAINTENANCE

SPS Supplies/Satellite/Yr.

Crew \& Work Facilities/20 Satellites

Crew \& Work Supplies/Yr/20 Satellites

POTV Maintenance Sortie Prop/Satellite/Yr

Sourçe: Reference 2.

\subsubsection{Implementation Scenario and Underlying Assumptions}

The Implementation Scenario for the reference SPS program consists of (1) an initial period, during which the LEO and GEO bases and the orbital transfer vehicle fleets are constructed; (2) a one-year period for construction of the first 5 GW SPS; and (3) a $291 / 2$ year operational phase, during which 59 SPS's are constructed at a rate of two per year. 


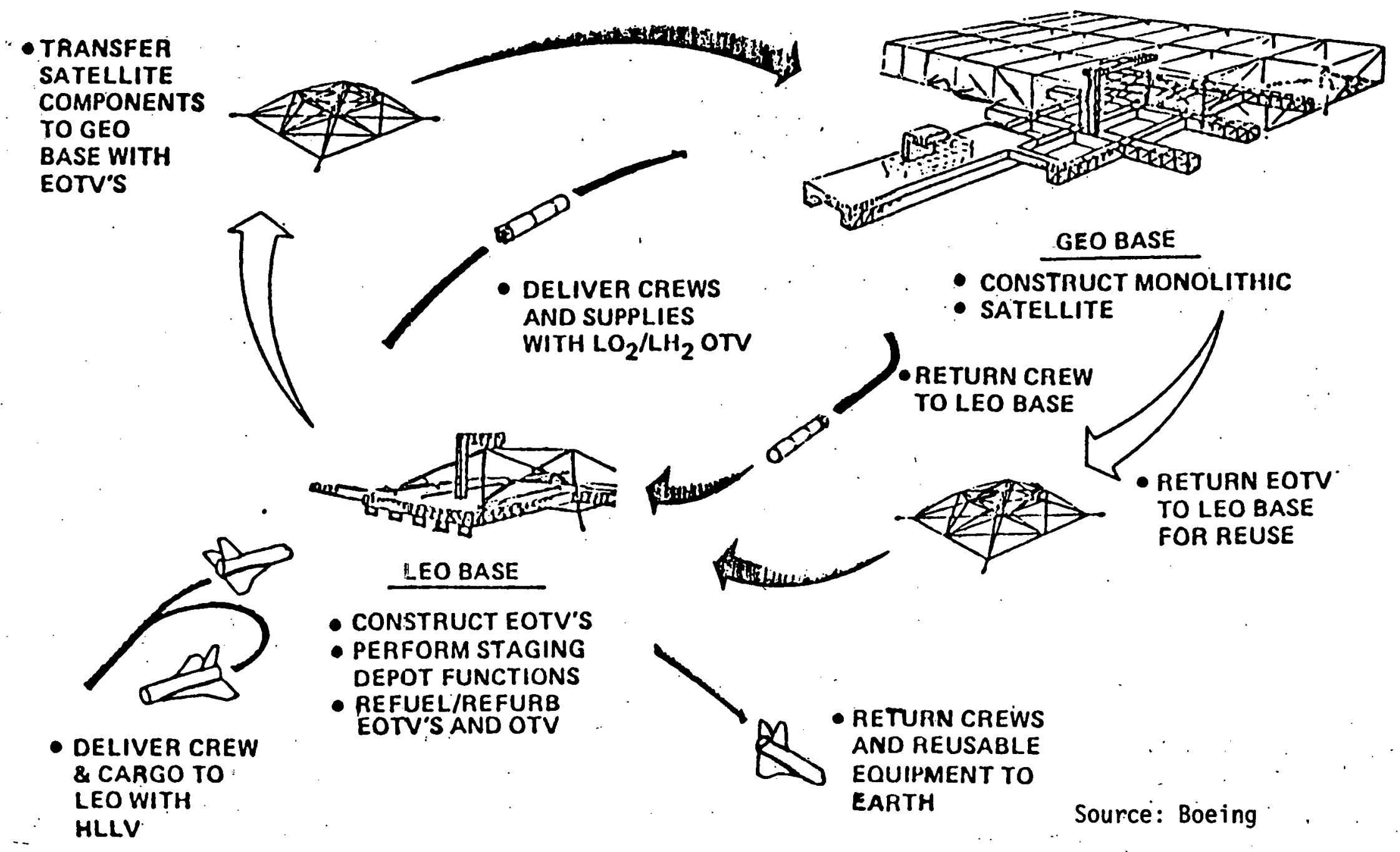


There are two documented versions of the implementation scenario. The Johnson Space Center (JSC) data book (Reference 2) defines an initial two year period for assembly of bases in LEO and GEO, and for fabrication of the orbital transfer vehicle fleet. The first SPS, requiring one year construction time, is then completed at the end of the third year. The Work Breakdown Structure (WBS) Document (Reference 4), however, defines the commercial phase commencing after six months of test operation of a.demonstration satellite, at which time construction of the orbital transfer vehicle fleet and GEn base begins. Construction of the first full-scale ( $5 \mathrm{GW}$ ) satellite is initiatcd 2 $1 / 2$ yedrs into this commercial phase. Again, nne year is allottcd for construction of the first $5 \mathrm{GW}$ SPS, so that $3-1 / 2$ years of the commercial phase have passed before the nominal production rate of two per year is established. Figure 2.3 compares these two versions of the SPS program implementation scenario. As can, be seen in this figure, the WBS version allows more time for orbital transfer vehicle production and GEO base construction prior to initiation of SPS construction. The JSC version allows only 1-1/2 years for these activities versus $21 / 2$ years in the WBS version. The other obvious difference between the two scenarios is that the WBS version allows for construction and test operation of a demonstration satellite prior to commercial SPS construction. Thus, in this version, construction of the LEO base is completed prior to construction of demonstration satellite; whereas, in the JSC version, LEO base construction consumes six months of the initial scenario. Clearly, the WBS scenario is more conservative in terms of time and therefore risk and higher in cost than the JSC scenario.

To define payload delivery requirements to accomplish the implementation scenario, crew requirements and maintenance requirements must be defined. The LEO base crew requirements for depot operations have been documented as 200 persons (JSC \& WRS). An additionàl 35 persons are based at LCO during OTV fleet construction. The GEO base crew requirements for SPS construction were documented as 440 persons. In addition, the GEO crew requirements for twicea-year maintenance of completed satellites is an additional 20 persons per satellite, so that 40 persons are added to the GEO maintenance crew each year, once the nominal production rate of two SPS's per year has been achieved. 
JOHNSON SPACE CENTER TRANSPORT SCÈNARIO (REFERENCE SYSTEM) (REFERENCE 2)

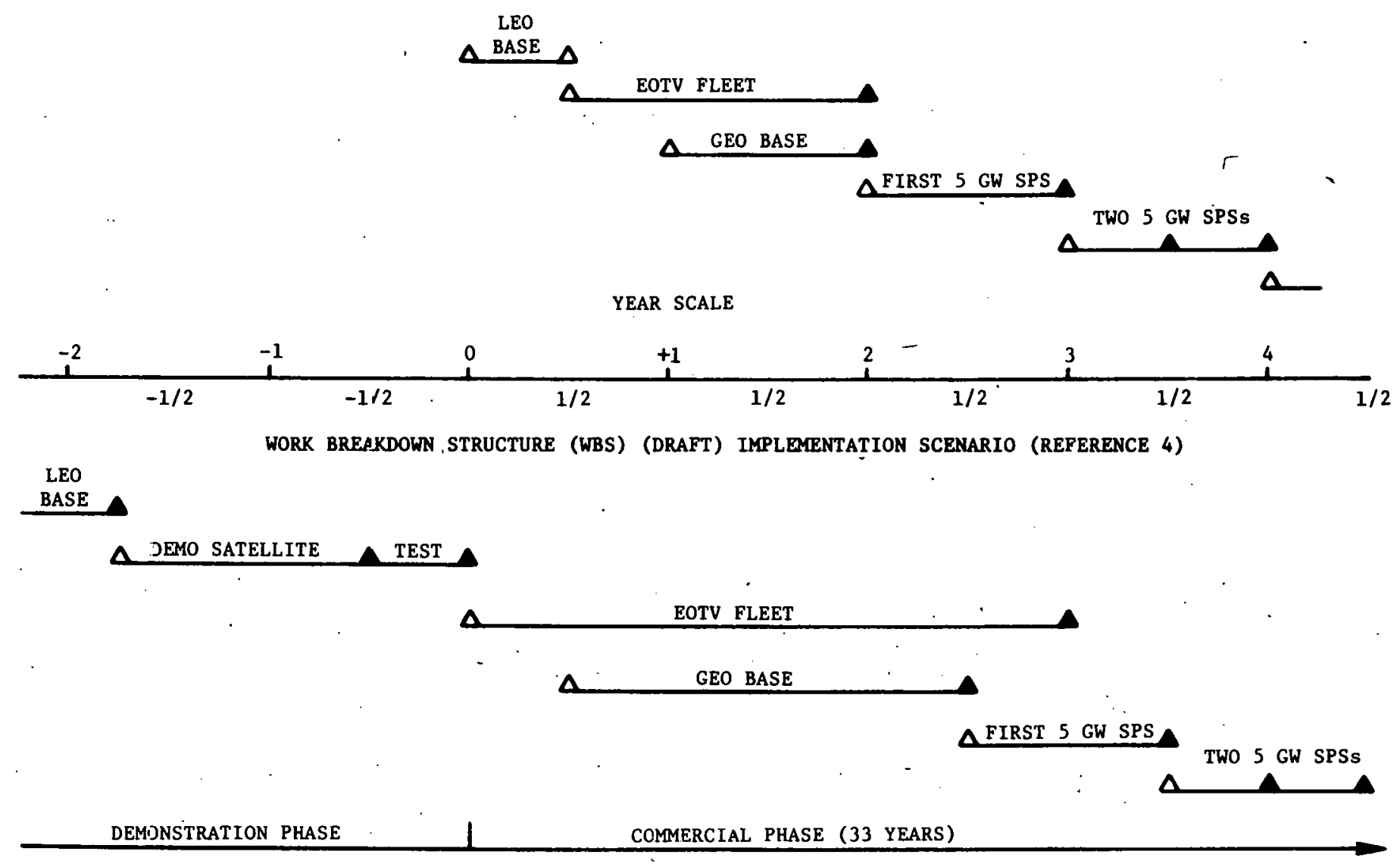

FIGURE 2.i.3 ALTERNATIVE SPS PROGRAM SCHEDULE SCENARIOS 
Crew rotation is assumed to be once every 90 days so that $\mathrm{crew}$ transportation requirements per year are four times the crew size which grows from approximately 700 to 1800 over the SPS construction phase.

A payload requirement which is related to crew size is consumables. Estimates for personnel consumables were documented as $200 \mathrm{~kg}$ per man-month (Boeing NAS 9-15196). Reference 3 estimated requirements for per sonnel consumables at $5 \mathrm{~kg}$ per person-day, including oxygen supplies. This amounts to $150 \mathrm{~kg}$ per person-month, compared to the Boeing estimate of $200 \mathrm{~kg}$ per personmonth. Annual requirements shown for personnel consumables shown in Table 2.1 are based on 1.SC. estimates which result in annual consumption of 1.7 melric tons per person-year or $141 \mathrm{~kg}$ per person-month. This is tight and does not specify any on-orbit storage of consumables. If the Boeing estimate, 42 percent greater, is used, the equivalent from one to three additional HLLV launches per year would be required as the program progresses through the $30^{3}$ year construction phase.

The area of human consumables is the only area of SPS planning where data exist to test independently the.SPS platform and operations mass requirement assumptions. It is expected that a similar range nf mass uncertainty (e.g., 42 percent or \pm 20 percent from some nominal value) can be shown for the SPS platforms and construction bases. The early stage of the SPS designs, however, does not permit this type of analysis on ot.her than a hypothetical basis. Under the program assumptions and mass estimates, however, the arithmetical translation of mass requirements into payloads has been done reasonably and correctly.

The basic JSC mass transport scenario and its requirements are summarized in Appendix B. The number of flights required for the HLLV was based on a net payload of 360 MT while the gross lift capability of the HLLV is pro-

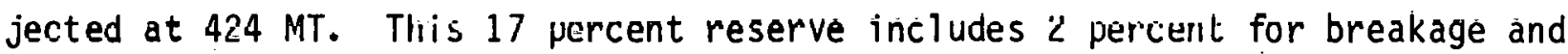
15 percent for packaging and palleting. These are reasonable allowances for average effect calculations, although considerable variance can be expected depending on the nature of the specific load being carried.

Because of the likelihood of growth in mass requirements for the SPS platforms and assembly bases, we recommend an additional 10 percent growth allowance in HLLV payloads and therefore numbers of flights. This is 
approximately half the uncertainty in human consumables requirements, but the SPS designs are much more subject to engineering efforts than are human comforts.

No additional growth allowance is recommended for the EOTV because the effect of larger payloads will be to slow the vehicle and make the trip longer. Longer trips (already 180 days) or more trips will change the fleet size requirement, but should not affect the cost per flight significantly. Fleet size considerations, however, are discussed later in terms of reliability and availability.

Table 2.1.4 summarizes the mass and personnel transport plan for the Reference System to illustrate the year-by-year growth in mass transport requirements. 
TABLE 2.1.4 MASS AND PERSONNEL TRANSPORT PLAN FOR REFERENCE SYSTEM

\begin{tabular}{|c|c|c|c|c|c|c|c|}
\hline Year & $\begin{array}{c}\text { SPS } \\
\text { Plat forms }\end{array}$ & $\begin{array}{l}\text { LEO Mass ( } 1) \\
\text { Inc EOTVs } \\
\text { (MT) }\end{array}$ & $\begin{array}{l}\text { GEO Mass } \\
\text { Excl Supplies } \\
\text { (MT) }\end{array}$ & $\begin{array}{l}\text { GE0 Base } \\
\text { Work Supplies } \\
\text { (MT) }\end{array}$ & $\begin{array}{l}\text { PoTv(2) } \\
\text { Payloads } \\
\text { (MT) }\end{array}$ & $\begin{array}{c}\text { Total (3) } \\
\text { Mass } \\
\text { (MT) } \\
\end{array}$ & $\begin{array}{c}\text { Number }(4) \\
\text { of } \\
\text { People } \\
\end{array}$ \\
\hline $\begin{array}{r}1 \\
2 \\
3 \\
4 \\
5 \\
6 \\
7 \\
8 \\
9 \\
10 \\
11 \\
12 \\
13\end{array}$ & $\begin{array}{r}2 \\
4 \\
6 \\
8 \\
10 \\
12 \\
12 \\
14 \\
16 \\
18 \\
20\end{array}$ & $\begin{array}{l}11389 \\
13315 \\
19580 \\
27798 \\
30594 \\
28576 \\
29636 \\
30498 \\
31515 \\
44233 \\
45194 \\
47570 \\
35397\end{array}$ & $\begin{array}{r}3188 \\
3943 \\
28888 \\
82927 \\
109225 \\
109229 \\
109239 \\
109248 \\
109258 \\
109273 \\
109249 \\
109288 \\
109302\end{array}$ & $\begin{array}{r}127 \\
455 \\
796 \\
1251 \\
1251 \\
1251 \\
1251 \\
1251 \\
1251 \\
1251 \\
1251 \\
1251 \\
1251\end{array}$ & $\begin{array}{r}123 \\
238 \\
476 \\
817 \\
909 \\
884 \\
998 \\
1020 \\
1180 \\
1156 \\
1270 \\
1292 \\
1452\end{array}$ & $\begin{array}{r}14827 \\
17951 \\
49264 \\
112793 \\
141979 \\
139940 \\
141124 \\
142017 \\
143204 \\
155913 \\
156964 \\
159401 \\
147402\end{array}$ & $\begin{array}{r}390 \\
520 \\
690 \\
650 \\
690 \\
720 \\
760 \\
800 \\
840 \\
910 \\
950 \\
990 \\
1030\end{array}$ \\
\hline 23 & 40 & 44133 & 109373 & 1251 & 1972 & 156734 & 1400 \\
\hline 33 & 60 & 50714 & 109484 & 1251 & 2720 & 164169 & 1800 \\
\hline
\end{tabular}

SOURCE: Reference 2.
(1) Includes an Average of 755 MT of LEO Base Supplies
(2) Transported to LEO by PLV
(3) Total Mass Delivered to Space; all mass in Metric Tons
(4) Includes 200 LEO crew +35 EOTV Canstruction Crew 


\subsection{SPS Designs to Meet Transportation Requirements}

In the last section, annual transporation requirements for the SPS space segment were categorized by transport mission (LEO or GE0), and expressed in metric tons (cargo) or number of man-flights (crew rotation). In this section, the discussion will focus first on the transport vehicle designs, flight times, and fleet requirements to meet the annual transportation requirements. The cost estimates for each transport element will be reviewed.

\subsubsection{Transport Vehicle Designs}

Five transport missions have been identified: (1) cargo transport between Earth and LEO; (2) personnel transport between Earth and LEO: (3) cargo transport between LEO and GEO; (4) personnel transport between LEO and GEO; (5) intra-orbital transport of cargo and personnel.

The cost estimates for and implications of the Reference Design vehicles, their production and use schedules to meet those missions are discussed in terms permitting a critical understanding of the choices made for the SPS program. The alternative designs and their implications are briefly discussed to indicate the reasons why they were not selected for the Reference Design and to indicate the conditions which would change that decision.

2.2.1.1 Heavy Lift Launch Vehicle (HLLV). Three candidate designs were identified in initial SPS studies: (1) a winged entry/recovery; (2) a ballistic entry/recovery; (3) a winged entry/recovery with expendable hydrogen tank. In both the Rockwell and the Boeing Definition Studies, recoverable launch vehicle design was based on the winged entry/recovery concept. One Rockwell design is a single-stage-to-orbit (SSTO) vehicle, with a 91 metric ton payload capability which looks and would operate much like an airplane. Another Rockwell design is a parallel burn, cross-fed propellant configuration. Both represent advanced technology. The leading Boeing design is a two-stage winged vehicle, with a 424 metric ton gross payload capability (360-374 metric tons net payload).

The Boeing HLLV design was selected as the reference design for the SPS Program because it requires a lower level of lechmulogy development and therefore provides a higher level of confidence that the vehicle could be 
developed for an SPS operational capability by the year 2000. The Boeing design uses many of the developments being incorporated in the Shuttle while the rockwell SSTO would require extensive efforts to develop the requisite technology, especially for the engines. There are also other designs which are intermediate in technology development requirements. The goal of all these designs is to provide high reusability and thus low operating costs in comparison with the Shuttle, which requires extensive refurbishment after each flight. The Boeing design for the HLLV was selected as a compromise between development cost and recurring cost with the advantage that its technoloqical readiness is believed to be higher than the competitors.

While the turn around time between flights for a design concept can be only roughly estimated at this time, the airplane-like configuration gives: promise of airplane-like operations. The projected turn around time of one day for the Rockwell SSTO concept would compare very well in terms of time, labor, and therefore, money to the Boeing design. The Boeing HLLV, with two stages, has four and five day turn-around times, and requires a large launch platform to erect the vehicle for a vertical launch.

Because the costs of the initial trip to LEO are the major (70 percent) component of transportation costs for operational SPS platforms, the goal of low recurring costs is imperative to permit low SPS costs. Low recurring costs imply a highly reusable vehicle with minimal costs in the refur bishment after each flight. The technological developments in the years before commitment to a specific SPS and its transport system may provide a better indication of whether truly significant cost reductions can be achieved with reasonable development expenditure for the SPS. Until such improvements in basic vehtcle technology are, or are indicated, to be available, the Boeing HLLV concept appears to be the reasonable choice.

2.2.1.2 Personnel Launch Vehicle (PLV). In the Rockwell transportation design, the HLLV provided crew transportation between Earth and LEO, so there was no dedicated personnel launch vehicle.

The Boeing Definition Study, however, specified a Space Shuttle derivative for crew and priority cargo transport between Earth and LEO. The PLV design consists of a winged flyback booster with four engines similar to 
the HLLV booster engines, a smaller version of the Shuttle external tank and the Shuttle orbiter. Its payload capability to LEO is 89 metric tons. No flight turn around time was specified.

The concept of the PLV as a personnel and light cargo vehicle may have some validity, but it is difficult to perceive at this time. The costper-flight is estimated to be very near that of the HLLV (\$10M). The payload ratio is 4.7 to one $(424 / 89)$ and safety-reliability should be very similar to that of the HLLV. Clearly, the cost-effectiveness of the PLV is open to question. Since the PLV (or a similar. Shuttle derivative) will likely be the major NASA vehicle for its programs in this period, the question of how existing vehicles are used in the SPS program needs thorough consideration. For example, test articles will probably be flown on them. Since the exact capability of Shuttle derivatives is conjectural at this time, the question of whether and how they can be used in a cost-effective manner remains open.

\subsubsection{Cargo Orbital Transfer Vehicle (COTV). Both the Rockwell} and Boeing Definition Study designs for the low-thrust COTV are based on an electric-powered, ion-propelled vehicle, with a payload capability of approximately 4000 metric tons (about ten HLLV payloads).

While the Boeing EOTV design was selected as the Reference Design, the implicit commitment to silicon photovoltaic cells has not been made by the SPS program because the knowledge does not yet exist to justify the commitment at this time. The selection of an electric propulsion vehicle was made because the very high fuel efficiency of these designs avoids the necessity of transporting large quantities of chemical propellants to LEO. This advantage is so large that the decision would probably not change unless two conditions are met: (1) the cost of constructing and using the electric propulsion vehicles is several times more expensive than is currently envisioned, and (2) the cost per pound of transporting propellants to LEO drops by at least 50 percent from that projected for the HLLV.

The fundamental design of the EOTV and the SPS satellites is expected to be very similar. The SPS will convert sunlight into electricity and electricity to microwaves which are beamed back to Earth. The EOTV will use the elcctricity to accelerate ions in an engine. Because of this fundamental 
similarity, if condition (1) occurs, the SPS concept is very.likely to have severe difficulty in being cost-competitive with terrestrial sources of power.

Since there is very little experience with electrical propulsions and no electrical stage has yet been flown, the uncertainties associated with this concept are large. Because of the similarity of EOTV design with that of the SPS platform, the uncertainty in EOTV cost estimates can only be that associated with the SPS platform. For purposes of calculations of the uncertainty in total transport costs, we assign the value of -15 percent to +100 percent. If other studies show the SPS platform cost uncertainty to have a different value, this value should be used as a substitute.

\subsubsection{Personnel Orbital Transfer Vehicle (POTV). The POTV pro-} vides rapid transport of crew and high priority cargo between LEO and GEO. The 'POTV is also used for maintenance sorties between the GEO base and the satellites. In both the Rockwell and Boeing Definition Studies, the POTV designs were based on a two-stage reusable vehicle capable of carrying out a round trip mission between LEO and GEO without refueling. In the Rockwell version, each of the stages weighed 91 metric tons and the payload capability was 91 metric tons, so that each POTV was assembled at LEO from three HLLV payloads (the Rockwell HLLV design payload specification was 91 metric tons). The Boeing Definition Study PTOV design entailed a larger two-stage chemically-powered vehicle (890 metric tons without payload) with a payload capability of 150 metric tons up (LEO to GEO) and 90 metric tons return. Neither of these two designs was chosen as the reference vehicle design. Instead, a single-stage vehicle requiring refueling at. GFo was selected, with payload capability of 90 metric tons, sufficient to sarry 80 passengers and 6600 man-days of crew supplies. This design reduces the total POTV propellant requirement, utilizing the more efficient EOTV to transport the POTV return propellant to GE0. The design is usually pictured with a passenger module. This module, however, is not included in the cost statements as it is considered to be part of the orbital support equipment. The est fmated mass and payload of the module used for performance calculations are reasonable and produce the stated results. The estimated turn-around time 
of five days is also reasonable under the assumption of a maintenance depot in LEO with frequent resupply of parts from the surface.

Chemical propulsion for humans from LEO to GEO was selected for the short trip time (5 $1 / 2$ hours, one way). While electric propulsion is more mass-efficient, the trip time would be of the order of weeks, resulting in a significant reduction in time spent on the work station and a long stay in the Van Allen radiation belts. In addition, solar particle radiation storms can take place with little or no warning and require prompt trips to shelters or evacuation of humans from space. Accordingly, it is unlikely that the POTV concept will change significantly, but the size or number of people transported will be subject to later optimization.

The Reference System transportation plans do not include any discussion or cost al lowances for emergency evacuation of GEO or LEO. This will require either a fleet of POTVs and a personnel module aboard the HLLV or a radiation shelter module with a big chemical OTV. The radiation shelter could al so serve as the LEO to surface personnel module. The low number of PLVs planned and their turn-around time appear to preclude use of the PLV for emergency evacuation. The number of POTVs required will range from 5 early in the program when the construction crew in GEO is approximately 440 to 20 near the end of the construction phase when almost 1200 SPS maintenance workers will be added to the 440 construction workers. Since the POTV is planned for orbital operations and maintenance work, there may be enough PTOVs for emergency evacuation. The large number needed toward the end of the program, however, suggests that at some point in the program the shelter/big OTV concept might prove cost-effective.

\subsubsection{Intra-Orbital Transfer Vehicle(s) (IOTV). The IOTVs are} viewed as being part of the orbital operations and not as part of the transportation system. The orbital operations have not been studied as intensively as the transportation requirements and the documentation is therefore not as extensive. The POTV has been proposed to meet requirements involving transport of large masses and/or numbers of people. There are some preliminary and unoptimized designs for lesser requirements such as the transfer of payloads from the HLIV to the EOTV and to maneuver payloads at GEO. In addition 
we expect there will evolve a requirement for a "one or two man" inspection/ service vehicle. All these will service the transport vehicles as well as the SPS and their costs, while small in terms of the overall transport budget, have no allocation included in present estimates of transport costs.

\subsubsection{SPS Transport Vehicle Cost Estimates and} Initial Investment Analysis

Parametric cost mudels (PCM) were used to determine the DDT\&E and TFU (Theoretical First Unit) cost estimates for each transport element (HLLV, PLV, EOTV, rUIV). Inese models take into account the mass, volume, and performance characteristics of individual subsystems of the vehicle, as well as subjective estimators of subsystem complexity and state-of-the-art (new design versus' off-the-shelf). The PCMs compute the DDT\&E and TFU cost estimates based on these estimates, as well as historical and parametric data from the aircraft and aerospace industries. The TFU estimates, associated with the costs of the production of the first element, can then be used with a learning curve to determine unit production costs. According to the JSC Data Book and statements from Boeing, a learning curve factor of $\lambda=0.85$ is applicable at the vehicle level for aircraft industry production. This means that the production cost of an individual unit falls 15 percent every time the production volume is doubled. That is, if the cost of the first unit is the TFU, the cost to produce the second un it is $.85 \times \mathrm{TFU}$, the cost to produce the fourth unit is $(.85)^{2} \times$ TFU, etc., or:

Cost of Nth unit $=\operatorname{TFU} \times N$ power $\left[\frac{\ln \lambda}{\ln 2}\right]$. where $\lambda=0.85$ fnr the aircraft
industry.

The DDT\&E and TFU cost estimltes developed from the Boeing Parametric Cost Model (PCM) are shown in Table 2.2.1, in 1977 dollars. Using the TFU cost estimates, the initial investment cost for each transport element can be determined, utilizing an 85 percent learning curve at the vehicle level. This analysis is shown in Table 2.2.1. The initial investment includes 6 HLLV's, 2 PLV's, 23 EOTV's, and 2 POTV's, and totals over 39 billion dollars (1977 dollars). 
It is interesting to compare the results of this analysis with the analysis in the WBS document, which computes the average unit costs of major subsystems of each transport element over the entire production period,

.TABLE 2.2.1. COST ESTIMATES WITH 85 PERCENT LEARNING

(Millions of 1977 Dollars)

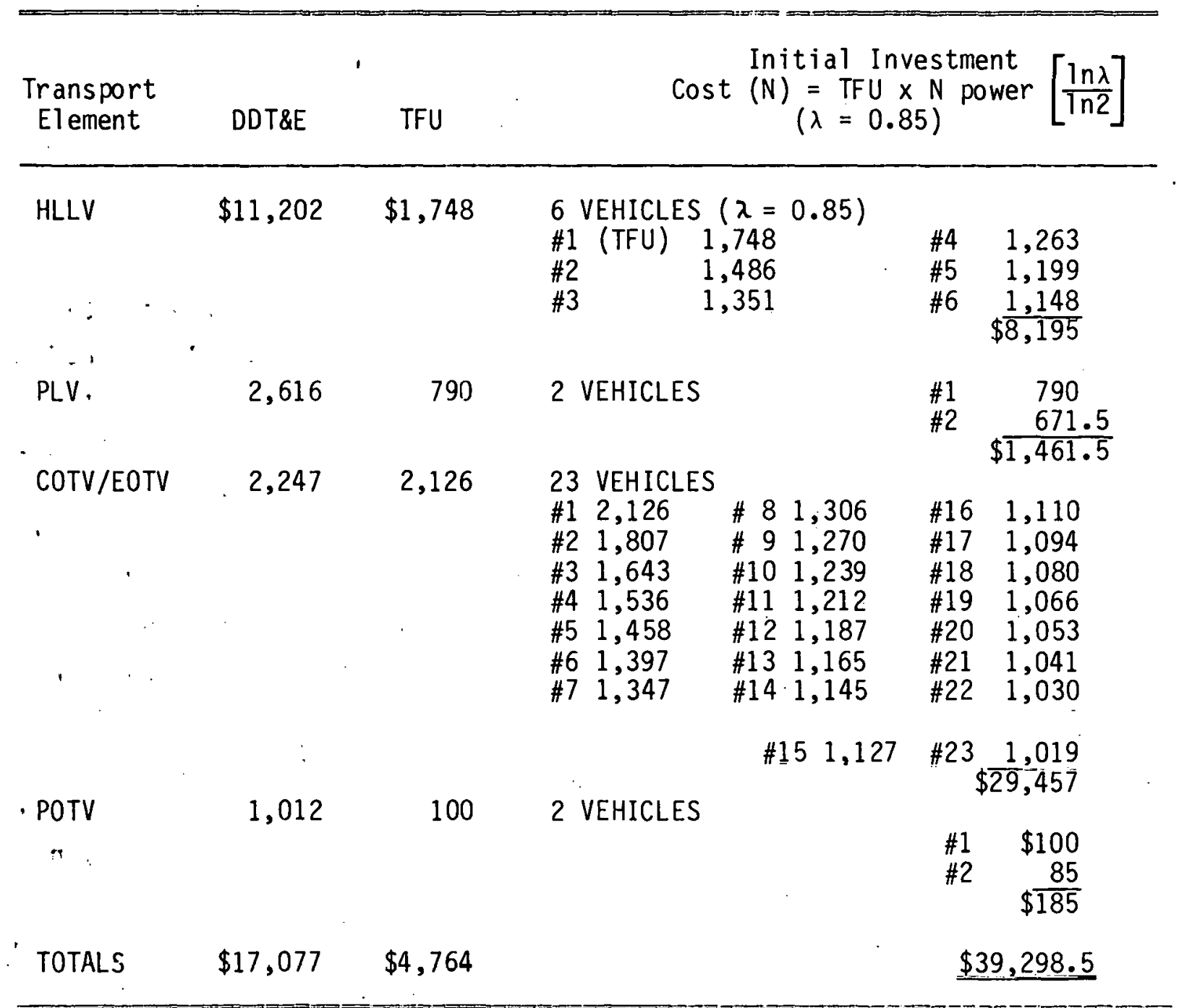

Source: Reference 2 (in DDT\&E and TFU) 
including refurbishment, and uses these figures in determining the commercial phase initial investment. The results of this analysis are summarized below.

$\begin{array}{lrl}\text { HLLV } & \$ 6,072 & \text { (6 stage } 1 ; 7 \text { stage } 2 ; \text { tooling \& GSE) } \\ \text { PLV } & 1,891 & \text { (2 boosters; } 2 \text { orbiters; 47 ET's; Tooling \& GSE) } \\ \text { COTV/ } & 5,990 & \text { (21 construction vehicles) } \\ \text { EOTV } & & \text { (8 maintenance vehicles) } \\ & 2,271 & \begin{array}{l}\text { (2 vehirles; tooling \& GSE) } \\ \text { POTV }\end{array}\end{array}$

(Millions of 1977 Dollars)

It should be noted that the WBS analysis determined the average unit costs of major subsystems based on the TFU's developed by the Boeing PCM and assuming learning curve factors of 85 percent to 90 percent, so that the large differences between the "strict" application of the learning curve at a vehicle level in the analysis of initial investment (Table 2.2.1) versus the WBS analysis based on average unit costs is not attributable to different TFU assumptions. The major difference between the two analyses is EOTV initial investment. Referring to the EOTV category in Table 2.2.1, it can be seen that the cost of the 21st unit, computed strictly according to an 85 percent learning curve, is $\$ 1,041$ billion, slightly less than half of the TFU cost. The average unit cost used in the WBS analysis is $\$ 285$ million, and is based, not on a learning curve assumption, but on a mixture of learning curve and "mature industry" costing. The reasoning is: (1) the annual production rate assumed, four EOTV's per year, implies high ennugh production ratcs of thrusters and solar cells to warrant use of mature irilustry costing (production cost is two times the material costs); (2) the production rates of the power conditioning components (processors, switchgear, etc.) is sufficiently high to warrant learning values of 70 percent (faster-falling learning curve than the 85 percent curve); and ( 3 ) other components with lower production rates are still costed with 85 percent learning assumption.(a)

(a) From SPS Transportation Workshop, JSC/Boeing SPS Orbit Transfer Vehicle Anal.ysis, Huntsville, Ala., January, 1980. 
The figures presented with these assumptions are shown below, and compared with the TFU subsystem cost estimates:

\begin{tabular}{|c|c|c|c|}
\hline JSC/Boeing & $\begin{array}{l}\text { Avg. } \\
\text { Unit } \\
\text { Cost } \\
\end{array}$ & $\underline{\text { IFU }}$ & $\begin{array}{l}\text { Avg. Unit } \\
\text { Cost/ } \\
\text { TFU } \\
\end{array}$ \\
\hline Power Generation/Distribution & $\$ 99.7$ & $\$ 924$ & $(10.8 \%)$ \\
\hline Electric Propulsion & 141.0 & 777 & $(18 \%)$ \\
\hline Avionics & 6.5 & 14 & $(46.5 \%)$ \\
\hline Programmatic & 36.6 & & \\
\hline Total & 283.6 & & \\
\hline
\end{tabular}

This costing approach is open to challenge. First, EOTV assembly. will take place at LEO, and so it is questionable that final production costs will be only two times the materials costs, even though this may be a valid cost assumption for ground-based mature industry production of individual components. Second, the nature of a cost curve based on learning implicitiy accounts for cost reduction as a function of production volume achieved. The rationale for using a 70 percent learning curve for power conditioning components, namely that the production rate warrants it, seems arbitrary. Documentation supporting these assumptions must be sought in further SPS study efforts via thorough studies of analogous production situations. While the mature industry assumption is questionable for early assembly of EOTV's in space, it is essential to the SPS platform and therefore to many aspects of the EOTV. Entire industries will have to be established for solar cell production and for the fabrication of SPS structure components. For the silicon photovoltaic SPS design $(5 \mathrm{~km} \times 10 \mathrm{~km})$ the production rate implied is 72 acres per day, 365 days per year. The structure will have the same requirement on an areal basis. 


\subsection{Costing Methodology Used In These Estimates,}

Its Appropriateness and Limitations

The methodology used to derive the basic cost estimates made for SPS studies is known under a variety of names including the "extrapolation method" or the "top-down method". Essentially, information on past programs relevant to the technology in question (in this case aerospace efforts for aircraft and space vehicles) has been collected to form a data base covering the level of effort and resources needed to produce systems and physical characteristics of the systems. This data base is then used to estimate the effort required to develop and produce a new system by extrapolating the effort-physical characteristic relationship to the region of the new system.

The effort required can be expressed either in terms of labor hours by various categories (engineering, production, etc) and materials or in terms of inflation-adjusted dollars. The alternate ways of expressing effort can be considered equivalent and are related to each other through the appropriate wage rates and prices; correctly selected rates provide not only market differentials in skills but also costs of benefits and overhead. The physical characteristics used to relate the effort required for given systems are usually elementary ones such as total weight of the system (or specific subsystems), electrical power consumption, heat dissipation, etc. These characteristics are frequently not of ultimate interest (such as payload) but reflect elementary properties common to all systems. These effort or resource requirements and the associated physical characteristics are usually stored in computer files and the Cost Estimating Relationships (CERs) used for such projects as the SPS are derived using statistical techniques. These relationships are, however, usually based on empirical curve-fitting as illustrated in Figure 2.3.1.

This figure shows the type of relationship which can be developed by using statistical techniques to derive a cost estimating relationship (CER) $(A)$ and error bonds $(B, C)$ when considering all available information." Techniques such as least-squares fits to elementary formulas are typically considered most appropriate. If there are theoretical or pragmatic reasons for excluding some data points or sets of data points, or weighting other points 


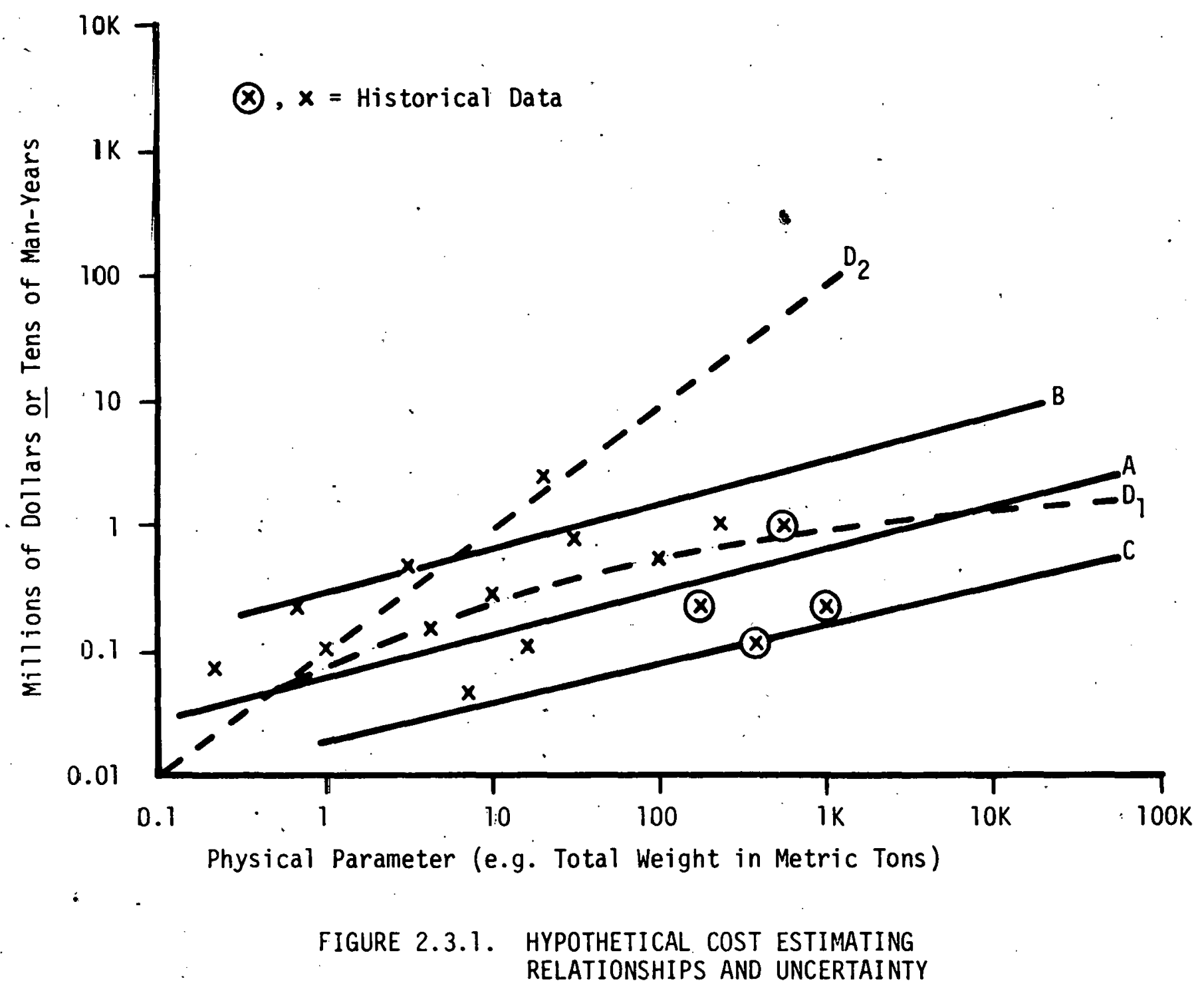


more strongly such as the circled $x^{\prime} s$, different relationships can be developed $\left(e . g ., D_{1}, D_{2}\right)$ from the same data. Thus, the development of appropriate CERs is as much an art as a science. The CER methodology evolved from operations research techniques developed during World War II and the methodology is capable of handling very complex situations and providing an assessment of the expected error. Error bands are thus indicated in Figure 2.3.1 for the hypothetical CER defined by line A. $\left(^{*}\right)$ The methodology for handling errors for an entire system based on the errors for individual CERs is complex, and applies to specific system estimates as contrasted with generalized statements which apply to all uses of the methodolog.y.

The CERs used for the reference vehicles are extracted from the Boeing Company's proprietary data base covering man-hours and materials for their past programs and are used to formulate their bids. our request for access to the Boeing CERs was denied for this reason. The Boeing estimates also did not include any documentation or estimate of the error associated with their estimates. This is also to be expected because the error estimates applied to the work breakdown structure could be used with analytical techniques and other publicly available information to give a good approximation to the CERs. Accordingly, the error estimates for this application must be stated from a general observation.

The usual error statements for this methodology are phrased in terms of \pm 10 or \pm 15 percent as applied to a specific design and contain assumptions that are usually not explicitly stated. These assumptions are: (1) The technology to be used is or will be available shortly and the gap between current technology and the proposed technology or capability is not large--a factor of 2 in capability is large in this sense. (2) The design costed is in fact used. If the design hypothesized for costing is not used because later information shows that design is not preferred for techricical reasons, the statement about its cost is not directly applicable to the replacement and the direct applicability of expenditures accummulated in investigating and

$\left({ }^{*}\right)$ See J. Klion, "Recent Experience in the Development and Application of Life Cycle Cost Models" in AGARD Lecture Series No. 100. (NATO Advisory Group for $R$ and $D$, ISBN-92-835-1321-5) 
developing the old design is a matter of luck and cannot be planned. This later assumption differs somewhat from the expectation in more conventional projects such as bridges and buildings where significantly different designs can be built for approximately the same total costs.

This costing methodology follows technical choices and usually does not direct them because the independent parameters (such as weight) usually reflect design choices rather than cause them. Thus in explaining this methodology and the certainty associated with its estimates, it can be said that the uncertainty for any given design. within the reach of current technology is \pm 10 percent \pm or 15 percent; the problem is selecting a design which one believes is technically sound and meets program goals.

This type of uncertainty statement then is an approximation to probabilistic statements based on variance in parameters in past programs. No specific calculations of the frequently quoted figures of \pm 10 and \pm 15 percent have been found in a search of the literature. It is expected that this is an empirical observation of the cost discrepancies in review of programs meeting the assumptions stated previously.

Since the HLLV and EOTV fall outside of first assumption, [that the growth in capability (payload) is incremented rather than a major leap], it might be expected that the uncertainty would be much larger than this estimate of \pm 15 percent. A separate assessment of NASA's historical experience made in section 2.4., however, shows that for the SPS vehicles proposed, the expectation is that the uncertainty is relatively low. This is primarily due to the relative conventionality of the Reference Vehicles in comparison with the Shuttle. The major exception is the EOTV which is acknowledged to be a major. step in technology. Even the' EOTV will, by the time of the SPS, have relevant experience if NASA builds a solar electric propulsion stage during the 1980's as has been proposed.

It is noted, moreover, that the Reference SPS program is not a fixed target; the SPS transport designs can be expected to change, perhaps radically, between the present and such time as test vehicles are built. The current cost estimates are not generic and cannot be applied to other designs with similar purpose but different technology. 
Alternative Methodologies can be grouped under the name of bottom-up or itemized costing techniques. These are usually applied to projects such as buildings, dams, or refineries where previous experience yields information on the actual labor and material costs to be expected. When design changes and accidents and strikes during the construction projects are excluded, the biggest sources of error are usually due to causes such as price changes in materials being greater than expected, or labor rates rising faster than expected -- in other words, misjudging inflation. The effect of accidents or strikes can be taken into the cost estimates on the basis of past experience as an expectation, but this is usually handled through insurance and specific labor agreements. The expected error on costs derived from itemized or bottom-up costing techniques is usually \pm 5 percent, with most of the error due to misjudgment of future supply and labor prices. These cost estimates are then turned into a bid by the contractor who wants a profit of from 10 percent to 20 percent on top of the costs. Bids based on a relatively low profit margin such as 10 percent will usually have a cost escalation clause which shifts the risk of price increases to the purchaser. Bids which are truly fixed price will include a profit margin, such as 20 percent, which insure the contractor against unexpected price increases.

Bottom-up estimating techniques, however, require highly detailed plans and designs, literally down to the number of nuts and bolts. The SPS designs have not been carried out to this level of detail, hence bottom-up estimates cannot be made. Accordingly, the top-down or extrapolation techniques are the only reasonable method of making the cost estimates for vehicles at this stage of the SPS program. For elements such as ground facilities, the estimates have been extrapolated from analngnus existing facilities when they could have been made by an architectural engineering firm using rough plans. The amount of effort required and the uncertainty of the ground facility requirements strongly suggests that the gain in certainty of these costs would not justify this additional expenditure at this time.

Application and Limits of the Methodology

The estimates derived using extrapolation techniques, specifically Boeing's parametric cost model, were then applied to the construction scenario 
requiring a total of 60 power satellites over a period of approximately 33 years with a brief program build-up phase leading to a satellite construction rate of two per year. The vehicle cost model yields separate estimates of the design and development cost (DDT\&E) and a theoretical first vehicle unit cost (TFU). Past experience in manufacturing shows that the first vehicle is the most difficult to make and that subsequent vehicles will cost less down to some distant limit at which the manufacturing labor efficiency increases very slowly with the existing equipment and facilities. This is approximated as a family of learning curves, as shown in Figure 2.3.2 where both individual and cumulative cost factors are shown for a variety of potential learning situations.

Boeing asserts that its experience with commercial aircraft and other projects indicates that the 85 percent learning curve is the most appropriate for most SPS vehicles and holds for total production runs into the range of $1300-1400$ (e.g., the Boeing 727). This is consistent with other experience in aerospace work where curves in the range of 70 percent to 90 percent are common and the production runs are typically less than 1000. (9)

The average unit hardware cost was then calculated from the total production run over the life of the program. The average cost per flight was then determined from the average hardware cost per flight (vehicle cost/ expected number of flights) and the estimated average costs of maintaining the vehicle on a per flight basis. The SPS transportation program costs, as stated, are then based on this average cost per flight times the number of flights required by the program. This method is appropriate for early stages of program planning, but has two major problems:

1. The early and high unit cost of the first batch of the vehicles is not clearly identified as a potential cash flow problem for the SPS prngram.

2. There is uncertainty associated with the close conjunction of the development program and the actual learning experienced on the first vehicles (as contrasted with the expected learning) and this uncertainty is also not clearly identified.

The major problem foreseen in the use of average un it cost calculations is that the transportation program will appear to have a smoother or 


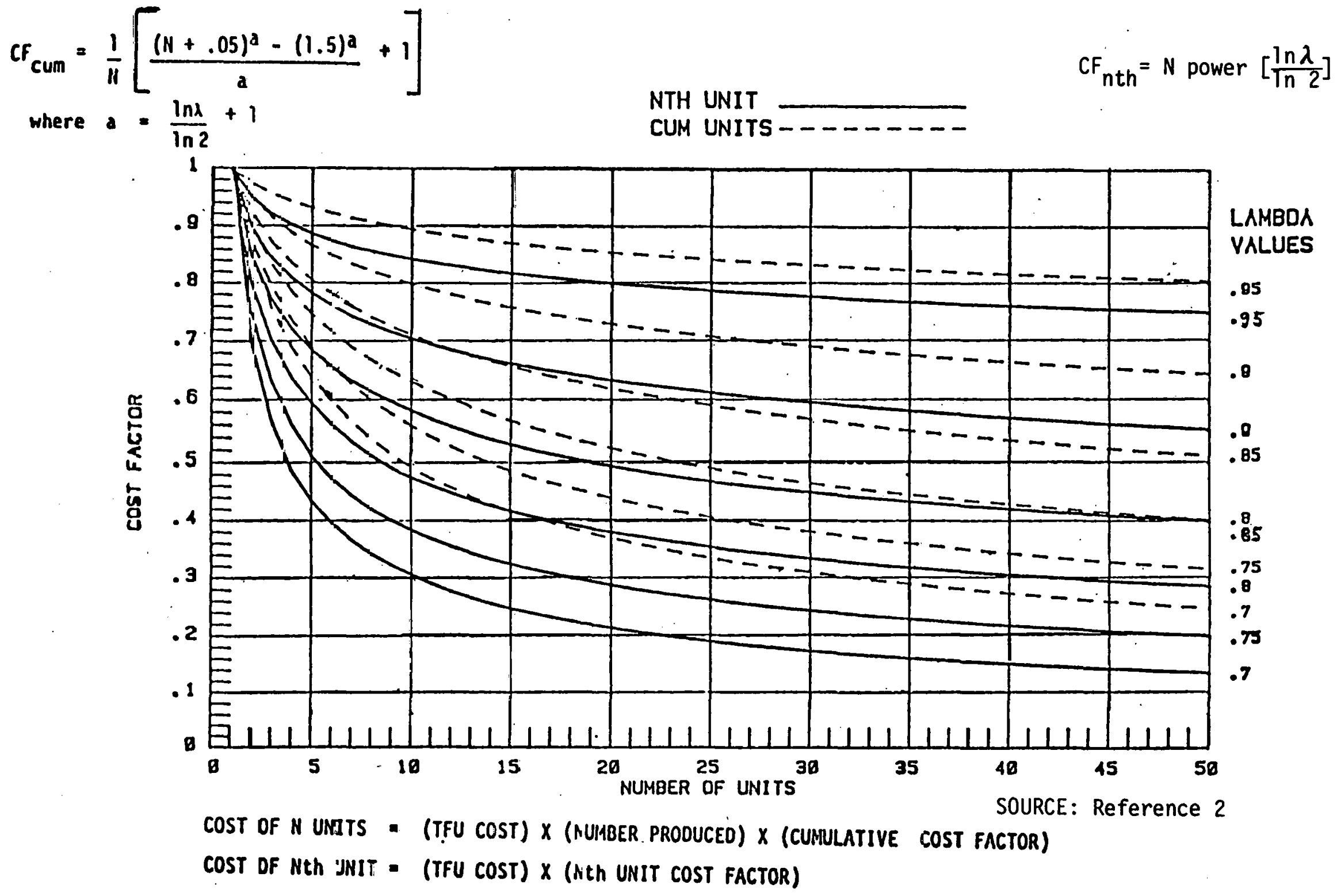


more uniform expenditure level than can be achieved when the strict learning curve calculations are used. This problem will be especially acute with the EOTV where additional assumptions about the learning effects on some high usage components have been made, and in the case of the PLV booster where the SPS program's use of the booster is low.

The problem of uncertainty in the costs due to failure to achieve the projected learning of 85 percent at any given time has been examined using elementary calculations of the effects of both small and large deviations in the estimates. If it is assumed that 85 percent learning can be achieved, as expected, the effect on the total program is small, but there would be a temporary larger cash funding requirement which would partially be recovered in later, lower costs.

The major uncertainties impacting total program costs of the SPS platform are still the recurring costs of reusing the SPS vehicles. The effects of large uncertainties in development and theoretical first unit costs are swamped by the extensive use of the vehicles. The effect of deviations from the 85 percent learning curve estimated by Boeing in the range of 80 percent and 90 percent learning curves result in per flight cost differentials of less than 10 percent if refurbishment is held constant, well within the uncertainty of the supporting CER's. This can be illustrated using Figure 2.3.2 giving the learning curves. The difference between 80 and 90 percent learning curves when the projected learning curve is 85 percent is approximately 10 percent on the cost factor scale. Since this factor applies only to the vehicle hardware cost and not to refurbishment and fuel, the effect on average transportation costs less. Thus, errors in estimating learning curves are expected to result in cost shifts well within the uncertainty of the CER methodology used.

Accordingly, while the use of average hardware unit costs in calculating the total program costs can lead to optimistic views of early program costs, the method selected for estimating these costs is reasonable and, of itself, does not magnify uncertainties. With the exception of the PLV booster, where the original SPS procurement of hardware is 2 units, the procurements are large enough to place the production over the "knee" of the learning curve so that the use of the average cost is reasonable, if not 
precise. The exception, the PLV booster, is an item which would very likely be procured for other space program activities, and thus incur a higher initial production.

With the use of the learning curve factors to achieve an average unit hardware costs, and estimates of refurbishment and full costs, the calculation of average costs per flight is straight-forward and has been done in an appropriate manner. The fuel and refurbishment costs have their own uncertainties, but the methodology, and resultaril cost estimates are fully appropriate at this stage of the SPS program. 


\subsection{Historical Experience}

\subsubsection{Theoretical and Historical Results}

". This report assesses the accuracy and completeness of the estimates for SPS space transport costs via analyses of the proposed program and the performance and its implications for the vehicles. These analyses have used past experience with launch vehicles and aircraft as the guide to determining areas where expenses may be different than projected, such as the need for additional vehicles if 100 percent reliability is not achieved as well as the potential problems associated with the rapid deployment scenario. The fundamental question remains, however, of whether the vehicles can be developed, built and operated under these costs and scenario proposed with the modifications determined in this report.

If the designs proposed are used in the SPS program, the conclusion is yes. In the face of historical examples of significant cost overruns in past and present military and space programs, it is necessary to support this conclusion with a justification and to illustrate this justification with some detailed examples. These examples also indicate some of the conditions, unstated assumptions and indirect costs which are not presented in the SPS transportation cost estimates, and which must be met for success.

One of these conditions has already been mentioned; that the designs proposed must be similar to those used. The substitution of a vehicle such as Rockwell's single-stage-to-orbit aerospace plane would drastically increase the uncertainty in costs. Development of new technology such as required for the Rockwell SSTO usually encounter unanticipated problems and the likelihood of cost growth would be very high. The historical analogy to selecting the aerospace plane would be the initial attempts at building workable launch vehicles and the Shuttle in which considerable difficulty was encountered because no prior experience was available in many of the development areas undertaken. The reference vehicles proposed for the SPS, however, use Shuttle and Solar Electric Propulsion technology in which there should be twenty to thirty years of experience by the time of the initial SPS. In the SPS development time-frame the Shuttle and Solar Electric technologies will be 
developed to the point where the effort will be one of scaling up existing technology rather than proving new concepts. The SPS vehicles would then be analogous to the Apollo-Saturn development. This program, while technically difficult and expensive was able to use the skills, experience and success of previous efforts in launch vehicles to achieve a phenomenal growth in capability in less than ten years.

The entire NASA program with a sub-categorization of the manned spaceflight program (excluding the shuttle) for the years 1959-1976 is given in Table 2.4.1 and is used to illustrate several pnints. The main point illustrated is that a cumplex proyram such as the manned spaceflight (MSF) program was able to accomplish its goals within its cost targets. The Apollo moon program was originally estimated at $\$ 20$ to $\$ 40$ billion (1960 dollars) or $\$ 40$ to $\$ 80$ billion in 1977 dollars. The low end of this range was achieved when NASA's R\&D funding for the manned spaceflight program (including Apollo predecessors) is considered ( $\$ 25 B)$. During this period, however, NASA was conducting vigorous programs in many areas, and much of this activity supported the manned program in addition to having its own goals. The R\&D funding should also be augmented by a major amount of the NASA Construction ( $\$ 2.9$ billion) and Research and Program management ( $\$ 8.9$ billion) expenditures during this period, since the manned program was the immediate justification for these expenditures. A precise allocation of these multi-purpose funds would require a detailed study itself. By noting that slightly more than half of NASA R\&D funding was expended on MSF, however, the al location of hal $f$ of these other funding is reasonable. When this amount $(\$ 5.9 \mathrm{hillion})$ is added to the $\$ 25$ billion for direct MSF expenditures, the total is $\$ 31$ billion or slightly more than half of the total NASA expenditures during the period 1959-1976.

The next point 11 lustrated is that the NASA program was vigorous and multifaceted during the period of the Apollo program. In addition to the major component of manned spaceflight, considerable effort, was expended in other areas including automated missions, aircraft lechnology and a strong generalized science and technology program. Much of this program indirectly, if not directly, supported the manned program. The SPS program, a similarly ambitious program, must also be supported in a similar manner. This type of support is not included in the transportation cost estimates, nor in any 
TABLE 2.4.1 NASA EXPENDITURES BY CATEGORIES (1959-76)

(Dollars in Billions)

\begin{tabular}{|c|c|c|c|c|c|c|c|c|c|c|c|c|}
\hline $\begin{array}{l}\text { Fiscal } \\
\text { Year }\end{array}$ & & $\begin{array}{l}\text { Inflation } \\
\text { Factors } \\
\text { (CPI) }\end{array}$ & $\begin{array}{c}\$, 77 \\
\text { NASA } \\
\text { Dutlays } \\
\end{array}$ & $\begin{array}{c}\text { NASA } \\
\text { Out lays } \\
\end{array}$ & $\begin{array}{l}\text { NASA } \\
\text { R\&D } \\
\end{array}$ & $\begin{array}{c}\text { NASA } \\
\text { Const. }\end{array}$ & $\begin{array}{l}\text { NASA } \\
\text { R\&PM }\end{array}$ & $\begin{array}{c}\text { Manned } \\
\text { Space } \\
\text { Flight } \\
\text { (w/o Shuttle) } \\
\end{array}$ & $\begin{array}{ll}\$ ; 77 \\
\text { MSF } \\
\text { (w/o Shuttle) }\end{array}$ & $\begin{array}{c}\text { Saturn } \\
V\end{array}$ & $\begin{array}{c}\text { Saturn } \\
\text { IB }\end{array}$ & $\begin{array}{l}\text { Engine } \\
\text { Devel. }\end{array}$ \\
\hline $\begin{array}{l}1977 \\
1976 \\
1975 \\
1974 \\
1973 \\
1972 \\
1971 \\
1970 \\
1969 \\
1968 \\
1967 \\
1966 \\
1965 \\
1964 \\
1963 \\
1962 \\
1961 \\
1960 \\
1959\end{array}$ & $\because$ & $\begin{array}{l}1.000 \\
1.073 \\
1.135 \\
1.239 \\
1.375 \\
1.460 \\
1.509 \\
1.573 \\
1.666 \\
1.756 \\
1.830 \\
1.883 \\
1.936 \\
1.970 \\
1.995 \\
2.020 \\
2.042 \\
2.063 \\
2.096\end{array}$ & $\begin{array}{r}2.096 \\
3.707 \\
4.034 \\
4.558 \\
4.997 \\
5.103 \\
5.904 \\
7.083 \\
8.294 \\
9.929 \\
11.171 \\
9.860 \\
8.217 \\
5.092 \\
2.539 \\
1.520 \\
0.827 \\
0.305 \\
118.090\end{array}$ & $\begin{array}{l}1.953^{\star} \\
3.267 \\
3.256 \\
3.315 \\
3.423 \\
3.382 \\
3.753 \\
4.252 \\
4.724 \\
5.425 \\
5.933 \\
5.093 \\
4.171 \\
2.552 \\
1.257 \\
0.744 \\
0.401 \\
0.145 \\
57.047 \\
\end{array}$ & $\begin{array}{r}1.490 \\
2.420 \\
2.422 \\
2.541 \\
2.623 \\
2.630 \\
2.991 \\
3.530 \\
3.946 \\
4.487 \\
4.741 \\
3.984 \\
3.317 \\
2.308 \\
0.936 \\
0.487 \\
0.256 \\
0.034 \\
75.146\end{array}$ & $\begin{array}{l}0.069 \\
0.085 \\
0.075 \\
0.045 \\
0.050 \\
0.044 \\
0.054 \\
0.065 \\
0.126 \\
0.288 \\
0.572 \\
0.531 \\
0.438 \\
0.225 \\
0.114 \\
0.098 \\
0.054 \\
0.025 \\
2.960\end{array}$ & $\begin{array}{l}0.400 \\
0.761 \\
0.760 \\
0.729 \\
0.749 \\
0.708 \\
0.707 \\
0.656 \\
0.652 \\
0.650 \\
0.619 \\
0.578 \\
0.416 \\
0.019 \\
0.207 \\
0.159 \\
0.091 \\
0.087 \\
8.946\end{array}$ & $\begin{array}{l}0.189 \\
0.293 \\
0.502 \\
0.905 \\
1.172 \\
1.421 \\
2.029 \\
2.175 \\
2.809 \\
3.007 \\
3.162 \\
2.938 \\
2.695 \\
2.174 t\end{array}$ & $\begin{array}{l}0.202 \\
0.333 \\
0.622 \\
1.244 \\
1.712 . \\
2.583 \\
3.191 \\
3.624 \\
4.933 \\
5.502 \\
5.954 \\
5.687 \\
5.308 \\
4.338 t \\
\\
\\
45.232\end{array}$ & $\begin{array}{l}0.020 \\
0.237 \\
0.217 \\
0.570 \\
0.687 \\
1.008 \\
1.097 \\
1.134 \\
0.969 \\
0.763 \\
0.3947\end{array}$ & $\begin{array}{l} \\
0.061 \\
0.139 \\
0.225 \\
0.274 \\
0.302 \\
0.333 \\
0.561 \uparrow\end{array}$ & $\begin{array}{l}0.007 \\
0.007 \\
0.021 \\
0.050 \\
0.133 \\
0.166 \\
0.166 \\
0.352 \uparrow \\
\\
0.901\end{array}$ \\
\hline
\end{tabular}

SOURCES: Reference 5, Reference 7

Foutlays for FYI976 are cistorted by transition quarter allowances.

tReadily available data cre summarized as "1963 and Prior". 
TABLE 2.4.2 ORIGINAL SHUTTLE ESTIMATES

\begin{tabular}{|c|c|c|}
\hline $\begin{array}{l}\text { PROGRAM } \\
\text { ELEMENT }\end{array}$ & $\begin{array}{l}\text { Original } \\
\text { Dollars (1973) }\end{array}$ & $\begin{array}{l}1977 \\
\text { Dollars }\end{array}$ \\
\hline $\begin{array}{l}\text { DDT\&E } \\
\text { Facilities } \\
\text { Investment (Orbiters) }\end{array}$ & $\begin{array}{l}\$ 5.150 \mathrm{~B} \\
\$ 0.300 \mathrm{~B} \\
\$ 1.000 \mathrm{~B}\end{array}$ & $\begin{array}{lll}\$ 7.081 & \mathrm{~B} \\
\$ 0.431 & \mathrm{~B} \\
\$ 1.375 & \mathrm{~B}\end{array}$ \\
\hline $\begin{array}{l}\text { Flight Charge }(1973) \\
\text { Flight r.harge }(1976)+\end{array}$ & $\begin{array}{l}\$ 10.45 \mathrm{M} \\
\$ 14.85 \mathrm{M}\end{array}$ & $\$ \$ 14.37 \mathrm{M}$ \\
\hline
\end{tabular}

+ Originally \$18 Million in 1975 dollars--see text for. discussion

adjustments we have suggested. It is noted that the total NASA expenditures in the Apollo period (1959-1976) when adjusted for inflation to 1977 dollars are $\$ 118$ billion or approximately the current estimate of the cost of the SPS through the first platform.

During the same period the cost for launch vehicles for the Apollo program, including both vehicle and engine development was $\$ 9.8$ billion or 38 percent of the Apollo program and 17 percent of the total program. Considering the differences between the two programs in terms of continuing use of the vehicles, the SPS vehicle costs and the Apollo vehicle costs are approximately the same percentage of program costs.

In contrast, the Shuttle Program, which is developing new technology, such as reusable thermal protection systems and reusable engines which are also required for use on the SPS vehicles, is being developed at a time when the NASA budget is tightly constrained. Support for the Shuttle must be extracted from other programs when trouble is encountered. Because of the technical advances which have yet to be completed, the Shuttle is behind schedule and consequently is ahead of costs. The original estimate is shown in Table 2.4.2 in the original 1973 dollars and as adjusted to 1977 dollars. Overruns are expected which are substantial in terms of absolute dollars but which may be on the order of 20 percent of the total program when adjusted for inflation. 
We have not been able to determine the equivalent cost overruns for the original, unmanned space launch vehicles, but expect overruns to have been of this magnitude rather than larger, with one notable exception, the Centaur. This cryogenic upper stage was a "first" and experienced significant problems before ultimate success. The relatively low underruns in most of the vehicle developments was due to several factors: (1) the space launch vehicles were developed from ICBM boosters (Thor-Delta, Atlas-Centaur and Titan) and from NASA sounding rockets (Scout). (2) development test flights were scheduled into the program and most the failures occurred and the problems resolved in this portion of the program. These vehicles also had initial and continuing reliability problems which have been only partially overcome in the process of extensive use, e.g., $151 \mathrm{fl}$ ights for the Delta, the most frequently used vehicle. The manned Shuttle, however, can be rated as a success only if no serious accident occurs in the planned six development launches or in the early operational phase.

In addition to the question of whether the SPS vehicles can be built within reasonable cost estimates, there is a question of whether the current vehicle technology can be scaled up to meet SPS requirements. Historical experience is very positive in this area. The Apollo vehicles were designed and built largely according to the original proposals from experience gained with ICBM boosters. In addition, the Delta vehicle, which started out as an ICBM derivative was uprated from a capacity of $45 \mathrm{~kg}$ (100 lbs) to $954 \mathrm{~kg}$ $(2,100 \mathrm{lbs})$ to the same reference orbit (Geosynchronous. Transfer), a factor of 21 improvement in payload during a period of less than 20 years. The progression in this design is illustrated in Figure 2.4.3. Progress toward increasing the capacity of other designs has not been as dramatic, mostly because the Delta was the vehicle with capability and cost desired by commercial users for communications satellites. As inferred by the drawings, the Delta has evolved significantly and this includes the replacement of all engiries and the guidance system.

An assessment of detailed Delta cost information(10) indicates that this growth in capability by a factor of 21 for the Delta has been accomplished with only modest growth in cost above that caused by inflation. The costs of using all launch vehicles were revised in the mid-1970's as part 

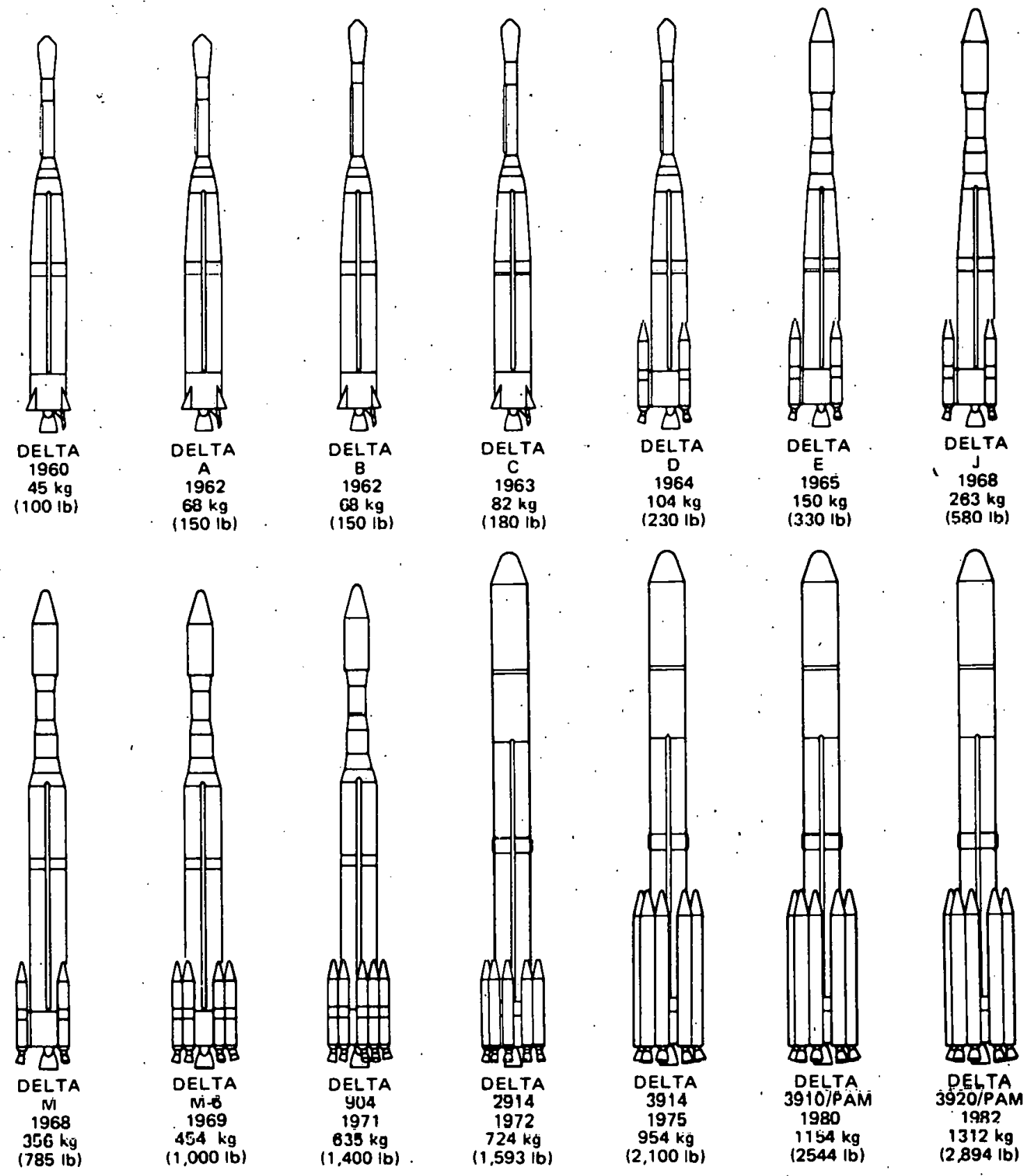

Geosynchronous Transfer Orbit Capability - ESMC

SOURCE: Reference 8

FIGURE 2.4.3 DELTA LAUNCH VEHICLE GROWTH 
of a government wide policy change to collect prorated costs for facilities and other investments which had not been collected previously. As a result, 'the Shuttle charge as well as those for expendable vehicles were revised upward. The previous charges covered items which are analogous to the SPS vehicle costs per flight while the new charges include the costs of launch facilities and civil service salaries which are not in the SPS vehicle costs.

The development costs for increasing the payload capability are also not directly included in the vehicle costs examined. Most have been paid directly from the overall Delta budget line, and our estimate of these expenditures is approximately 25 percent of the total expended on the Delta program. Charges after the mid-1970's, however, include an allocation for developments subsequent to the policy change. Other vehicles such as the Atlas, Titan and Scout have had payload capability growth in the same period, but this growth has not been as dramatic. This is due both to technical reasons--they started from higher relative capabilities--and due to lack of demand for increasing the payload capacity above that which existed.

This discussion, then, indicates that substantial payload growth can occur at reasonable cost and at a pace dictated by demand, here defined as a willingness to invest for the capability.

This discussion addressed two questions of whether it is possible to (1) develop the requisite capacity of the SPS vehicles and (2) within cost estimates. The conclusion drawn is that it is indeed possible under the constraint that the developments do not stretch technology availability. This is not, of course, a guarantee that the SPS vehicles will be built within precisely defined cost limits, only an indication that it is possible. There are, unfortunately, counter-examples of developments which met both of these criteria and still had major overruns. 
2.5 Conclusions and Recommendations

\subsubsection{Cost Uncertainty Estimate}

The vehicle design and first unit costs estimated by the contractors have been found to be reasonable in terms of the advancement in capabilities and technology required. The designs selected; with the exception of the EOTV, are extensions of current launch vehicle technology and thus have relatively low uncertainties in relation to more ambitious designs. The unc.ert.aint.y assnciat.er with the Cost Estimating Relationship (CER) methodology used for the Reference Vehicle cost estimates is in the range of 10 to 15 percent, and is typical of uncertainties in aerospace programs at this stage of development. Because the cargo vehicles (HLLV and EOTV) require a substantial increase beyond current capacities, the statement that the uncertainty lies within this range implies successful completion of the Shuttle and Solar Electric Propulsion Stage programs under way or planned by NASA.

An alternative way of viewing the level of development uncertainty is to consider the effect of an unanticipated and significant development problem which is not revealed by the testing program until the design and initial. units well underway. The resolution of this problem within the same basic design would likely take from 6 to 18 months and involve tens to hundreds of millions depending upon the stage of progress when the problem was perceived. Because designs are in many respects modular, some efforts can proceed and others would be blocked; exactly which cannot be foreseen. The direct effect of a $\$ 200$ million extra expenditure to resolve a problem on the HLLV, for example would be a two percent overrun on development. Because other activities would be stalled during a period of high expenditures, the indirect effects could cause a-total overrun of one or two billion dollars. or 10 to 20 percent. This level of overrun, while large in terms of absolute dollar amounts, is the uncertainty inherent at this stage of program planning. In the case of the other chemical propulsion vehicles, both the design efforts and development problems are expected to result in lower dollar amounts but the effects of any significant problem would have a similar percentage impact.. The EOTV, sharing many of the same components of the SPS platform, and required to be available 
earlier, is expected to have a larger uncertainty. Because of this uncertainty at this stage of the program, it is expected that research efforts will be directed toward reducing that uncertainty so that at the time a commitment is made, there will be information and design experience establishing approximately the same level of uncertainty as for the chemical propulsion vehicles. At this time, however, the EOTV has a larger uncertainty due to untested.technology. Because of the potential problems of an untried and tested technology, specifically large space structures, uncertainty statements in this area are necessarily subjective, until experience is available for more explicit comparisons.

\subsubsection{Reliability Assumption Impact}

The SPS program costs for transportation âre based on an ambitious scenario which assumes 100 percent reliability for the vehicles. The use of this 100 percent reliability assumption is considered to be appropriate only for initial planning and program sizing calculations and must be supplemented by a thorough assessment of the problems which can occur when space vehicles have major accidents. A preliminary examination of these problems indicates that additional vehicles are required to assure the ability to meet the proposed construction rate of two'5 Gigawatt platforms per year.' An increase in investment costs of about 10 percent would allow purchase and use of reasonable number of additional vehicles. The exact level of increase depends upon a determination of acceptable program risks and the consequences of . specific events or accidents. Accordingly, we make two recommendations in this area:

(1) The cost estimates for space transportation should be increased to reflert. additional costs of having reserve vehicles on hand.

(2) The exact level of reserve vehicles should be determined as part of revisions to the SPS operating and cost plan. The plan should specify the potential risks and determine reasonable responses to those risks to maintain SPS construction schedules in the event of the likely disruptions in transport capibility. 
The special development of the Personnel Launch Vehicle (PLV), and specifically the booster, for use in the SPS is questioned. The use of a personnel module aboard the HLLV, if acceptable for safety, would avoid a development expense and have about the same recurring cost per,flight as. the HLLV. The development money could then be spent later, an important programmatic and economic consideration, for additiond HLLV's and provide some of the reserve vehicles needed to assure launching capability in the event of ar.ridents or other disruptiuns. The concept of a small cargo/personnel carrier is, however, considered valid. Adaptation of the then existing space Shuttle should be considered for initial testing of SPS components and subsystems and for unusual cargos which may appear as the SPS program becones more precisely defined. The major reason for questioning the additional development of the PLV booster is that it results in significant additional costs without resulting in a subsequent cost savings and at the same time has no clearly defined role which cannot also be performed by the HLLV.

\subsubsection{Major Source of Uncertainty (EOTV)}

The EOTV has the highest cost uncertainty because experience in many of the technologies is not as advanced as in the other vehicles. Most of the relevant technologies in propulsion are well along in development and should be thoroughly understood when NASA develops and flies, as planned, a solar Electric Propulsion Stage. The remaining major technological problems arc photovoltaic cells and large space structures. Both of these are key technologies for both the SPS platforms as well as the EOTV. Solar cell technology will be pursued for terrestrial energy conversion purposes and thus is very likely to produce a technology and manufacturing infrastructure which can be adapted to SPS platform and/or EOTV use almost independently of the SPS program. The SPS program will have to develop the light-weight spaceworthy cell and assure production capability of approximately 72 acres per day (if Silicon is chosen). In an area where significant non-governmental interest has already been shown, this is considered a manageable if demanding task. 
Space structures, however, are being pursued only by NASA and the major demand in the near-term is likely to come from NASA-engendered programs and the SPS program. In comparison with photovoltaic cells, little work has been done in large space structures and there is no operational experience. Accordingly, the costs as well as the technology is highly uncertain and this is identified as an area requiring extensive efforts if SPS is to succeed. There is, however, no reason to believe that the EOTV presents any problem that would not also be encountered with the SPS power platform. Thus the EOTV cost uncertainty is approximately that of the SPS platform and much higher than that of the other transport components. For purposes of calculating an overall program uncertainty, the values - 15 to 100 percent are assigned, if other studies of the SPS platform indicate higher (or lower) uncertainty, that value can reasonably be used in place of ours.

There is another potential problem associated with the EOTV cost estimates; that of using the average unit cost for the EOTVs as being the representative cost. For other vehicles the initial production run can carry the production cost down to the point where the actual cost approximates the average unit cost. For the EOTV, however, the ability to make this rapid progress is much more uncertain. Many of the components have projected learning cost reductions which are dependent upon the demand for SPS platform components in addition to the demand for their use on the EOTV. If the full production rates for these components are not achieved in a timely manner, the costs for the EOTV can be severely distorted. If the production rate goals are initially missed, but ultimately achieved, thi.s would result in a significant delay in achieving the expected EOTV average unit cost. Accordingly, further study to determine and document the likely path of EOTV costs is recommended.

\subsubsection{High Labor Leaverage on Space Transportation}

SPS vehicle costs have been stated in terms of dollars per flight based on an expected life of the vehicle and expected refurbishment labor hours and rates. Only the fuel costs (15 percent of the cost of the HLLV, for example) do not have a significant, recurring labor component. While the underlying cost estimates are based on labor estimating relations which have 
been translated into dollars, it is all too easy to disassociate the dollar estimates from the underlying manpower requirements. The estimates made for all aspects of the program assure that the imputed labor levels are high. The labor cost leverage on the SPS vehicles is accordingly very high and misestimates of the labor requirements or the real rates of that labor will carry through to the transportation costs directly and proportionately.

There is no evidence that the labor and resulting costs are incorrectly made. The Shuttle program, however, which was to have been operational at this joint in time when the SPS vehicle estimates were made, and thus provide confirmatory information for the SPS estimates, is delayed by developilienl problems. The labor estimates for vehicle refurbishment must therefore be regarded as planning estimates, unconfirmed by directly applicable experience. The uncertainty in the refurbishment estimates for the SPS vehicles is accordingly high. The goal of near-term SPS vehicle investigation efforts should be to reduce both the refurbishment labor requirements and the uncertainty associated with them.

\subsubsection{General Assessment}

The space transportation designs and their cost estimates reflect an early stage of program evolution. Considerable effort has been directed toward making the designs and their cost estimates the best that can be achieved at this point in time with 1 imited funding and with the goal of providing a complete and complex system which can be available by the year 2000. The effort has largely been successful and most of the remaining problems in cost estimation which can be addrcssed by alldiys1s (rather than development) are considered to have a relatively small impact on the transportation cost estimates. The major exception to this statement is the yeneral problem of safety and vehicle reliability and the impacts of these matters on plans and costs. This problem should be explicitly addressed in the early future and the projected costs of overcoming plausible misfortunes should be included in future cost studies. It is acknowledged that to consider these problems in the first program estimates to receive broad public exposure would require a large number of assumptions which. can engender controversy on their own. 
Accordingly deferral of the problem to the near future is reasonable, but acknowledgment of the problem at this time is needed to provide credibility for all program cost estimates as the transportation costs are recognized as a cost driver of the SPS program. This report has indicated some of these cost impacts and it is hoped that these estimates will be useful until replaced by better ones. 
2.40

\section{THIS PAGE \\ WAS INTENTIONALLY \\ LEFT BLANK}




\subsection{REVIEW OF VEHICLE CONCEPTS AND PERFORMANCE}

A brief technical evaluation of the SPS Transportation System was conducted to provide insight into the difficulty of development programs planned, and to aid in the evaluation of cost allocations. The evaluation consisted of three main activities: (1) Comparison of transportation system weights with present systems and designs to determine whether or not the projected weights can reasonably be expected to be achieved; (2) Identification and assessment of the level of technology required for major vehicle hardware elements (e.g. rocket engines); and (3) Analysis of vehicle mission performance to verify that the vehicles as defined by the contractors would produce the performance quoted.

\subsection{Heavy Lift Launch Vehicle (HLLV) Concepts and Cost Impacts}

\subsubsection{Boeing HLLV}

The Boeing HLLV concept is shown in Figure 3.1.1. It is a winged, two stage series-burn configuration designed for vertical take-off and horizontal landing (VTOHL). Both stages are fully reusable. The booster (first stage) uses 16 Liquid 0xygen/Liquid Methane engines. The orbiter uses 14 Liquid Oxygen/Liquid Hydrogen Space Shuttle Main Engines (SSMEs). An airbreather propulsion system has been provided on the booster for flyback to the launch site. The orbiter has four $\mathrm{LO}_{2} / \mathrm{LH}_{2}$ orbital maneuvering system (OMS) engines for orbit transfers, rendezvous maneuvers, and de-orbit for the return flight.

3.1.1.1 Boeing HLLV Weights. A weight statement for the Boeing HLLV is given with Figure 3.1.1. As shown, the vehicle gross liftoff weight (GLOW) is $10,978,400 \mathrm{~kg}$ (including a $424,000 \mathrm{~kg}$ payload). Booster liftoff weight (BLOW) is $7,813,700 \mathrm{~kg}$ and orbiter liftoff weight (OLOW) without payload is $2,740,700 \mathrm{~kg}$.

For any rocket stage the key parameter that is a measure of design efficiency from the standpoint of weights is the mass fraction. Mass fraction is the ratio of propellant (fuel + oxidizer) weight to total stage weight. 

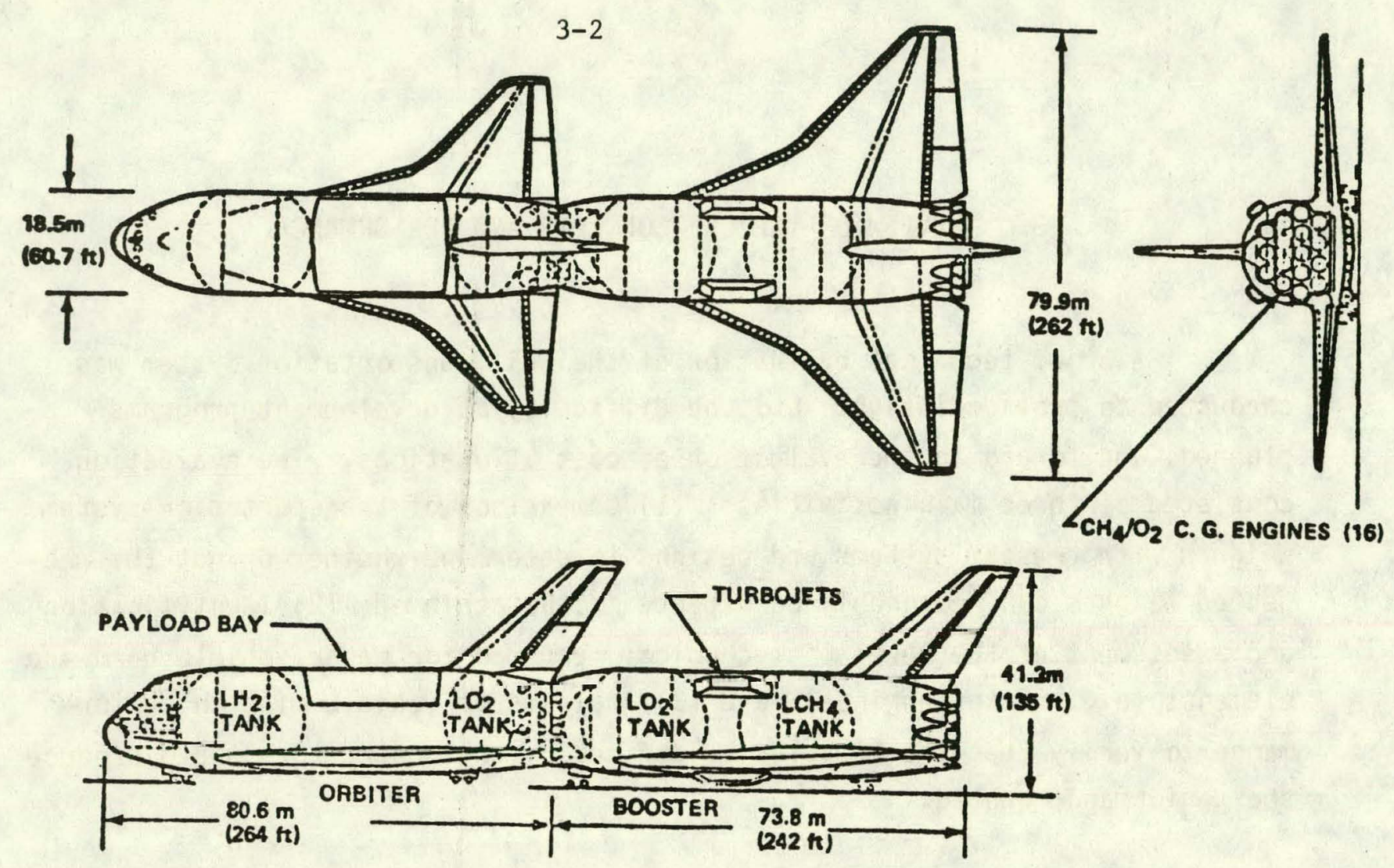

Two-Stage Winged Vehicle Design Characteristics

\begin{tabular}{|l|c|c|c|}
\hline & ORBITER & & BOOSTER \\
\hline GLOW & & $10,978,400$ & \\
BLOW & - & & $7,813,700$ \\
BOOSTER FUEL (LCH $)_{4}$ & - & $1,708,900$ \\
BOOSTER OXIDIZER (LO2) & - & & $5,126,700$ \\
BOOSTER INERTS & $2,740,700$ & & 978,100 \\
OLOW-LESS PAYLOAD & 329,400 \\
ORBITER FUEL (LH $)$ & & - \\
ORBITER OXIDIZER (LO 2$)$ & $1,976,200$ \\
ORBITER INERTS & 435,100 & & - \\
ASCENT PAYLOAD & 424,000 & & - \\
RETURN PAYLOAD 15\% & 63,500 & & - \\
MASS FRACTION & 0.841 & & 0.875 \\
ENTRY WEIGHT-NO PAYLOAD & 395,200 & & 936,600 \\
-WITH RETURN P/L & 156,000 & & - \\
START CRUISE WEIGHT-NO P/L & - & & 932,900 \\
-WITH RETURN P/L & - & & - \\
LANDING WEIGHT-NO PAYLOAD & 391,800 & & 846,700 \\
-WITH RETURN P/L & 452,600 & & - \\
\hline
\end{tabular}

*MAINSTAGE + FLIGHT PERFORMANCE RESERVE

(ALL MASS DATA IN $\mathrm{kg}$ ) 
Thus, for the HLLV orbiter, the mass fraction is:

$$
\frac{329,400+1,976,200}{2,740,700}=0.84 .
$$

The mass fraction for the booster is 0.87 .

These values were compared to the mass fraction of the present Shuttle Orbiter which is similar in design to the HLLV. However, unlike the HLLV, the Shuttle carries most of its $\mathrm{LH}_{2} / \mathrm{LO}_{2}$ propellants in an external tank (ET) attached to the belly of the orbiter (see Figure 3.2.1). HLLV tankage is internal. The Shuttle mass fraction was calculated based on the Orbiter/ET combination and its value is 0.87 .

The HLLV Orbiter mass fraction is less than that of the Shuttle because the integral tankage leads to a much larger orbiter vehicle than would otherwise be required. The disposable tank design of the Shuttle saves weight. The HLLV mass fraction is the same as the Shuttle even though the booster al so has internal tankage. The improved mass fraction occurs for several reasons: (1) economies of scale--the booster is several times the size of the Shuttle, (2) the booster fuel (methane) is much more dense than hydrogen leading to reduced tank size, and (3) the booster is not exposed to reentry conditions so that thermal protection requirements and weights are less.

The conclusion resulting from the above discussions is that the Boeing HLLV mass fractions appear reasonable based on present experience, and should be achievable in the 1990-2000 time frame. Internal tankage is expected to save costs at very high use rates associated with the SPS.

\subsubsection{Boeing HLLV Level of Technology.}

\section{Airframe}

The previous discussion of weights indicates that weight allocations for airframe elements is adequate. The structural materials specified (7075T73 titanium, 7075 aluminum, etc) are standard materials currently available. The only major potential problems identified are in the thermal insulation 
required for the HLLV orbiter. First, the vehicle thermal protection system (TPS) basically is the same as for the current Shuttle, i.e. externally applied Silica tiles. The Shuttle system is currently experiencing flight qualification problems that could lead to an increase of up to $20 \%$ in tile system weight. The question then arises as to whether the HLLV orbiter weight allocation for the tile system is adequate. Upon examination of the data, it is. The fraction of the HLLV orbiter inert weight allocated to thermal protection is 0.12 . The corresponding fraction for the Shuttle is 0.10 . Therefore the HLLV allocation in this cursory analysis appears to be adequate.

A second problem arises from the need to insulate the orbiter liquid hydrogen and liquid oxygen propellant tanks. In the case of Shuttle, propellants are carried in the separable External Tank (ET--see Figure 3.2.1), which is expended on each flight. The Shuttle and all other launch vehicles to date have used expendable tank insulation or insulation that might be reused a maximum of 10 or so times*. A significant development effort may be required for an insulation system that would be reusable, with little or no maintenance, for the life of the orbiter*.

\section{Engines}

The $0_{2} / \mathrm{H}_{2}$ engines for the HLLV orbiter are, as noted previously, the same as those developed for the present Space Shuttle (the SSME). As such they represent off-the-shelf hardware and should present no significant developmental problems.

The $\mathrm{O}_{2} / \mathrm{CH}_{4}$ booster engines represent significant increase in performance over present engines using hydrocarbon fuels. The key measure of rocket engine performance is specific impulse (Isp) which is defined as the engine thrust force divided by the total weight. fl nw rate of all propellants and is measured with units of seconds. The Isp projected for the Boeing HLLV booster engine is 352 seconds. The highest Isp for comparable engines produced to date is 305 seconds for the F-1 on the Saturn V Booster (Apollo Program). However, the F-1 was designed some 20 years ago and no new engines

\footnotetext{
*T/C with G. Woodcock, Boeing Aerospace
} 
of this type have been developed since. For the HLLV engines, the 352 second Isp would be achieved by using SSME technology. High speed pumps would be used to produce an approximately 3-fold increase in engine chamber pressure. That pressure increase, when coupled with a high expansion ratio nozzle, will produce the desired performance increase. No new technology development is needed, but a complete engine development and test program will be required. One area of possible concern is the reliability of the large cluster of engines used on both the booster and the orbiter. The booster uses 16 engines, and the orbiter 14. For a completely successful launch 30 engines must function correctly. If it is assumed that the reliability of individual booster and orbiter engines is the same, then the reliability of the HLLV propulsion systems (probability that all 30 engines will operate successfully) is the reliability of an individual engine raised to the 30 th power. Now the reliability of engines on NASA launches historically has been 0.99 or better. The Delta/Thor MB-3 engine has posted a record of 144 launches without a single failure. Assuming limits of 0.99 and 0.9999 for an individual engine reliability range then overall propulsion system reliability becomes:

\begin{tabular}{cc}
$\begin{array}{c}\text { Engine } \\
\text { Reliability }\end{array}$ & $\begin{array}{c}\text { Propulsion System } \\
\text { Reliability }\end{array}$ \\
\hline 0.99 & 0.74 \\
0.999 & 0.97 \\
0.9999 & 0.997
\end{tabular}

These results illustrate the point that high system reliability requires very high engine reliability. To achieve 0.99 propulsion system reliability would require 0.9996 engine reliability. If this very high engine reliability is not achieved then it will be necessary to cope with occasional engine failure conditions by adjustments in engine design and flight operations. First the engines must be designed so that failures do not produce catastrophic results, but rather only an "engine out" condition. Second, the loss in performance due to engine out conditions must be factored into payload delivery planning. If the vehicle design full payload is carried then "engine out" occurrences could necessitate mission aborts. Alternatively, the number 
of aborts required could be minimized if payload were reduced and/or if payload scheduling were tailored to alleviate the problem. Present scheduling calls for a number of the HLLV flights to carry $\mathrm{O}_{2} / \mathrm{H}_{2}$ propellants to orbit for use in the Personnel Orbit Transfer Vehicle (POTV) and for other uses. If instead of using scheduled flights for this purpose, a quantity of $\mathrm{O}_{2} / \mathrm{H}_{2}$ for the POTV were carried on each flight, then this propellant might be available to the HLLV in "engine out" situations to el iminate the need for many mission aborts. Using this strategy the HLLV full design payload could be carried, but a portion of each payload would be POTV propellants. If this strategy were adopted it would generate a need for long-term (up to months) storage of $\mathrm{O}_{2} / \mathrm{H}_{2}$ propellants. The difficulty and cost of arromplishing this would have to be weighed against the advantages accrued to HLLV operations. Performance calculations indicate that if the payload is reduced approximately 10 percent and the fuel load is as stated, the HLLV would reach the desired orbit if one engine on each stage had to be shut down. If the mission were entirely successful, the fuels could be stored in orbit for orbital use.

\subsubsection{Boeing HLLV Performance.}

The performance of the Boeing HLLV was evaluated using Battelle's launch vehicle performance analysis computer program. Results agreed with those of Boeing $\left(424,000 \mathrm{Kg}\right.$ delivered to a $477 \mathrm{Km}$ orbit at $\left.31^{\circ}\right)$ to within 5 percent. The difference is believed to be a result of our approximations used to expedite analysis and not to a deficiency in the vehicle specifications. Thus, given the present design, the Boeing HLLV should be able to deliver the quoted performance.

Previous discussions have revealed circumstances which conld lead to reduced performance. First, the hooster requires devclopment of a new enigine exhibiting a significant increase in specific impulse over similar existing engines. Second, the use of a total of a 30 engines increases the possibility of having to operate with one more engines out on some flights. The impact of these considerations on HLLV performance was evaluated. Booster engine Isp is listed at 352 seconds, whereas only 305 seconds has been achieved with present engines of that type. HLLV performance at an intermediate booster Isp of 340 seconds was determined and found to be approximately $400,000 \mathrm{Kg}$ del ivered to orbit, 6 percent lower than the nominal $424,000 \mathrm{Kg}$. 
With regard to the engine out condition three cases were examined (1) one booster engine out, (2) one orbiter engine out, and (3) two engines out (one booster, one orbiter). The results are shown in Table 3.1.2.

\section{TABLE 3.1.2 ENGINE OUT PERFORMANCE PENALTY (Boeing HLLV)}

\begin{tabular}{|c|c|c|}
\hline $\begin{array}{c}\text { Number of } \\
\text { Engines Out }\end{array}$ & $\begin{array}{c}\text { Payload } \\
\text { Delivered } \\
(\mathrm{kg}) \\
\end{array}$ & $\begin{array}{r}\text { Percent } \\
\text { Payload } \\
\text { Reduction } \\
\end{array}$ \\
\hline $\begin{array}{l}\text { None } \\
\text { One Booster } \\
\text { One Orbiter } \\
\text { One Booster and } \\
\text { One Orbiter }\end{array}$ & $\begin{array}{l}424,000 \\
396,000 \\
412,000 \\
386,000\end{array}$ & $\begin{array}{l}- \\
7 \\
3\end{array}$ \\
\hline
\end{tabular}

\section{1 .2 Rockwell HLLV}

The Rockwell HLLV concept is shown in.Figure 3.1.3. It is a winged, two-stage, parallel burn configuration designed for vertical take-off and horizontal landing (VTOHL). Both stages are fully reusable. The booster has 7 Lox/RP-1 engines that operate on a gas generator cycle. The orbiter has 4 Lox/Hydrogen engines. An air breather propulsion system is installed in the booster for flyback to the launch site. The orbiter maneuvering propulsion system was not specified.

The Rockwell concept differs from the Boeing concept in a number of ways. It is a much smaller vehicle that delivers only a little more than half the payload $(227,000 \mathrm{Kg}$ versus $424,000 \mathrm{Kg})$ to orbit. It is a parallel burn (both stages ignited on the pad) configuration, whereas the Boeing HLLV is series burn. The Rockwell vehicle uses fewer but larger engines. The orbiter engines are significantly larger (twice the thrust) than the Boeing engines (which were standard SSMEs). 


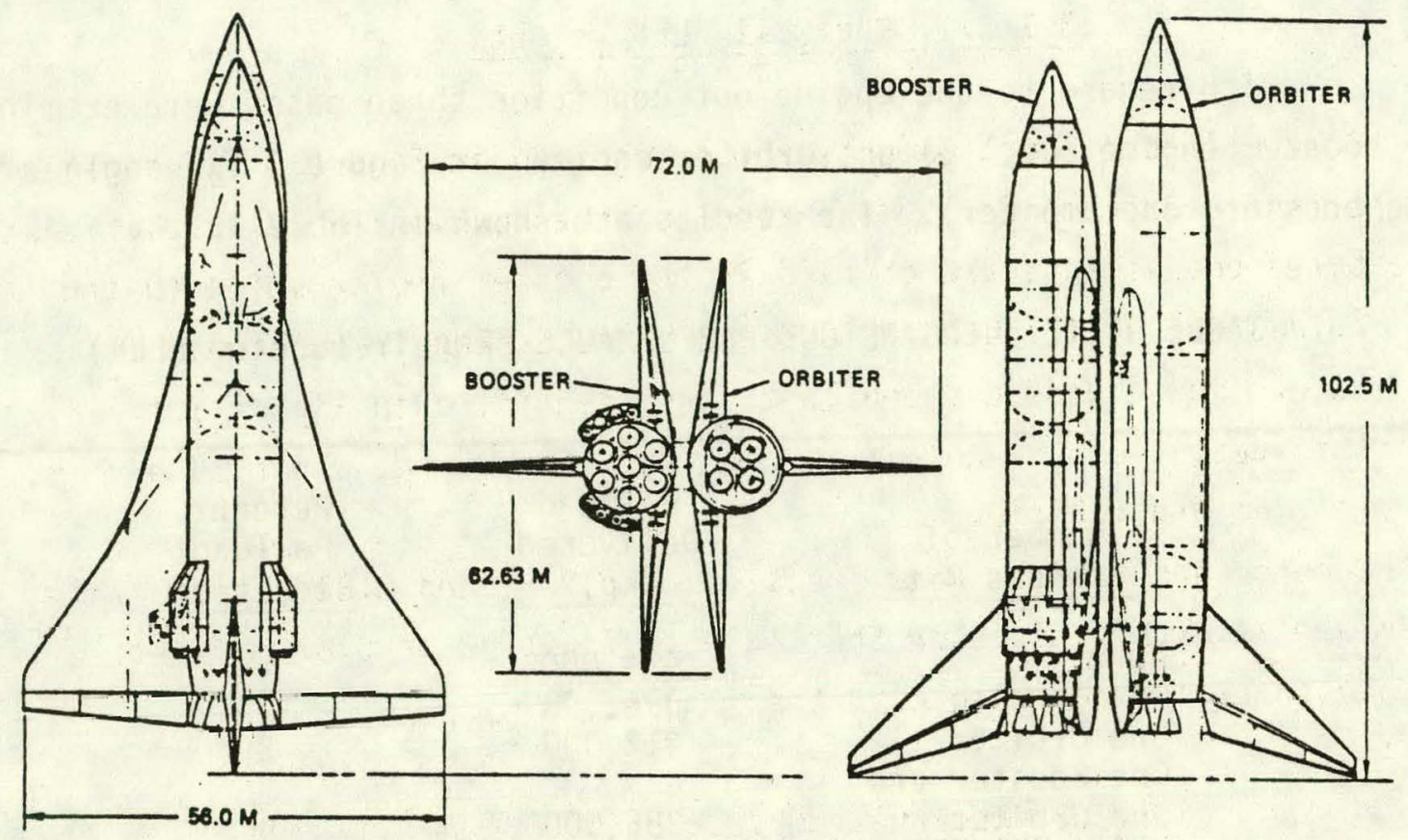

HLLV Weight Statement $k g \times 10^{-3}\left(1 b \times 10^{-3}\right)$

\begin{tabular}{|c|c|c|c|}
\hline SUBSYSTEK & 2NDS & STAGE & IST STAGE \\
\hline $\begin{array}{l}\text { FUSELAGE } \\
\text { IING } \\
\text { VERTICAL TAIL } \\
\text { CANARD } \\
\text { TPS } \\
\text { CREW COMPARTMENT } \\
\text { AVIONICS } \\
\text { PERSONAEL } \\
\text { ENVIRONGENTAL } \\
\text { PRIME POWER } \\
\text { HYDRAULIG SYSTEM } \\
\text { ASCENT ENGINES } \\
\text { RCS SYSTEM } \\
\text { LANDING GEARS } \\
\text { PROPULSION SYSTEMS } \\
\text { ATACH AND SEPARATION } \\
\text { APU } \\
\text { FLYYACK ENGII:ES } \\
\text { FLYBACK PROPULSION SYSTEM } \\
\text { SUBSYSTEMS } \\
\text { DRY WEIGKT } \\
\text { GROWTH MARGIII (15\%) } \\
\text { TOTAL INERT WT. }\end{array}$ & $\begin{array}{r}103.41 \\
39.20 \\
5.70 \\
1.39 \\
52.59 \\
12.70 \\
3.86 \\
1.36 \\
2.59 \\
5.44 \\
3.86 \\
26.93 \\
9.59 \\
18.38 \\
\text {. } \\
= \\
5 \\
286.99 \\
43.05 \\
330.04\end{array}$ & 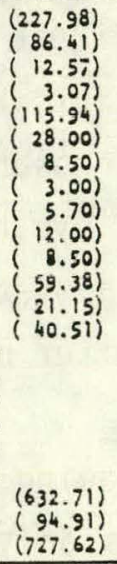 & 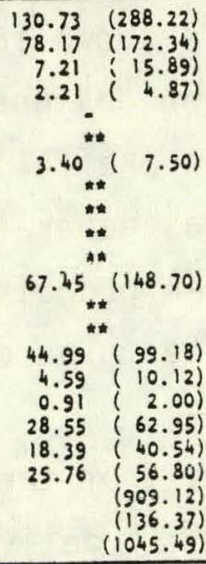 \\
\hline
\end{tabular}

\begin{tabular}{|l|c|c|c|c|}
\hline & \multicolumn{2}{|c|}{ FIRST STAGE } & \multicolumn{2}{c|}{ SECONE STAGE } \\
\cline { 2 - 5 } & LB & KG & LB & KG \\
\hline USABLE & 9.607 & 4.358 & 3.481 & 1.579 \\
:ROSSFEED & 1.612 & 0.732 & $(1.612)$ & $(0.731)$ \\
TOTAL BLRUED & 7.995 & 3.626 & 5.093 & 2.310 \\
RSSI DUALS & 0.040 & 0.018 & 0.020 & 0.009 \\
RESERVES & 0.045 & 0.020 & 0.024 & 0.011 \\
RCS & 0.010 & 0.005 & 0.018 & 0.008 \\
OH-ORBIT & - & - & 0.095 & 0.043 \\
BOIL-OFF & - & - & 0.010 & 0.005 \\
FLY-BACK & 0.187 & 0.085 & - & - \\
\hline TOTAL LOAOSO & 9.889 & 4.486 & 3.648 & 1.655 \\
\hline
\end{tabular}

HILV Mass Properties $\times 10^{-6}$

\begin{tabular}{|lcc|}
\hline & KG & LB \\
GLOW & 7.14 & 15.73 \\
BLOW & 4.92 & 10.84 \\
WP1 & 4.49 & 9.89 \\
ULOW & 2.22 & 4.89 \\
WP2 & 1.66 & 3.65 \\
PAYLOAD & 0.23 & 0.51 \\
\hline
\end{tabular}

FIGURE 3.1.3 ROCKWELL HLLV DRAWING AND MASS STATEMENT 


\subsubsection{Rockwell HLLV Weights}

Rockwell. HLLV inert we ights are summarized in Figure 3.1 .3 together with propellant requirements. One feature of the Rockwell HLLV is that part of the orbiter propellants are carried in the booster and crossfed to the orbiter engines during flight. This reduces the tankage requirement for the orbiter stage. The crossfed propellants are identified in Figure 3.1.3. Gross liftoff weight of the Rockwell HLLV is $7,140,000 \mathrm{~kg}$, about 30 percent less than the Boeing vehicle.

Booster and orbiter mass fractions are 0.88 and 0.81 respectively. These compare favorably with the Shuttle mass fraction of 0.87 defined in 3.1.1.1 and should be achievable in the 1990's.

\subsubsection{Rockwell HLLV Level of Technology}

\section{Air Frame}

Material requirements for the Rockwell concept should be no more demanding than those for the Boeing concept. As with the Boeing vehicle, the . possible concerns are with the orbiter thermal protection system (TPS) and reusable propellant tank insulation (see 3.1.1.2). The TPS weight allocation appears adequate. The fraction of orbiter inert weight devoted to TPS is 0.18 , compared to 0.10 for the Space Shuttle.

\section{Engines}

Both the booster and orbiter engines represent new developments. The orbiter engines are conceptually similar to the SSME, and, for the most part, reflect. SSME level technology. However, they are much larger and operate at a higher Isp (467 sec versus $455 \mathrm{sec}$ ). To produce the higher Isp in an engine that must operate in conditions ranging from sea level to vacuum may require some new technology (c.g., a variable geometry nú $\angle l e$ ).

The booster engine concept is similar to that for Boeing. It is a high chamber pressure, high Isp (352 seconds) hydrocarbon fueled engine: The fuel used is RP-1 (which is very similar to kerosene). Development of the engine should require no new technology and present no special problems above those for the Boeing engine. 
The engine reliability question is substantially different for the Rockwell HLLV than the Boeing vehicle. A total of 11 engines are required compared to 30 for the Boeing concept. Thus, individual engine reliability is less critical to overall propulsion system reliability. Assuming limits of 0.99 and 0.9999 for individual engine reliability, overall propulsion system reliability becomes:

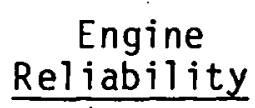

0.99

0.999

0.9999
Propulsion System Reliability

0.90

0.99

0.999

Thus, 0.99 propulsion system reliability can be achieved with 0.999 engine reliability, a level not far above that demonstrated with current engines. Hence, the smaller vehicle with fewer engines considerably alleviates the system reliability problem. However, it should be pointed out that dependence on fewer, larger engines will produce larger impacts on performance when an "engine out" situation does occur, and safe and successfur operations will require that the engines be designed so that failures are not catastrophic.

3.1.2.3 Rockwell HLLV Performance. Performance of the Rockwell HLLV is quoted as $227,000 \mathrm{~kg}$ to a $487 \mathrm{~km}$ orbit at 31.6 degrees inclination. Based on the present vehicle specifications, Battelle's performance analysis agrees with that result.

Performance of the Rockwell concept is dependent on achieving a significant gain in booster Isp from present levels of around 300 seconds (for that type of engine) to 352 seconds. The effect of an arbitrary shortfall of 12 seconds in Isp was analyzed. At 340 seconds bonster Isp, the HLLV payload is reduced 7 percent to approximately $210,000 \mathrm{~kg}$. Examination of engine out conditions demonstrates that, as should be expected the performance of a vehicle with fewer larger engines is penalized more when one or more of those engines fails to function. Results of the analysis are summarized in .Table 3.1.4. The strategy for use of the Rockwell HLLV would probably be to design for high reliability and abort those few flight where an engine out situation occurs. 
The Rockwell parallel-burn concept has never been implemented and this represents a slightly higher. level of technical uncertainty than for the Boeing design. The cost uncertainty is therefore slightly higher.

TABLE 3.1.4 ENGINE OUT PERFORMANCE PENALTY (Rockwel1 HLLV)

\begin{tabular}{ccc} 
Engines Out & $\begin{array}{c}\text { Payload } \\
\text { Delivered } \\
(\mathrm{kg})\end{array}$ & $\begin{array}{c}\text { Percent } \\
\text { Payload } \\
\text { Reduction }\end{array}$ \\
\cline { 1 - 2 } $\begin{array}{c}\text { None } \\
\text { One Booster }\end{array}$ & $\begin{array}{c}227,000 \\
198,000\end{array}$ & - \\
One Orbiter \\
One Booster and & 181,000 & 13 \\
One Orbiter & $\star$ & $*$ \\
\hline
\end{tabular}

3.2 Personnel Launch Vehicle (PLV) Concepts and Cost Impacts

\subsubsection{PLV Technical Assessment}

The Personnel Launch Vehicle (PLV) is used to transport personnel and priority cargo to Low Earth Orbit (LEO). The PLV is an evolutionary deriva-. tion of the Space Shuttle. The vehicle consists of a winged liquid propellant fly back booster that uses four Oxygen/Methane engines similar to the Boeing HLLV booster engines, a smaller version of the Shuttle External Tank (ET), and the Space Shuttle Orbiter. The PLV is shown in Figure 3.2.1.

Since the PLV orbiter is the Shuttle orbiter it presents no technological or developmental problems. The booster uses technology very similar to the HLLV booster and therefore presents no problems not previously addressed in the HLLV discussion. For the HLLV booster only two potential problems were identified: the reliability of multiple engine systems and a possible shortfall in engine performance (inability to achieve the full Isp increase to 352 seconds).

* Loss of two engines produces low liftoff thrust-to-weight ratio (1.14). Abort would probably be required; if not, the performance penalty would be unacceptably large. 


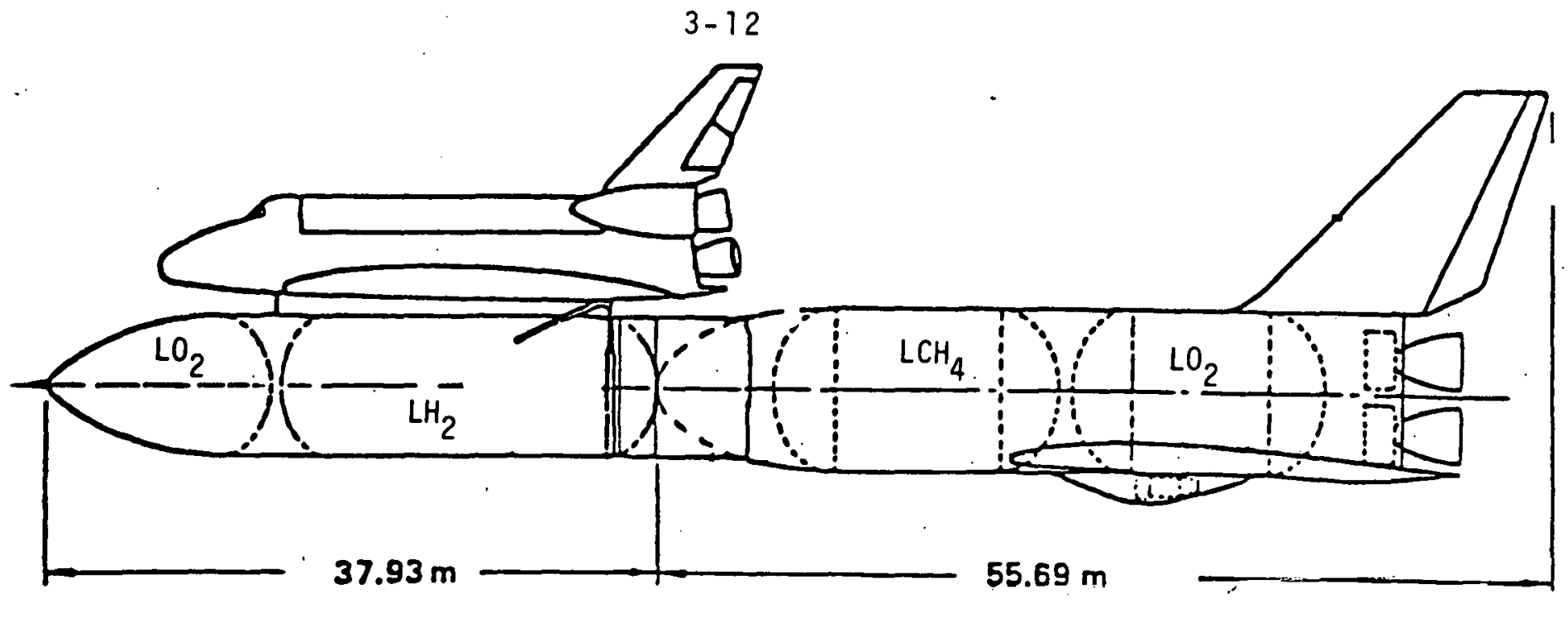

FLYBACK BOOSTER MASS SUMMARY

ORBITER/ET MASS SUMMARY

\begin{tabular}{|c|c|c|c|}
\hline Item & Mass $(\mathrm{Kg})$ & Item & Mass $(\mathrm{Kg})$ \\
\hline Wings & 31,940 & Structures & 21,146 \\
\hline Tail & 4,930 & Thermal Protection & 1,631 \\
\hline Body & 68,490 & Propulsion \& Mech. Syst & 1,710 \\
\hline Induced Envir. Protect. & 9,050 & Electrical System & 66 \\
\hline Landing \& Aux. Systems & 9.710 & Orbiter Attachments & 1,492 \\
\hline Propulsion - Ascent & 51,320 & Change Uncertanty & 686 \\
\hline Propulsion - RCS & 960 & ET Inert Mass & $(26,731)$ \\
\hline Propulsion - Flyback & 13,800 & Unusables & 1,530 \\
\hline Prime Power & 1,190 & ET Meco Mass & $(28,261)$ \\
\hline Eleet. Conv. and O1st. & 960 & Orbiter 103 Prelaunch & \\
\hline Hydr. Conv. and Dist. & 4,320 & Mass w/o Payload. & 91,605 \\
\hline Surface Controls & 2,020 & Orbiter/ET Inert Mass & $(119.866)$ \\
\hline Avionics & 1,450 & & \\
\hline Environmentai Control & 210 & & \\
\hline Growth Allowance & 16,200 & & \\
\hline Dry Mass & $(216 ; 460)$ & r & \\
\hline Restduals and Reserves & 12,700 & & \\
\hline Landing Mass & $(229,160)$ & & \\
\hline Flyback Fuel & 26,260 & & \\
\hline Inflight Losses & 3,900 & & \\
\hline Inert Mass & $(259,320)$ & & \\
\hline
\end{tabular}

FIGURE 3.2.1 PLV DRAWING AND INERT MASS STATEMENT 
The PLV booster has only 4 engines (The HLLV booster has 16) and consequently the reliability concern is greatly reduced. The effect of any small to moderate engine performance shortfall could probably be accommodated by increasing propellant capacity if necessary, in the external tank. The major source of uncertainty for costs lies with the booster development costs, and the integration of the Shuttle with the booster.

\subsection{Cargo Orbit Transfer Vehicle (EOTV) Concepts and Cost Impacts}

\subsubsection{Boeing EOTV}

The Boeing Cargo (Electric) Orbit Transfer Vehicle (EOTV) concept is shown in Figure 3.3.1. The EOTV is an electric propulsion vehicle used to transport satellite components from the LEO staging depot to the GEO construction base. It consists of a solar array, a payload mounting and docking platform, and ion thruster modules at the four corners of the vehicle. The EOTV is designed to be fully reusable with servicing between flights. The Rockwell EOTV is conceptually similar to the Boeing design. Both are portions of an SPS platform delivering power to ion engines instead of a microwave antenna.

3.3.1.1 Boeing EOTV Weights. Boeing EOTV weights are summarized in Figure 3-6. One of the key parameters of interest in evaluating electric vehicle design efficiency is the power generation specific mass. That specific mass is defined as the ratio of power generated in watts to power generation system mass $(\mathrm{kg})$. Presently achievable values are in the 60-200 range. The EOTV design generates $\sim 206$ MW power, so its power generation specific mass is:

$$
\text { specific mass }=\frac{206,000,000}{951,000}=216 \mathrm{w} / \mathrm{kg}
$$

This value is stretching present technology, but considering lead time available and economics of scale, it should be achievable. 


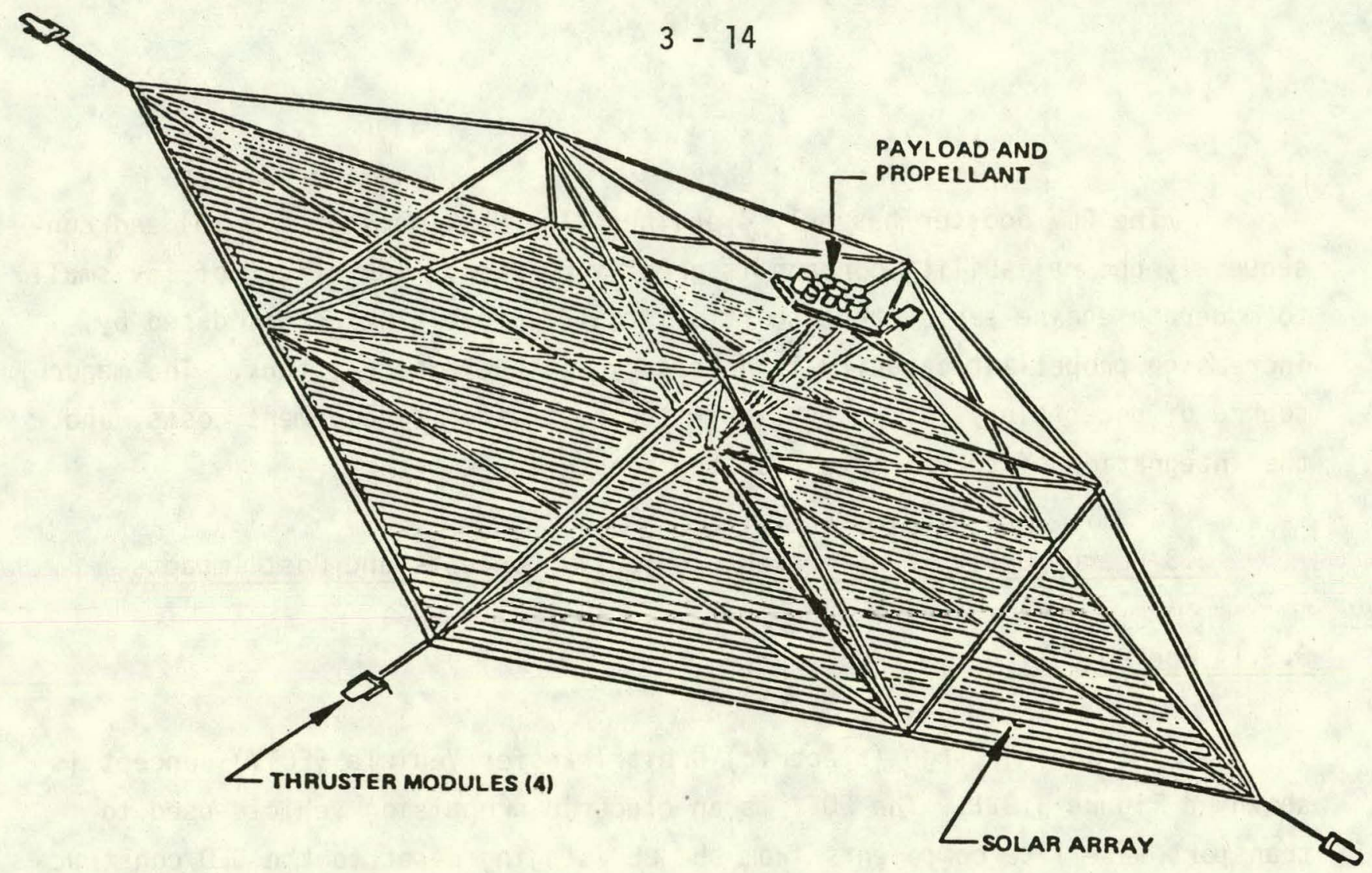

EOTV Mass Summary

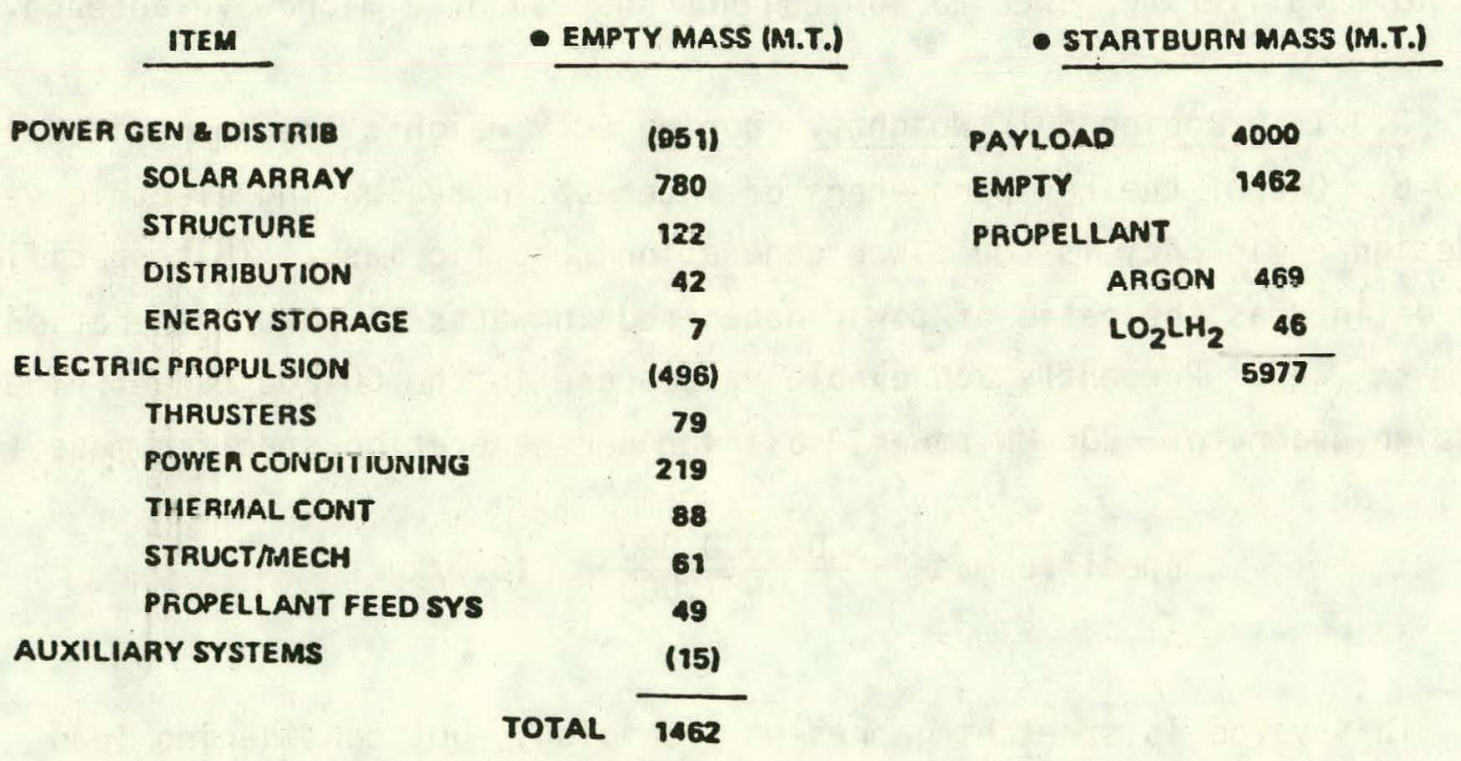

FIGURE 3.3.1 EOTV DRAWING AND MASS STATEMENT 
3.3.1.2 Boeing EOTV Level of Technology. There are a number of issues concerning the technology required to develop the EOTV. These include: on-orbit fabrication and system assembly, restoration of solar cells damaged by Van Allen Belt radiation, orbital collision hazards, thruster scale-up, and thruster lifetime. These issues are discussed briefly below.

The question of fabrication and assembly is one that is shared with the Solar Power Satellite itself. In both cases, the technology required must yet be demonstrated and is key to the entire SPS concept.

The silicon solar cells used to generate power will be significantly damaged (up to $40 \%$ power loss) as the EOTV passes through the Van Allen radiation belts. Most of the damage is probably repairable using a laser annealing device incorporated into the system; however, the operational concept represents advanced technology--its effectiveness and workability will have to be proven in the development program. The Rockwell GaAlAs solar cells on their EOTV would have a definate advantage in self annealing at operating temperatures.

The EOTV will have a cross sectional area of 1.6 million square meters. As it travels between LEO and GEO it will be exposed to the hazard of collision with the orbiting objects (active and inactive satellites, and debris). A specific analysis of this problem was not performed, but some indication of the magnitude of the hazard can be derived from previous studies.

In 1977, NASA was considering the development of a lightweight "Solar Sail" that would use light pressure to provide propulsion for interplanetary and Earth orbital space missions.[6] The cross sectional area of the sail was $625,000 \mathrm{~m}^{2}$, a little over a third the area of the EOTV. The orbital collision hazard for Solar Sait LEO to GEO missions was evaluated and the probability of a collision was found to be 0.1 per mission. However, when the size of objects encountered (many are very small) was considered along with the ability of the sail to survive collisions, the probability of successful passage to GEO was estimated at 0.977 .

[6] Haglund, et. al., "Solar Sail Technology Readiness Report," NASA Jet Propulsion Laboratory, July 18, 1977. 
Since the EOTV is significantly larger than the sail and the mission profiles are similar (but not the same)* it can be expected that the probability of collisions with the EOTV is $0.1-0.3$ or greater. Because the EOTV is based at a lower altitude $(470 \mathrm{~km})$ than the sail $(1200 \mathrm{~km})$ and debris hazards are significantly higher at lower altitudes, the EOTV hazard could be much greater than the sail hazard. Given that the EOTV'planned lifetime is 10 missions; the probability of damage is high. This entire problem area needs to be examined to determine its effect on the operations and cost. Also the inverse problem.needs to be considered--potential damage inflicted on active spacecraft by the FOTV. nebris removal and its associaled custs have not been considered in elther the SPS Reference System or in this study.

The EOTV thrust is to be provided by $120 \mathrm{~cm}$ ion engines. Current NASA ion engine technology is based on $30 \mathrm{~cm}$ engines. Consequently, there arises a question as to how difficult the scale-up to $120 \mathrm{~cm}$ might be. In the 1950 's a $150 \mathrm{~cm}$ engine wàs built and initially tested by NASA.** Although the engine had life limiting features, it is expected that the extension of current technology (scaling) would provide performance and lifetimes equivalent to the current $30 \mathrm{~cm}$ engines. The ion engines are to last the life of the vehicle (10 missions). However, certain engine components (the ion acceleration grids and perhaps the cathode) must be replaced after each round-trip mission. Reliable operation should be achievable if these refurbishment operations are performed.

3.3.1.3 Boeing EOTV Performance. Boeing EOTV performance was evaluated using a low-thrust vehicle performance approximation algorithm。** The

* Sail mission begins at $1200 \mathrm{~km}$ and reaches GF $n$ in 250 days; COTV mission begins at $4 / U \mathrm{~km}$ and reaches GEO in 180 days.

** At that time NASA was considering a manned Mars mission that would use the larger thruster.

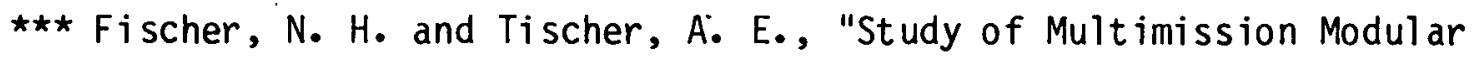
Spacecraft (MMS) Propulsion Requirements," NASA Contract NAS7-786, Battelle Columbus Laboratories, August 8, 1977. 
results indicate that for the reference $4,000,000 \mathrm{~kg}$ payload to GE0, the 180 dayflight time quoted by Boeing is reasonable (Battelle's estimate is 170-200 days). The Boeing quote of a 40-day return ffight to LEO with a $200,000 \mathrm{~kg}$ payload is also reasonable (Battelle's estimate is 40-45 days).

As noted in section 3.3.1.1, the achievement of a 216 watts/kilogram specific mass for the power generation system may be difficult. If a lower value is obtained then a performance penalty will result. If a specific mass of 150 is achieved instead of 216 , then vehicle hardware mass will increase $400,000 \mathrm{~kg}$. This would necessitate reducing the upbound payload by $400,000 \mathrm{~kg}$ (a $10 \%$ reduction), or the payload could be held constant if flight time were increased approximately 7 percent to 193 days.

\subsection{Personnel Orbit Transfer Vehicle Concept and Cost Impacts}

The Personnel Orbit Transfer Vehicle (POTV) is shown in Figure 3.4.1 It is a single-stage $\mathrm{LO}_{2} / \mathrm{LH}_{2}$ vehicle designed to transport personnel and priority cargo from LEO to GE0. Propulsion would be provided by five 19,800 pound $(88,000$ newtons) thrust staged-combustion engines that would operate at an Isp of 470 seconds. The POTV would be capable of transporting a $90,000 \mathrm{~kg}$ payload from LEO to GEO. The entire vehicle propellant load would be used on the up-bound trip. The vehicle would then be refueled in GEO with propellant delivered by the EOTV. The EOTV. is reasonably viewed as being more efficient at fuel transportation than any chemically propelled vehicle such as the POTV.

\subsubsection{P0TV We1ghts}

Figure 3.4.1 provides a POTV mass statement. Based on that data the POTV total mass is $216,000 \mathrm{~kg}$ and its propellant mass fraction is 0.94 . To determine if 0.94 is a reasonable value for the POTV, the mass fractions of NASA's current Centaur stage (an $\mathrm{O}_{2} / \mathrm{H}_{2}$ orbit transfer stage), a proposed growth version of that stage (the Reusable Large Tank Centaur, or RLTC) and the Apollo/S-IVB/IU and S-II were used for comparison. The Centaur is a $16,000 \mathrm{~kg} \mathrm{O} \mathrm{O}_{2} / \mathrm{H}_{2}$ stage with a mass fraction of 0.86 . The RLTC is a 25,000 $\mathrm{kg} \cdot$ stage with a mass function of 0.90 . The comparison is as summarized in Table 3.4.2. 


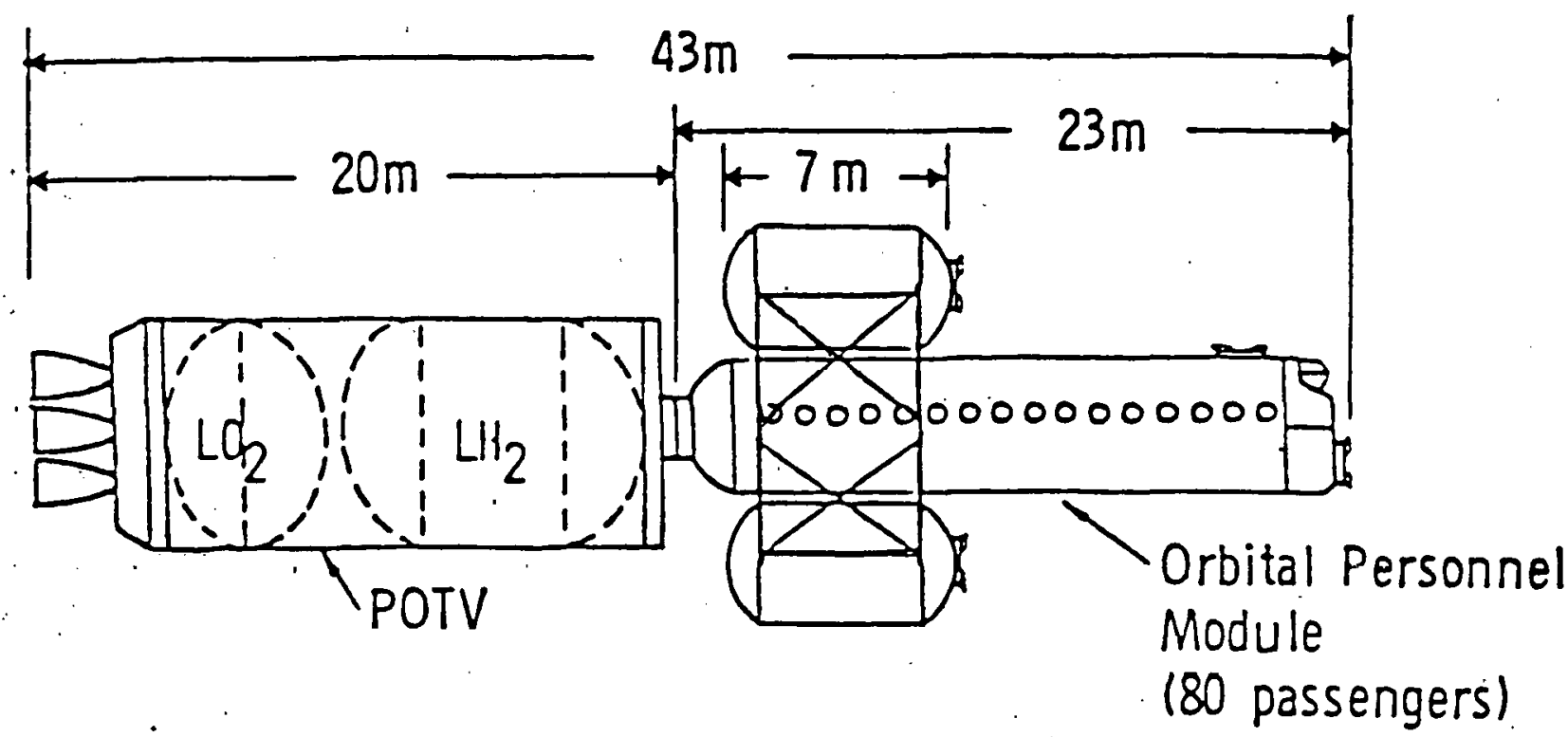

NOTE: Personnel Module Costs NOT in POTV Costs

\section{POTV MASS STATEMENT}

Item

Structure and Mechanisms

Ma in Propulsion

Auxiliary Propulsion

Avionics

Electric Power System

Thermal Control

Contingency (15\%)
Mass (kg)

$\begin{array}{r}6,900 \\ 2,500 \\ 500 \\ 300 \\ 450 \\ 1,030 \\ 1,750 \\ \hline 13,430\end{array}$

90,000

203,000

$216.5 \mathrm{MT}$

FIGURE 3.4.1 POTV DRAWING AND MASS STATEMENT 
TABLE 3.4.2 POTV MASS FRACTION COMPARISON WITH LOX/LIQUID HYDROGEN STAGES

\begin{tabular}{lrc}
\hline Stage & $\begin{array}{r}\text { Stage } \\
\text { Mass } \\
(\mathrm{kg})\end{array}$ & $: \begin{array}{c}\text { Mass } \\
\text { Fraction }\end{array}$ \\
\hline Centaur & 16,000 & 0.86 \\
RLTC & 25,000 & 0.90 \\
S-IVB/IU & 119,655 & 0.87 \\
POTV & 216,000 & 0.94 \\
S-II & 497,509 & 0.90 \\
\hline
\end{tabular}

A mass fraction of 0.94 would appear to be somewhat optimistic based on historical values. However, these are 1960's designs and the size of the POTV brings in an economy of scale factor that may make 0.94 reasonable.

\subsubsection{POTV Level of Technology}

The POTV represents only a moderate step forward in design from present vehicles. The engines are based on Shuttle engine (SSME) technology. As noted in 3.4.1, the improvement in mass fraction to 0.94 represents somewhat of a challenge, but it is not an unreasonable goal for a vehicle of that size in the 1990's. However, the on orbit handling and storage requirement of POTV $\mathrm{O}_{2} / \mathrm{H}_{2}$ propellants may be cause for concern.

The present operational concept assumes the POTV would be refueled in GE0. The GEO propellant supply would be maintained by carrying propellant to GEO with the EOTV. Oxygen and Hydrogen propellants are cryogenic and difficult to store for any extended period. The EOTV will require 180 days to transport its propellants to GEO, to which must be added the GEO storage time. Active cooling of the propellants will have to be provided on the EOTV and in GE0. The availability of abundant power will help to resolve this problem but the cooling equipment must be counted as part of the EOTV payload. This level of detail has not been addressed in the SPS delivery scenario. 


\subsubsection{POTV Performance}

POTV performance was evaluated for the LEO to GEO mission assuming the specified stage weights and engine performance (Isp $=470$ seconds) would be achieved. The analysis results are tentative since the weight statement (Figure 3.4.1) does not identify what portion of "Total Propellant and Fuel Cell Fuel" is allocated for $\mathrm{O}_{2} / \mathrm{H}_{2}$ main stage propellants. If approximately 93 - 95 percent of those propellants are $\mathrm{O}_{2} / \mathrm{H}_{2}$ main stage prope 1lants then the quoted performance of 90,000 delivered to GEO is reasonable.

\section{5 l/tility/Intraorbltal Trangfer Vehicles}

These vehicles are not included in the SPS Reference System Transportation Subsystem and accordingly have not been reviewed in detail. The area of orbital operations has not been defined to provide the level of information needed to make the same type of investigation and judgements as has been done for the transport vehicles.

At least three different intraorbital vehicles have been proposed for orbital operations:

(1) A large maintenance/supply trạnsport vehicle. The POTV has been suggested for the mission and the POTV performance appears appropriate. There is some concern, however, that the long potential duration of the SPS matntenance missions may require some modifications to the fuel system and engines such that the. POTV and the large IOTV are not truly interchangeable.

(2) A medium to small stage lu transfer and maneuser HLLV payloads at LEO and GEO., A small vehicle using POTV technology has been proposed and briefly illustrated.

(3) A small vehicle to transport a few (1 to 5) people to and from short-duration tasks has been illustrated but not described technically.

While these vehicles are not part of the transportation category in the WBS, and the costs during the life of the SPS will be miniscule in comparision to Earth-to-LEO vehicles, their costs in absolute terms will be in 
the hundreds of millions per year. They will also require servicing and place a demand on orbital vehicle maintenance facilities.

\subsection{Launch, Recovery and Refurbishment Facilities}

The ground based vehicle service facilities appear to have been adequately covered in parametric estimates and reasonably and appropriately costed. Since these facilities and manpower requirements have not been documented by specific designs and staffing plans, it is difficult to provide a definitive assessment of their accuracy and certainty. Major facilities required to service the vehicles have been indicated with a cost breakout (see Appendix B). The staffing requirement of 6425 man-years per year for both vehicle operations and maintenance has been costed at $\$ 40$ per man-hour and this is a very reasonable est imate which covers both direct labor as well as indirect labor and materials. This implicit costing method will be discussed later in the context of overall staffing requirements.

The vehicles proposed for the Reference System are relatively labor intensive for what might be expected in the time after the turn of the century. The possibilities of labor reduction through development and design of components and systems with much longer use life than is currently envisioned is clearly indicated. Since the detailed designs for both the Reference System vehicle components and service facilities are not available, the area of service requirements is considered to be very uncertain. We rate this, subjectively, at \pm 25 percent (1 standard deviation). This is to be interpreted as agreement with the Boeing/JSC estimate, while asserting that a great deal of design and planning remain to"be accomplished in this area.

In examining the related SPS documentation, we find that there is concern that Kennedy Space Center may not be large enough to support the volume of transportation required. It also appears that an equatorial or other launch site would require an additional $\$ 2$ to $\$ 6$ billion dollars depending upon whether it were located on land or on an offshore platform. These estimates do not include specialized equipment.

The need for an additional site may be required or desired to provide internationalization of the SPS. The technical need, however, is considered 
slight because the gross volume of the SPS compares with the freight volume through a major airport such as Los Angeles. A rate of approximately 400-500 tons per day is relatively small for any major trucking firm. Other supplies to operate the launch site and generate the launching fuel will probably require revitalized rail or other ground transport, but are not expected to be quantitatively different from rapid growth of one moderately sized city to a medium-sized city.

The use of the EOTV for transport from LEO to GEO is al so expected to reduce the advantage of an equatorial site in terms of cost of transporting mas3 to GEO. "The high Isp of electriral propulsion permits the plane change from 28 degrees to the equator from KSC with relatively low fuel costs and the rotational velocity of the Earth in assisting the vehicle is less than a seven percent advantage in terms of payload to LEO. Thus, while the additional cost of an equatorial site would be eventually recaptured, there is no great technical advantage. The equatorial site would al so represent a "front-end" cost.

If an additional launch site is required, it.could also be located in south Texas in a relatively unpopulated area and have approximately the same advantages and disadvantages as KSC. The vehicles would leave the lower atmosphere before croșing land and the latitudes in south Texas are the same or less than at KSC.

\subsection{Staffing and Production Implications}

The only explicit staffing estimate avallable is for the vehicle operations and maintenance facilities at KSC. The approximately 6425 manyears per year is considered to be reasonable for the direct labor required for the launch vehicles and the $\$ 40$ per hour used to estimate the cost reflects aerospace overhead and materials requirements in 1977. Because of. the WBS definition of transportation, there is concern that indirect requirements and their costs have not been captured. Since there is no plan or model of the manpower requirements--the labor hours and resultant costs have been estimated parametrically--it is possible to judge the staffing requirements only in a very gross sense. 
Specifically: The transportation cost per SPS is $\$ 2.8$ billion with two SPSs per year. At $\$ 40$ per hour for direct staff (and which includes materials and indirect staff and overhead), the direct staff estimate is:

$$
\frac{2 \text { SPSS } 0 \$ 2.8 \times 10^{9} \text { (Transport Cost) }}{\$ 40 / \text { hour } \times 2080 \text { hours } / \text { work year }}=67,307 \text { man-years }
$$

For transport at $\$ 12.5$ billion per SPS, the total staffing is:

$2 \times \$ 12.5 \times 10^{9}$ (Total Cost) $=300,480$ man-years $\$ 40 /$ hour: 2080 hours/work year

The implicit transportation staff is 67,000 out of a total of 300,000 SPS staff, or 22 percent, and this estimate applies to the vehicles only.

For comparison, the air carriers (airlines) employed 292,300 people in 1975 with revenues of $\$ 14.9$ billion and the aircraft industry employment was 514,000 with revenues of $\$ 29.5$ billion.* The average of revenues per employee was \$26/hour (1975) and when this is adjusted for inflation to 1977 by the consumer price index, this becomes $\$ 30 /$ hour. This is compared to $\$ 40 /$ hour used as an aerospace/R\&D equivalent for the SPS in 1977 dollars.

The 33 percent difference between $\$ 30$ and $\$ 40$ causes some question as to the appropriateness of the $\$ 40 /$ hour estimate for the SPS and the SPS vehicles. This concern is reduced, however, by noting that the SPS is, by its design and construction methods, a capital and materials intensive project. The aircraft and air transport industries, believed to be the best analogy for the SPS transportation system, have low relative labor intensity. For example, the equivalent electrical power company figures for 1975 are: Employment, 314,000; Revenues $\$ 46.9$ billion; and $\$ 72$ per employee-hour.

Thus, the imputed staffing for the SPS transport system is viewed as appropriate. No further judgement of the adequacy of the estimate can be made at this time because the detailed planning has not been done, nor should it be intensively pursued until space Shuttlc actual result.s are available.

* Statistical Abstract of the U.S., 1977. 
3.8 Fleet Requirements, Production Implications and Space Construction \& Servicing

The fleet requirements for the Reference Program appear adequate under the assumption made: that the vehicles have 100 percent reliability. We consider this assumption to be unrealistic and recommend reserves of 10 percent or at least one additional vehicle in an analogy to airline operations. Typical airline reserve allowances range from one extra vehicle for ten to fifteen scheduled vehicles. The existence of this reserve permits a delay rate of approximately five percent. of $f l$ ights and cancellation rate of approximately onc percent of flights. Detailed specifications of the impact of this allowance on initial fleet procurements is made in Section 1.3.8. It is expected that as the SPS program progresses, this type of reserve allowance will be made on the basis of detailed risk assessment studies and the number of vehicles will be adjusted.

The additional vehicles, as well as the proposed initial fleet, should present no overall production problems if the assumptions made in the implicit SPS technological forecast are reasonable. These assumptions are reasonable projections of capabilities fifteen to twenty years in the future and are supported by reasonable estimates of the research and development money needed to achieve those capabilities. The major area of concern is the space structures. In contrast to areas such as photovoitaic cells and launch vehicles, very little work has been accomplished in this area and the uncertainties are very high.

The lack of experience in space structures also applles to a lesser degree to space operations. The ability to conduct operations with little or no pre-planning to meet unexpected events has only one successful experience: the repair of the Skylab orbital station after a solar cell panel was ripped off during launch. This success, however, is an indication that unanticipated problems can be overcome.

The problems and costs of orbital operations are not part of the Transportation Work Breakdown Structure because they also support orbital operations. Because the level of effort devoted to orbital operations has not been as great as for the vehicles, we are unable to comment on these plans or 
to discuss the uncertainty of these costs. Items not covered in the Transportation WBS, but which directly impact vehicle operations and costs are:

(1) Construction/and repair facilities for the EOTV at LEO

(2) Repair facilities for chemical vehicles at LEO and GEO

(3) Fuel storage and transfer facilities at LEO and GEO

(4) Parts and mechanics at LEO and GEO.

Future studies should allocate a reasonable portion of these to the transportation system so that misjudgements as to true costs are not made. One example is the transportation cost of one man-year of labor at GEO. The individuals will be rotated so that one person will be in space for only three months so that for every job four trips will have to be made. If the PLV/POTV vehicles are used, and the costs of shipping fuel to LEO and GEO are allocated to these trips, the current transport cost for one man-year is $\$ 1.2$ million without considering other requirements the individual will need. The amount should be increased by the allocation for orbital facilities costs for support of these flights and then used in automation trade-off studies. This relatively high transport cost is one of the reasons we recommend adapting a personnel module to the HLLV. If the HLLV is used in place of the PLV, the transportation cost of a man-year is reduced, under similar calculations, to $\$ 780$ thousand per man-year. 


\section{APPENDIX A \\ SPS CONCEPT AND REFERENCE SYSTEM DESCRIPTION}

SOURCE: Argonne National Laboratories 
THE SATELLITE POWER SYSTEM CONCEPT

AND CURRENT REFERENCE SYSTEM DESCRIPTION

\section{A.1 BACKGROUND}

In the current Satellite Power System (SPS) concept, there would be a number of solar satellites in geosynchronous orbit. Each satellite would collect solar energy and convert it to an approprlate form for transmission to a recelving station on earth, where it would be converted to electricity for delivery to utility networks.

This concept was first proposed in 1968. In the period 1971 to 1977, the National Aeronautics and Space Administration (NASA) investigated the basic thechnical feastbility of the concept, studied energy transmission and reception, and conducted technical assessments at the Johnson and Marshall Space Centers. In 1976, onerall responsibility for the concept was given to the Energy and Development Administration (ERDA), and an ERDA task force report recommended an evaluation study. These activities led to the establishment of a SPS Concept Development and Evaluation Program (CDEP) to be conducted by the Department of Energy (DOE) and NASA. This program started in 1977 and is to end in 1980.

The objective of the CDEP was to develop an initial understanding of the technical feasibility, economic practicality, and the social and environmental acceptability of the SPS concept. CDEP results include: (1) statements of what is known and what is uncertain with respect to the SPS concept and (2) future program recommendations.

\section{A.2 SPS POTENTIAL BENEFITS}

If ongoing SPS explorations were to point the way to a system that was technically feasible, economically competitive, and enviromentally and socially acceptable, the benefits would be enormous.

- The SPS would be deployed in the years 2000-2050, a time when the world will need to rely more and more on renewable or inexhaustible energy resources.

- The SPS is the only solar energy system that would not need large energy storage systems to provide baseload power. -

- The SPS would have minimal environmental impact. In particular, SPS energy conversion processes would not produce $\mathrm{CO}_{2}$, and waste heat would be radiated into space. Minimum weather and climatic effects are anticipated. 
- The problems associated with fuel conversion technologies (mining, transportation, residuals disposal, etc.) are completely avoided.

- Available U.S. space technology and capability could be applied to meet a national need, and U.S. competence in space would continue to grow.

\section{A. 3 SPS CONCEPT}

The SPS is a concept to provide baseload electric power and has the following essential elements: (1) a sollar collector in geosynchronous earth orbit (GEO), (2) a conversion and transmission system for transferring energy to earth, and (3) a receiver for gathering the transmittèd energy and interfacing with electric utility delivery networks. These elements are illustrated in Fig. A.1.

The solar collector would be located in space, some $35,800 \mathrm{~km}$ above the earth in a geosynchronous, equatorial orbit. Therefore, the satellite would remain in continuous, line-of-sight contact with its receiver on earth. In this orbit, the satellite would be illuminated by sunlight over $99 \%$ of the time. In order to deliver 5,000 MWe, an individual satellite would have to have an area of approximately $50 \mathrm{~km}^{2}$.

A variety of energy conversion systems have been proposed and studied. Silicon cell and gallium aluminum arsenide cell photovolealc systems have received the most attention. Other energy conversion systems have also been considered, including thermal cycle heat engines (e.g., Rankine, Brayton). In the heat engine concept; large solar reflectors concentrate the sunlight on a boiler surface, thus heating a working fluid that is used to drive curblne generators.

The electricity produced at the satellite could be converted to microwave energy and formed into a narrow beam precisely aimed at the ground receiver. Power transmission by lasẹt light could be an àttractive alternative, with the advantage of significantly reduced land use requirements.

If microwaves were used to transmit the power, the ground receiver would be a large receiving and rectifying antenna (rectenna), which would reconvert the energy into electricity for baseload utility service. If laser light were used, the ground-based receiver might be a heat engine. 


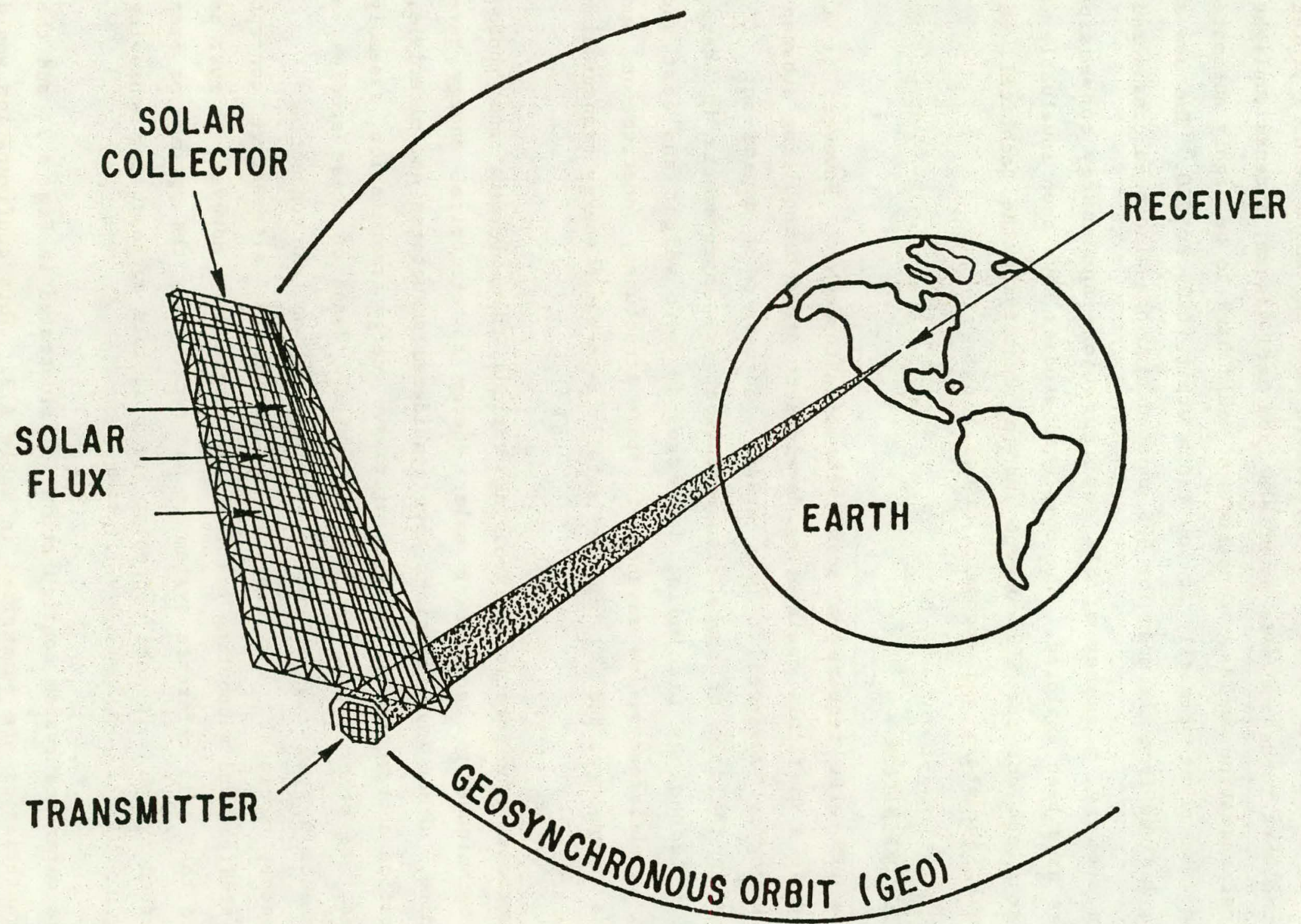


The current concept anticipates construction of 50-100 satellites with a total power output in the range of 250-500 GWe. Construction in space of SPS structures would be a formidable task and would require protection of the work force and some materials from hard vacuum, intense sunlight, and natural radiation fields. Construction would have to be highly automated and could take place primarily at low earth orbit (LEO) or GEO. The use of materials derived from the moon for SPS construction has also been considered.

In summary, a number of SPS configurations and energy conversion approaches have been explored. The completed studies have been invaluable in helping to flesh out the SPS concept and in identifying the tcchnical, enviromental, societal, and economic issups.

\section{A. 4 SYSTEM DEFINITION}

The SPS will require no scientific breakthroughs. However, it is recognized as a difficult engineering development project requiring substantial technological advances in many areas. Success will depend on: reductions in the cost of space transportation, (2) improvements in energy conversion technology (including decreases in unit weight and cost and increases in efficiency), (3) advances in space structures, construction, and operations technology, and (4) improved satellite-to-earth energy transmission characteristics.

Numerous configurations involving various thermodynamic and photovoltaic techniques for converting solar energy to electrical energy have been studied. Other investigations have considered structures and materials, transportation approaches and systems, microwave energy transmission, assembly techniques, and other aspects of the SPS system. Based on these studies, a SPS reference system was defined to serve as the basis for conducting environmental, socictal, and comparative assessments; alternative concept tradeoff studies; and supporting critical investigations. However, it must be emphasized that this reference system is not necessarily the optimum or even the preferred system. It does represent one plausible approach for achieving SPS goals.

The reference system configuration is illustrated in Fig. A.2, and the main characteristics are summarized in Table A.3. This configuration would provide $5 \mathrm{GW}$ of electric power at the comercial grid interface. Sixty units 
would be placed in geosynchronous orbit and provide $300 \mathrm{GW}$ of power. Approximately six months would be required to construct each satellite system.

of the energy conversion approaches studied, two photovoltaic options were considered for the reference design. In one option, silicon (Si) cells were used, with a basic cell efficiency of $17.3 \%$. In the other option, gallium aluminum arsenide (GaAlAs) cells, with a basic cell efficiency of $20 \%$, and concentrators for focusing the solar energy on the cells were used. Although Si technology is more advanced than GaAlAs technology, the GaAlAs option has the potential for providing a lighter-weight system and, by the use of concentrators, it offers the promise of self-annealing of radiation damage occurring in the cells. 


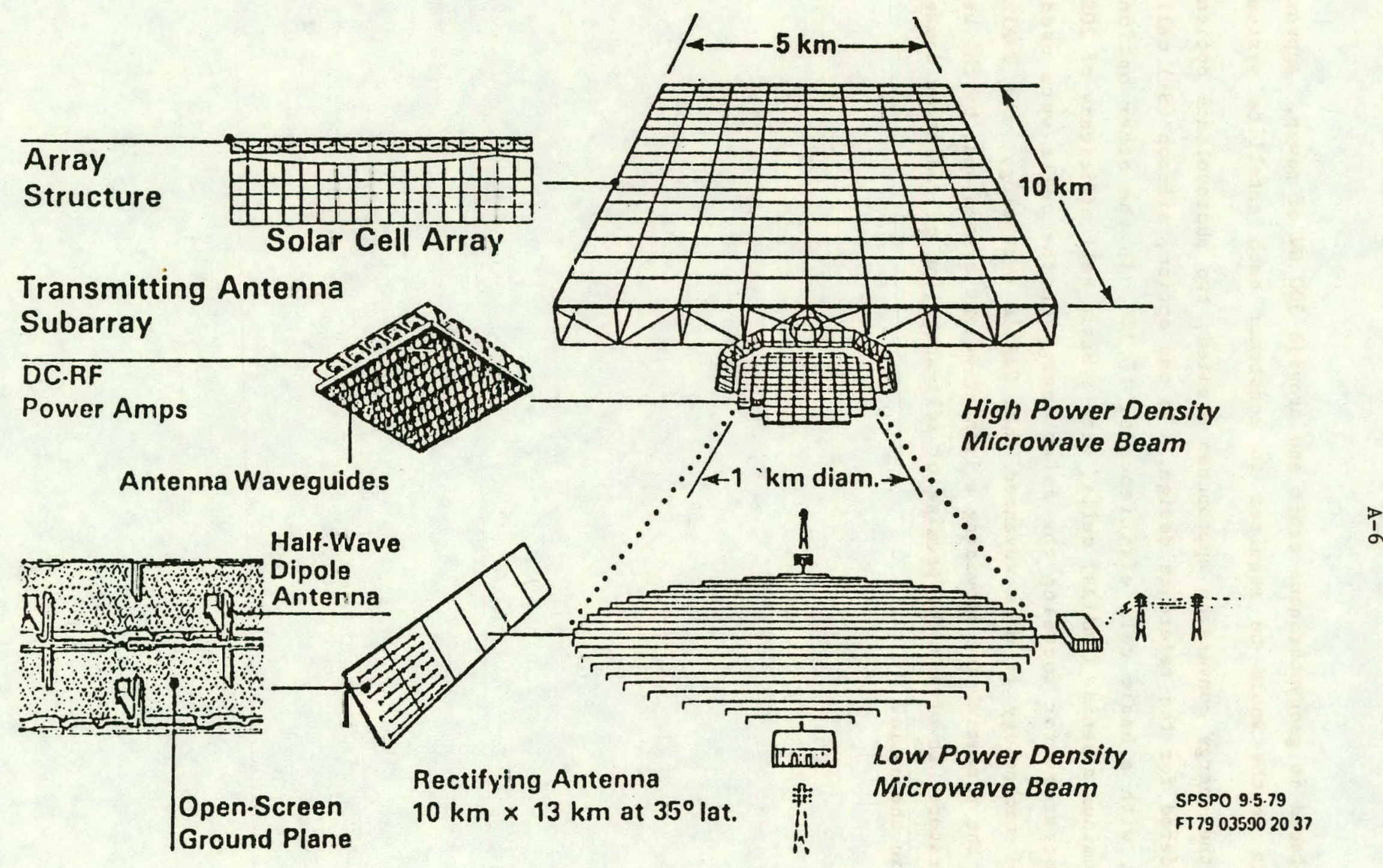

F1g. A.2 Reference System Configuration 
Table A.3 October 1978 Reference System Characteristics

\section{System Characteristics}

Generation Capability (Utility Interface):

300 Gigawatts - Total

5 Gigawatts - Single Unit

Number of Units: 60

Design Life: 30 Years

Construction Rate: 2 Units/Year

Construction Time: 6 Months/

Satellite

\section{Satellite}

Overall Dimensions: $10 \times 5 \times 0.5 \mathrm{~km}$

Structural Material: Graphite Composite

Satellite Mass: $35-50 \times 10^{6} \mathrm{~kg}$

Geosynchronous Orbit: $35,800 \mathrm{~km}$

\section{Energy Conversion System}

Photovoltaic Solar Cells: Silicon or. Gallium Aluminum Arsenide

Power Transmission and Reception

DC-RF Conversion: Klystron ( $10^{5}$ Tubes)

Transwitting Antenna Diameter: $1 \mathrm{~km}$

Frequency: 2.45 Gigahertz

Power Density at Rectenna Edge: $1 \mathrm{~mW} / \mathrm{cm}^{2}$
Rectenna Dimensions: $10 \times 13 \mathrm{~km}$ Rectenna Exclusion Dimensions: $\sim 11.5 \times 14.5 \mathrm{~km}$ Peak Power Density: $23 \mathrm{~mW} / \mathrm{cm}^{2}$ Power Density at Exclusion Edge: $0.1 \mathrm{~mW} / \mathrm{cm}^{2}$

Space Transportation System

Earth-to-LEO - Cargo: Vertical Takeoff, Winged 2-Stage (425 metric ton payload)

- Personnel: Modified Shuttle

LEO-to-GEO - Cargo: Electric Orbital Transfer Vehicle

- Personnel: Two-Stage Liquid Oxygen/Liquid Hydrogen

Space Construction

Construction Staging Base - LEO: $2480 \mathrm{~km}$

Final Construction - GE0: $235,800 \mathrm{~km}$

Construction Crew: $\sim 600$

The energy collected and converted to electricity aboard the satellite must be transmitted to the microwave power transmission system at high voltages $(\sim 40 \mathrm{kV})$. The transmission system provides for the conversion of DC power to microwave power and for its transfer to earth at a frequency of $2.45 \mathrm{GHz}$. Maximum power density at the center of the beam would be 23 $\mathrm{mW} / \mathrm{cm}^{2}$, while at the edge of the ground receiving antenna (rectenna) and at 
the exclusion distance, the power density would be only $1 \mathrm{~mW} / \mathrm{cm}^{2}$ and 0.1 $\mathrm{mW} / \mathrm{cm}^{2}$ respectively.

The rectenna design is a series of serrated panels perpendicular to the incident beam. Each panel has a steel mesh ground plane with 75-80\% optical transparency.

Development of the SPS will require a new space transportation system. For economic reasons, the system must be designed for reuse. A heavy lift launch vehicle capable of single-mission delivery of about 425 metric tons of material and equipment and a personnel launch vehicle for the transportation of personnel and priority cargo between earth and the LEO staging base wolld be required. In addition, transfer of cargo and personnel from the LEo staging base to the construction base at GEO would require a personnel orbital transfer vehicle and an electric cargo transfer vehicle.

In addition to the reference system, emerging technologies and concepts that could have a beneficial impact on SPS development require further evaluation. For example, a thorough investigation of the use of a solid-state microwave system is warranted, since it has the potential for high reliability, lower cost, and optimum lower unit power output. Also, some problems associated with microwave energy transmission could be avoided by using lasers. Potential benefits of this system include smaller land requirements, elimination of microwave frequency interference, and reduced biological and ecological impacts. 
APPENDIX B

SPS TRANSPORTATION COST ESTIMATES

SOURCE: JOHNSON SPACE CENTER 
EW4-79-212

HoV 1.41979

TO: MASA Headquartors

Attn: RES-I/H, D, Calahan

FRON: EA4/Assocfate Director for Program Development

SUBJECT: SPS Transportation System Cost Estimates

JSC is in the process of preparing a cost date book detalling the estimated cost of each major SPS subsystem. The cost est mates, based on the SPS Reference Systen, are collected by work breakdown structure element, and the support information used in the preparation of the estimate is included with each estimate.

The space transportation system section of this data book is now virtually complete. The dato from this section, along with some expismitory material is enclosed for your review and coment. Specifically, the following are included.

1. A definition of the cost categories used.

2. An explanation of the cost estimating methodology used.

3. Learning curves.

4. An SPS Implementation scenaric description.

5. A vehicle inforation package

- vehicle definition

- vehicle design description

- vehicle mass statement

- detalled vehicle cost estimate

- vehicle cost per filght calculation

6. A transportation cost sumary.

The information presented on the transportation system is simflar to the information presented to United Engineers for their evaluation of the ground systeins.

Original Signed By

Robert 0 . Piland

bcc:

Robert 0. Plland

Argone Nat. Labs/M. Samsa

Enclosure 


\section{DEFINITION OF COST CATEGORIES}

DDT\&E Costs: The design, development, test, and evaluation account includes all costs associated with the engineering and support required to translate the SPS performance specification into a detailed design. It includes the preparation of detailed drawings for hardware fabrication, assembiy and system integration. Also included are all required tests, hnth ground and flight, together with any test facilities required. Aiso included are the costs related to test evaluation, data reduction and design modification. Specifically not included in the DDT\&E costs are the costs associated with the construction of production facilities and the launch and recovery facilities associated with the SPS transportation system. These costs are separately accounted so that they may be amortized over the SPS implementation scenario.

IFU: The theoretical first unit costs are those costs associated with the production of the first identifiabie SPS elemerit or subsystem produced by the full-scale production processes. It is a useful point of departure for the application of learning technique to determine average unit production costs. It includes costs after the completion of the DDT\&E phase, but before the initial operation of the first SPS.

Averaye Unit Cost: The average unit cost is the cost associated with the production of a typical SPS system, subsystem or element. It is essentially the average cost of the unit produced to comply with the implementation scenario. It includes all quality assurance costs, manufacturing costs, production test costs, etc., associated with an on-going program. 
Virtually all the DDT\&E and TFU transportation system costs were estimated using the Boeing developed Parametric Cost Model (PCM) computer program. This program requires both factual and judgemental input. information. Factual input data includes subsystem descriptors such as the nature of the subsystem, its mass, volume, performance characteristics, etc. Judgemental input data includes the estimators opinion of the subsystem complexity and the degree to which it represents a new design vs. an off-the-shelf design.

The PCY program then computes both an estimate of both the DDT\&E and TFU cost from a data bank of historical aircraft and aerospace parametric cost data. The PCM estimate of the TFU vehicle cost along with the number of vehicles to be produced to meet the requirements of the implementation scenario is used with the learning curve to obtain an estimate of the average unit cost.

Aircraft industry experience indicates that a learning curve factor of $\lambda=0.85$ is applicable at the vehicle level. Experience with jet aircraft production indicates that this relationship holds true to the loopth unit and beyond. Average unit costs were estimated at the vehicle level only and not at the subsystem level.

A11 costs were computed in 1977 dollars. To adjust the estimates to current year dolilars (1979), multiply by 1.15. Launch facility costs are estimated as part of the ground.systems cost and are not included in the transportation costs. 


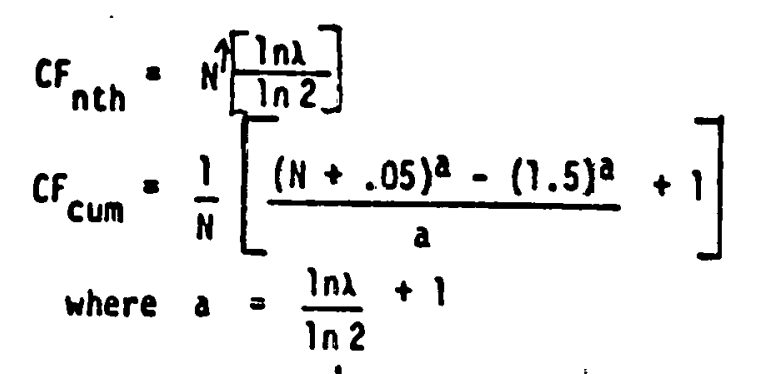

\section{LEARNING CURVE FACTORS}

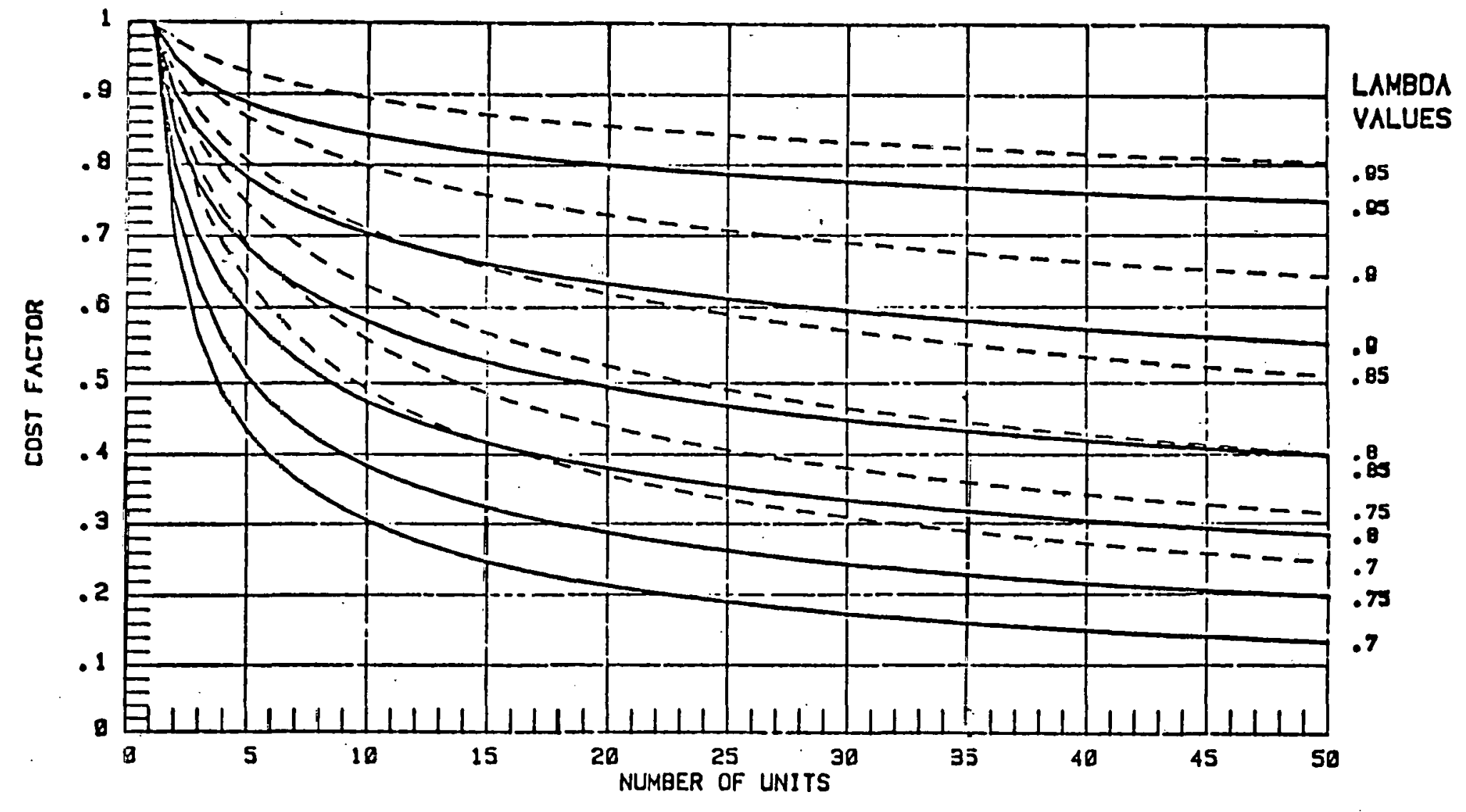

COST OF N UNITS $=$ (TFU COST) $\times$ (NUMBER PRODUCED) $\times$ (CUMULATIVE CCST FACTOR) COST OF Nth UNIT = (TFU COST) $\times$ (Nth UNIT COST FACTOR) 
Implementation Scenario Many of the costs of SPS elements are strong functions of the quantity produced or, as in the case of the transportation systems, the flight frequency. This scenario describes a total program of $32-1 / 2$ years duration from first launch to the completion of the 60 th $5 \mathrm{GW}$ reference SPS. The following assumptions were made in the derivation of this scenario:

- An initial two year period for the assembly of construction base in both low earth orbit (LEO) and geosynchronous orbit (GEO) and the fabrication of the Electric Orbital Transfer Vehicle (EOTV) fleet. Six months are devoted to the LEO construction base, 1-1/2 years to the fabrication of the EOTV fleet and completion of the GEO base at the end of the second year.

- The first SPS requires 12 months construction time and is completed at the end of the third year of the scenario.

- 59 subsequent SPS's are completed at the rate of one every six months.

- In space, crews are changed every 90 days.

The transportation requirements for the scenario were derived in the following manner. First, the weight and number of personnel required for each major item of equipment or function requiring space transportation were identified. Next, the characteristics of each of the space transportation vehicles: The Heavy Lift Launch Vehicle (HLLV), the Personnel Launch Vehicle (PLV), the Electric Orbital Transfer Vehicle (EOTV), and the Personnel Orbital Transfer Vehicle (POTV) were identified. Finally, a program scenario summary lists the number of flights per year made by each type of vehicie, the number of each type of vehicle required and when replacement vehicles are needed. 
PAYLOAD CHARACTERISTICS

(All Weights in Metric Tons)

SPS

Satellite (1)

Allowance for Breakage (2\%)

50,984

Total per Satellite

1,020

52,004

LEO BASE

Base

Crew Facilities Supplies/Yr

1,603

Wurk Facilities Supplies/Yr

72

GEO BASE

Base

Crew Facilities Supplies/Yr

Work Facilities Supplies/Yr

4800

568

683

EOTV

Vehicle

Propellant/Flight

1,462

Refurbishment/Flight

515

40

POTV - CREW ROTATION/SUPPLY

Stage

14

Propellant/Flight (Up/Dn)

$200 / 185$

Refurbishment/Flight.

0.1

Personnel Module

53

SPS MAINTENANCE

SPS Supplies/Satellite/Yr

236

Crew \& Work Facilities/20 Satellites

Crew \& Work Supplies/Yr/20 Satellites

1154

POTV Maintenance Sortie Prop/Satellite/Yr

206

25 


\section{CREW IN ORBIT}

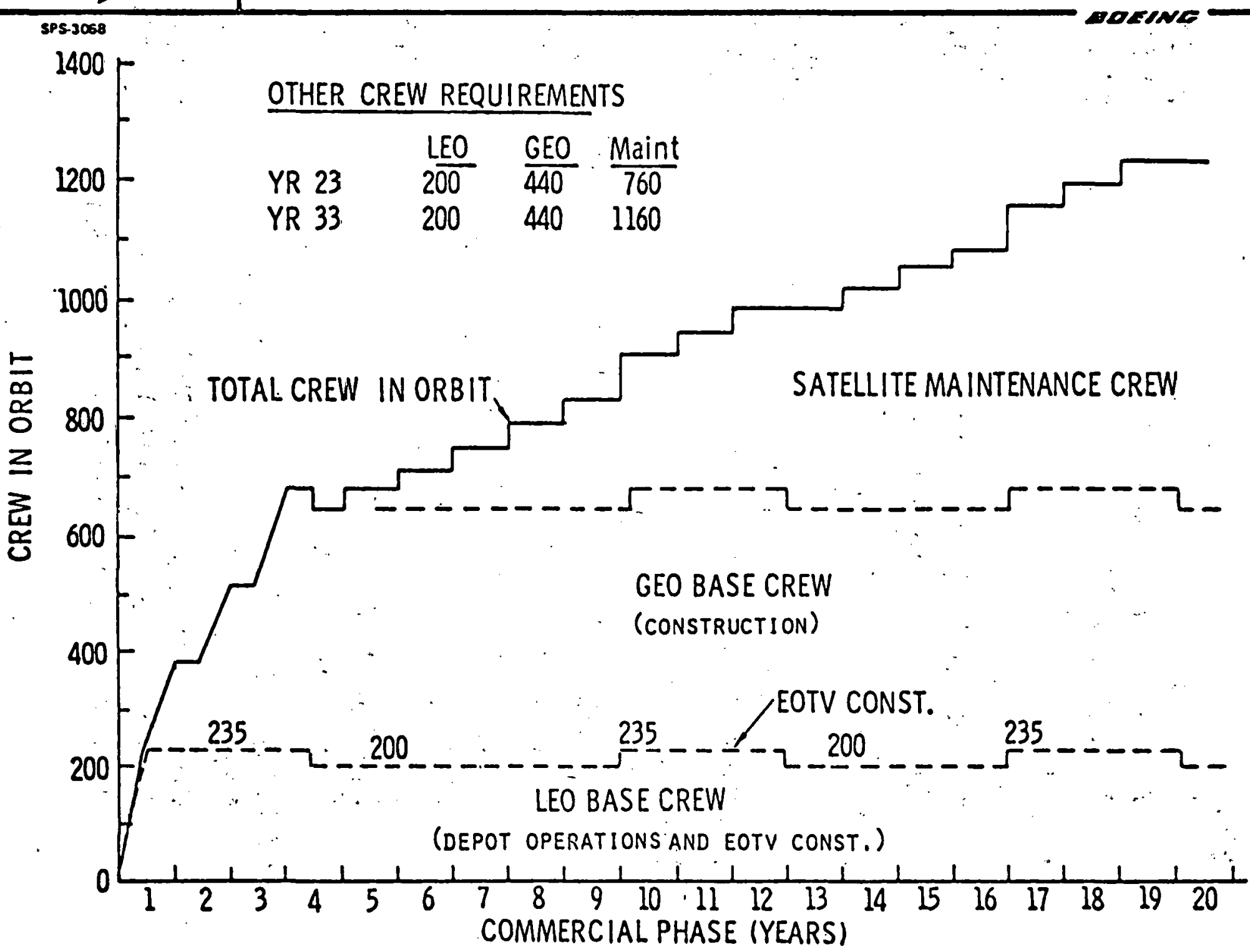




\begin{tabular}{|c|c|c|c|c|c|c|c|c|c|c|c|}
\hline YEAR & $\begin{array}{l}\text { SAT. } \\
\text { QTY. }\end{array}$ & $\begin{array}{l}\text { LEO } \\
\text { BASE } \\
\text { SUPPLI } \equiv S\end{array}$ & $\begin{array}{l}\text { EOTV } \\
\text { CONST }\end{array}$ & $\begin{array}{l}\text { EET } \\
\text { NAINT }\end{array}$ & $\begin{array}{l}\text { EOTV } \\
\text { CONST. }\end{array}$ & $\begin{array}{l}\text { LOADS } \\
\text { MAINT }\end{array}$ & $\begin{array}{l}\text { FOTI } \\
\text { CONST }\end{array}$ & $\begin{array}{l}\text { FLEET } \\
\text { MAINT }\end{array}$ & $\begin{array}{l}\text { POTV } \\
\text { CONST }\end{array}$ & $\begin{array}{l}\text { DOEFINE } \\
\text { POTV PAYLOAD }\end{array}$ & \\
\hline 1 & - & 555 & 9280 & - & 2575 & - & 1554 & - & 123 & - & \\
\hline 2 & - & 78.5 & 9450 & - & 2918 & - & 3030 & - & 238 & - & \\
\hline 3 & - & 785 & 13405 & - & 27094 & - & 5390 & - & 476 & - & \\
\hline 4 & 2 & 725 & 17607 & 226 & 80108 & 916 & 8470 & 770 & 748 & 69 & \\
\hline 5 & 4 & $725^{\circ}$ & 18807 & 1744 & 106406 & 838 & $84 B 4$ & 834 & 794 & 115 & \\
\hline 6 & 6 & 725 & 17345 & 396 & 105410 & 1310 & 8470 & 1640 & 748 & 136 & \\
\hline 7 & 8 & 725 & 17345 & $6 ? 2$ & 106420 & 2107 & 8484 & 2460 & 794 & 204 & \\
\hline 8 & 10 & 7.25 & 17345 & 678 & 106429 & 2292 & 8470 & 3280 & 748 & 272 & $\infty$ \\
\hline 9 & 12 & 725 & 17345 & 877 & 106439 & 2764 & 8484 & 4114 & 794 & 386 & \\
\hline 10 & 14 & 785 & 29041 & "01017 & 106454 & 3561 & 8470 & 4920 & 748 & 408 & \\
\hline 11 & 16 & 735 & 29041 & 1130 & 106458 & 3746 & $8<84$ & 5754 & 794 & 476 & \\
\hline 12 & 18 & 785 & 27579 & 4167 & 106468 & 4218 & 8470 & 6569 & 748 & 544. & \\
\hline 13 & 20 & 725 & 17345 & 1469 & 106481 & 5245 & 8484 & 7374 & 794 & 658 & \\
\hline 23 & 40 & 725 & 17345 & 2769 & 106559 & 10133 & 8470 & 14824 & 748 & 1224 & \\
\hline 33 & 60 & $725^{\circ}$ & 17345 & 4294 & 106665 & 15357 & 4570 & 23780 & 748 & 1972 & \\
\hline
\end{tabular}

ALL MASS IN METRIC TONS 


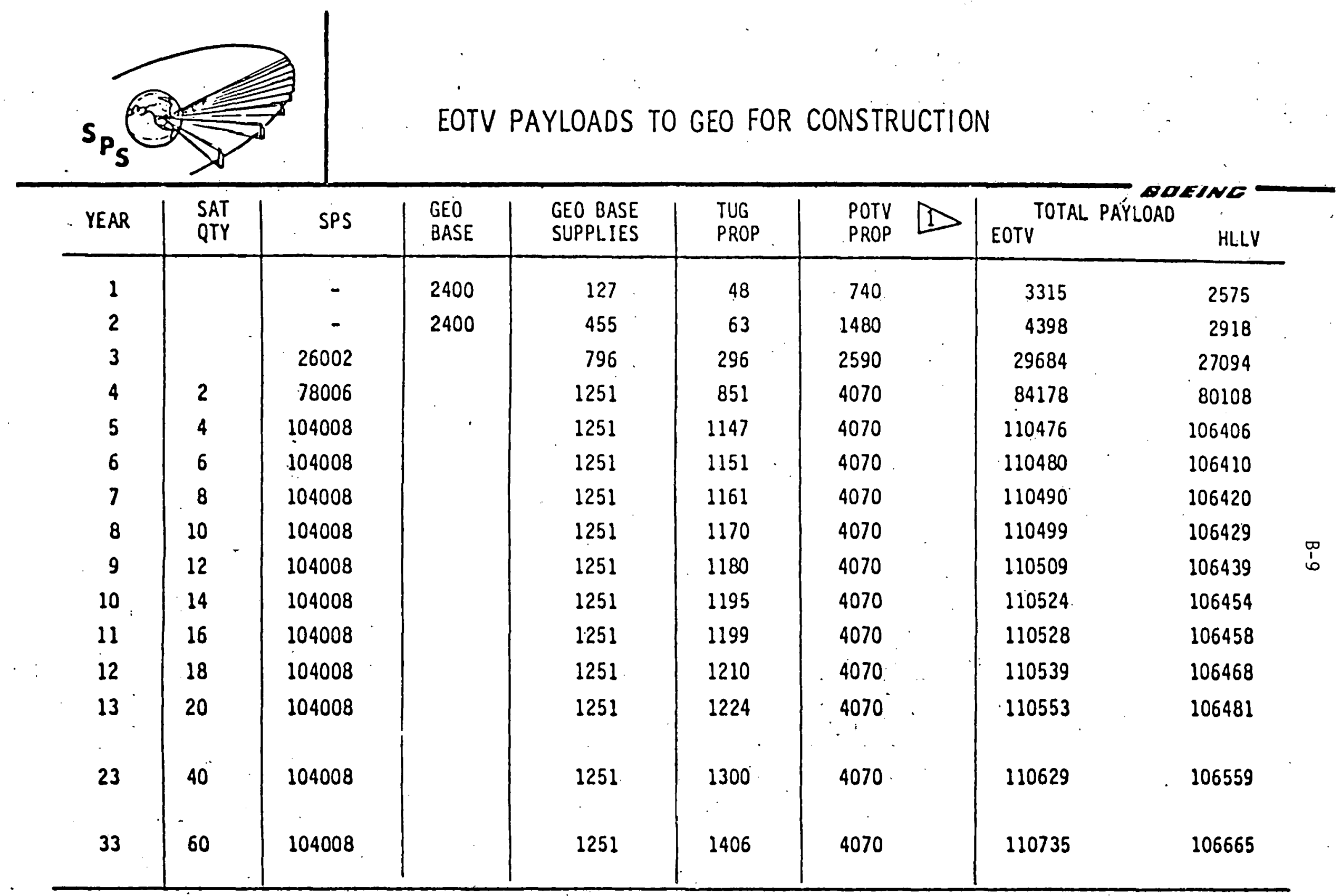

[1. Not incl. in EOTV contribution to HLLV P/L since all POTV prop. is charged to POTV fleet.

ALL MASS IN METRIC TONS 


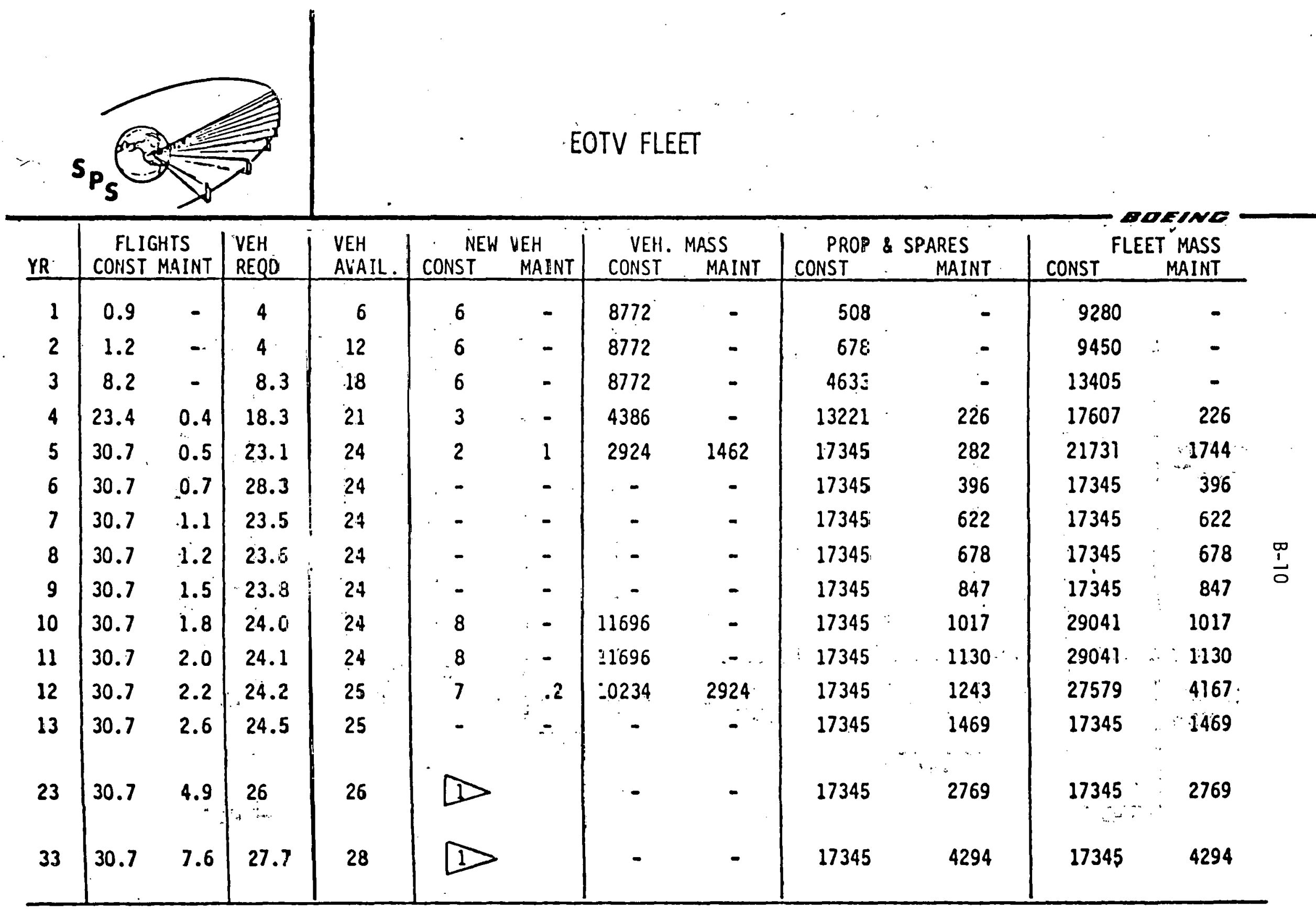

D These years miss the time period when new EOTV's are constructed.

ALL MASS IN METRIC TONS 


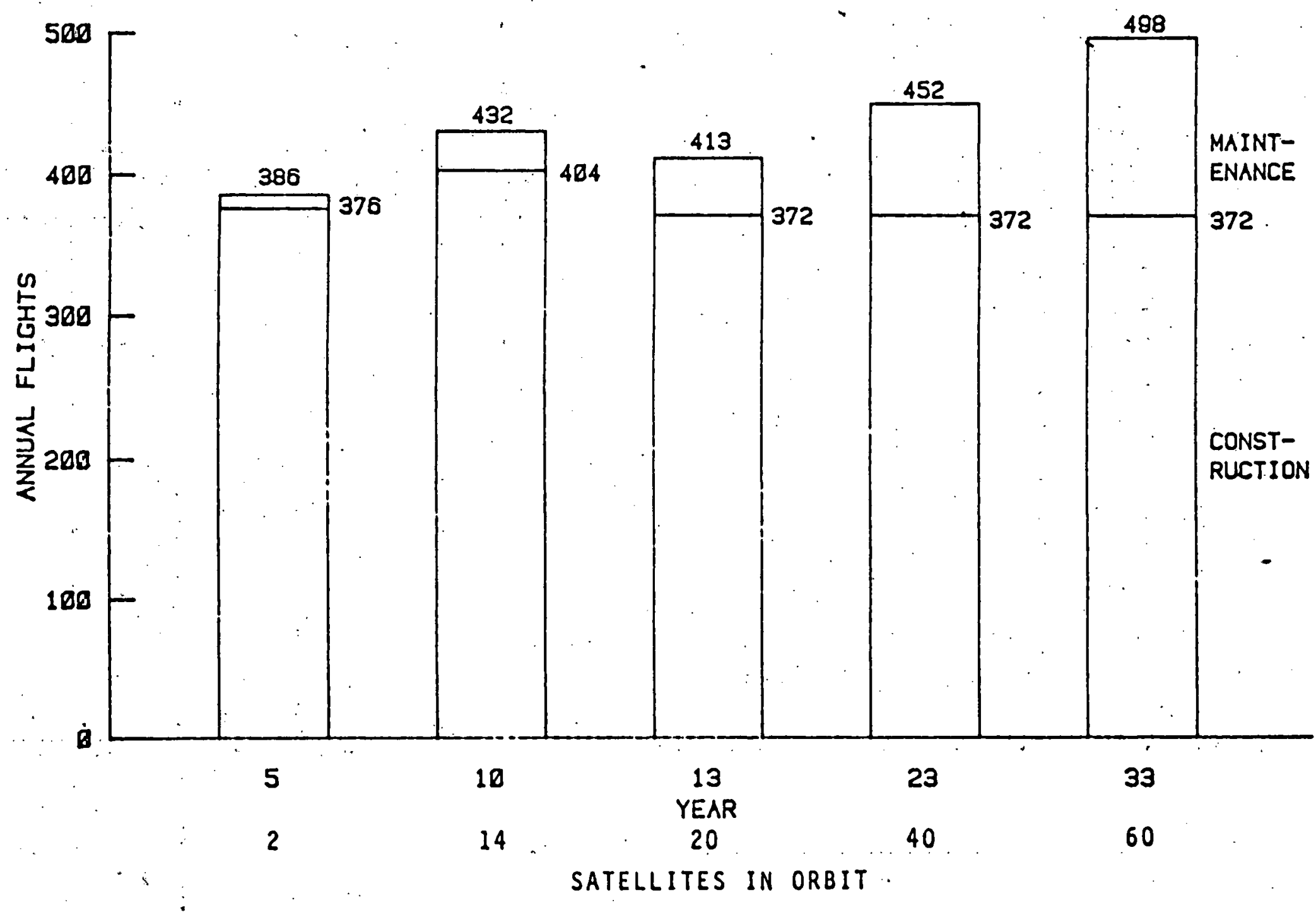

罢

RUCTION 


\section{PLV FLIGHTS}

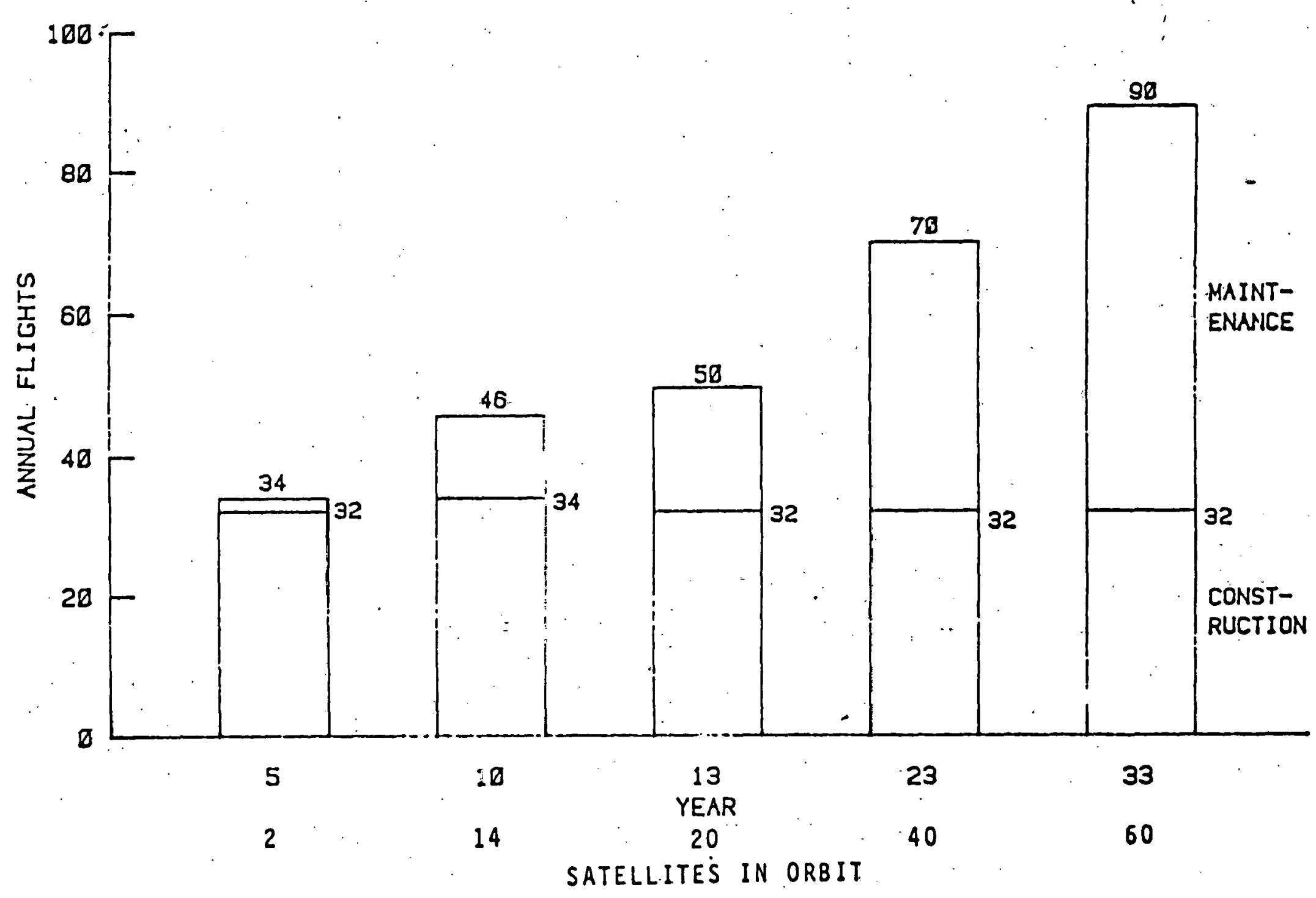




\section{E'OTV FLIGHTS}

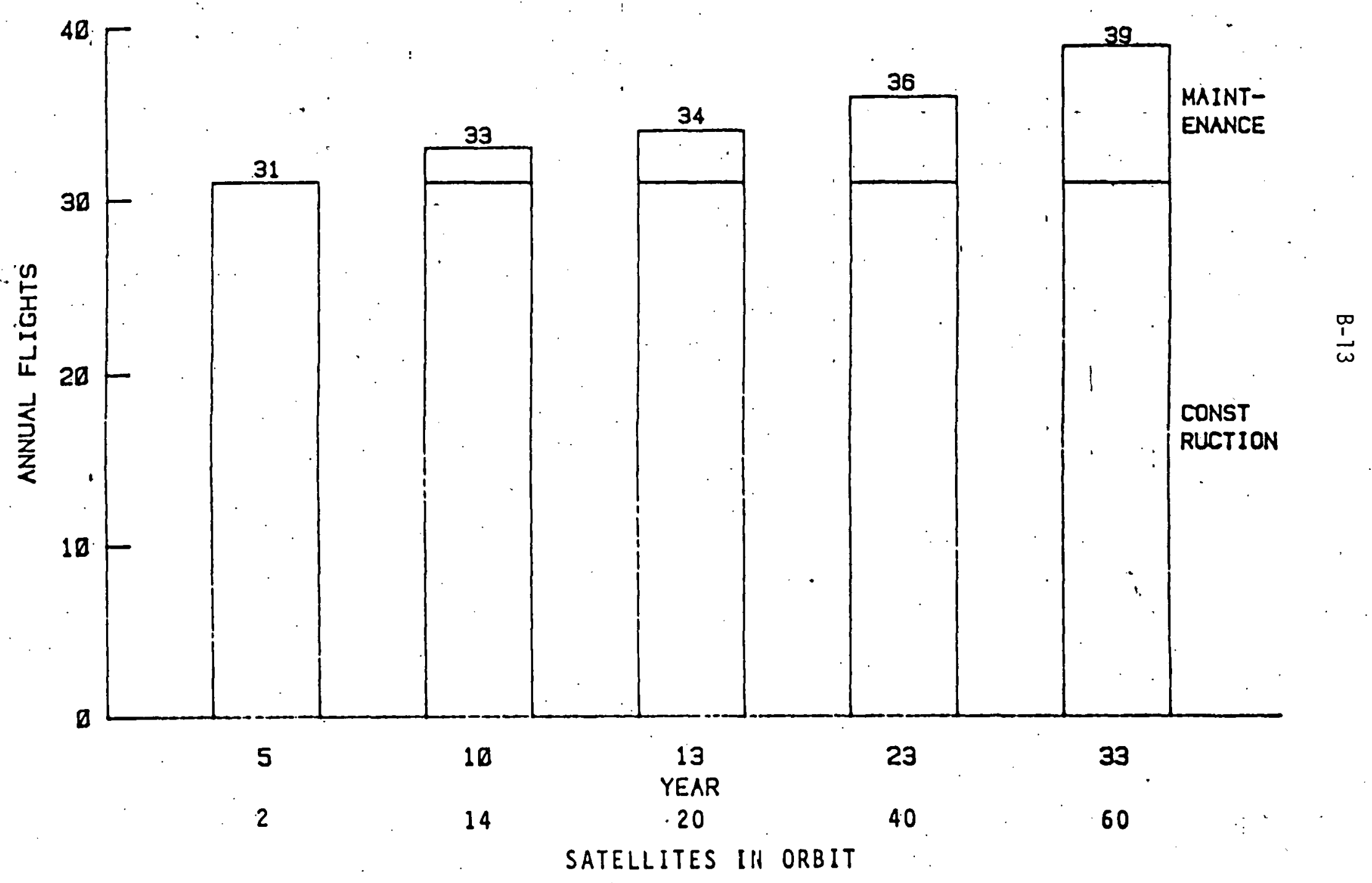




\section{POTV FLIGHTS}

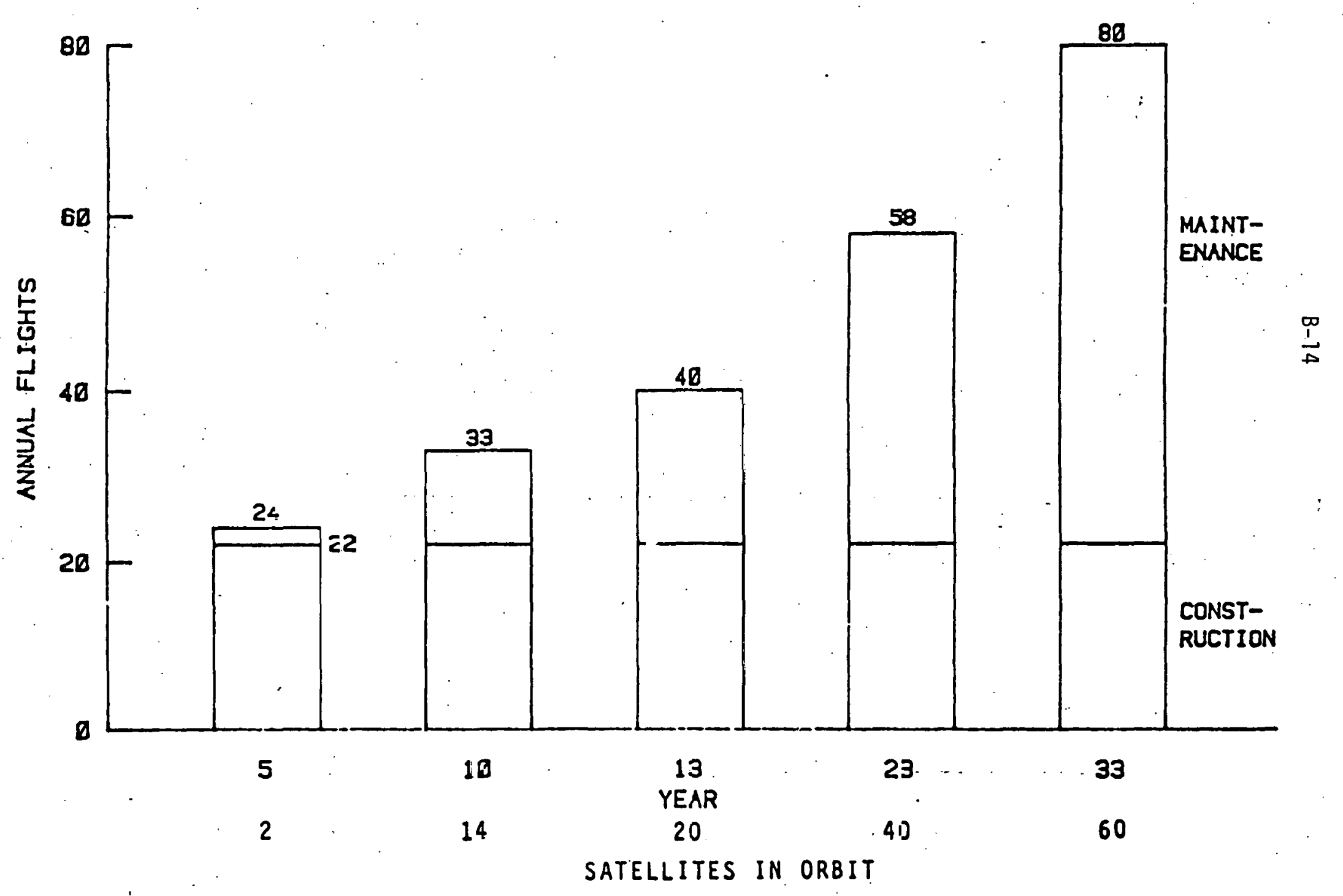




\section{TRANSPORTATION VEHICLE QUANTITIES}

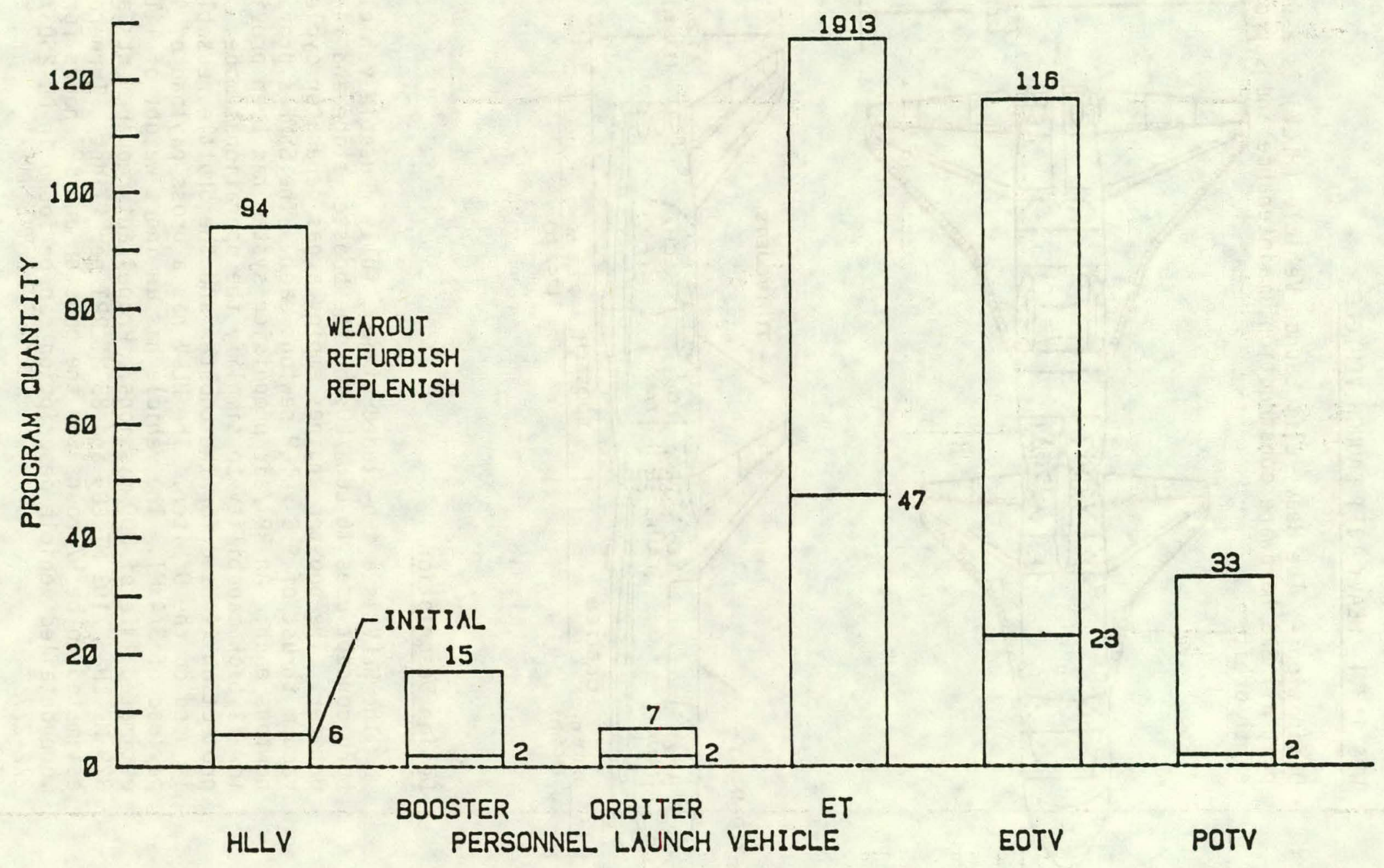

$\frac{1}{v}$ 


\section{WBS 1.3.1 HEAVY LIFT LAUNCH VEHICLE}

Definition - The Heavy Lift Launch Vehicle (HLLV) is a vehicle used to transport all SPS hardware construction, ma intenance and support equipment to low earth orbit.
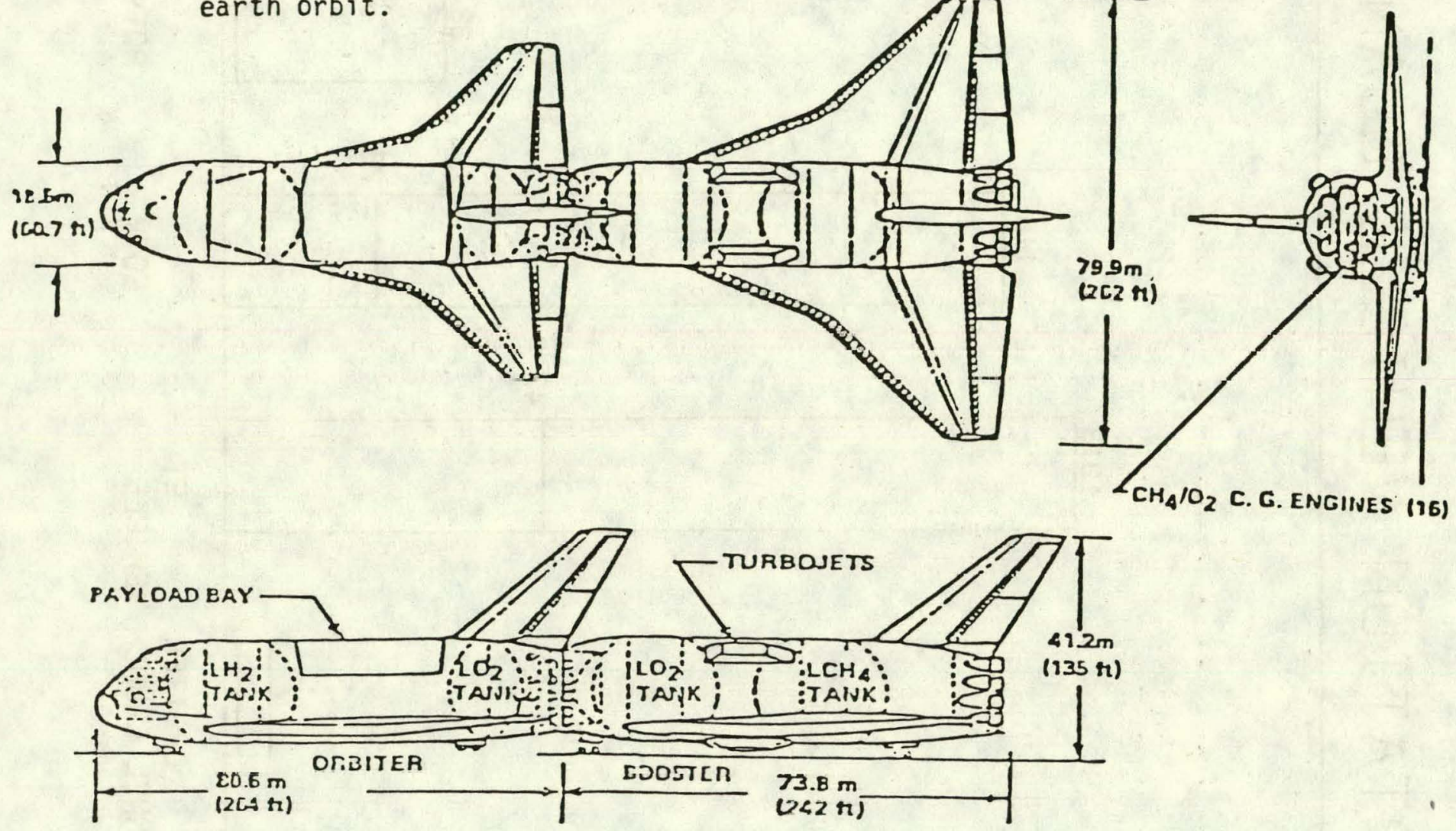

Design Description

The HLLV is a two-staged winged, fully reusable vehicle. The series burn concept uses $16 \mathrm{LCH}_{4} / \mathrm{LO}_{2}$ on the booster stage and $14 \mathrm{SSME}$ 's on the Orbiter. The booster engines employ a gas generator cycle to generate a vacuum thrust of $9.8 \times 10^{6}$ newtons each. The SSME's provide $2.1 \times 10^{6}$ newtons each. An RPI/air propulsion system has been provided on the booster for flyback capability to simplify the operational mode. Heat sink thermal protection is used for the booster and the Shuttle reusable surface insulation is used on the Urbiter. The HLLV has a gross payload of 424 MT and a net payload of 374 MT. The vehicle has an inert weight of 1413 MT and has an estimated life of 300 missions. Propellant requirements are $1709 \mathrm{MT} \mathrm{LCH}_{4}$; $329 \mathrm{MT} \mathrm{LH}_{2}, 7103 \mathrm{MT} \mathrm{LO} 2$ and $85 \mathrm{MT} \mathrm{RPI}$ per flight. Turnaround time is estimated to be 97 hours for the booster and 127 hours for the Orbiter. A more detailed vehicle description can be found in DD-25037-3, pp. 255-267 and 272-277. 


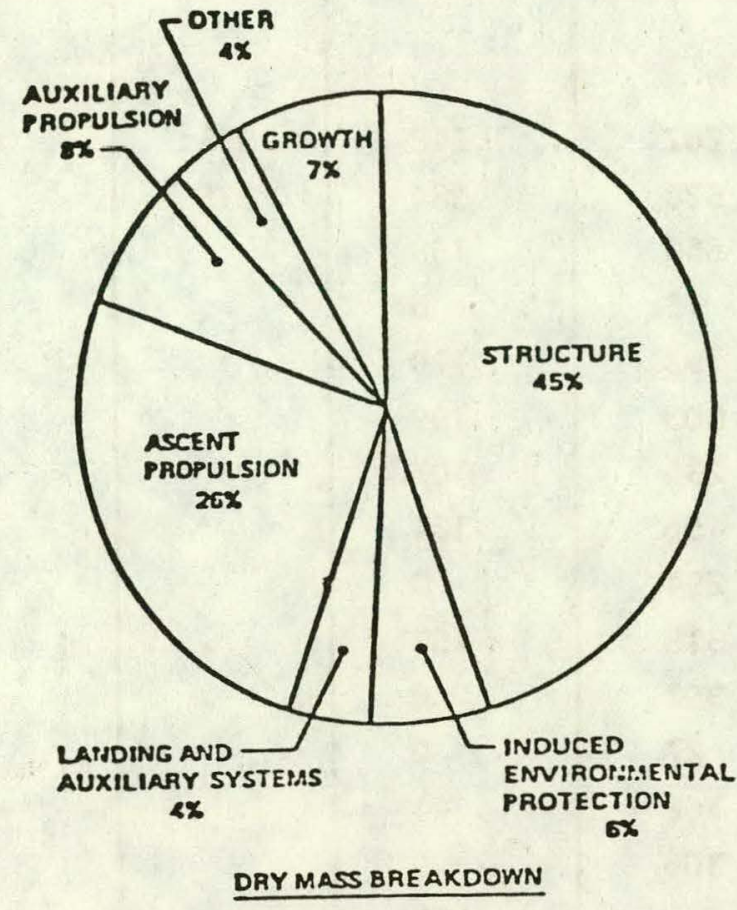

STRUCTURE

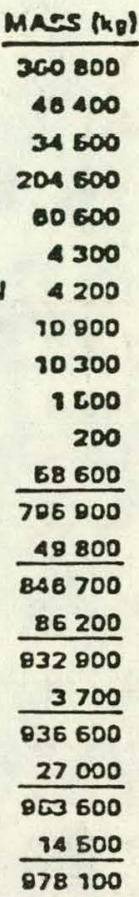

OBiter Mass Statement

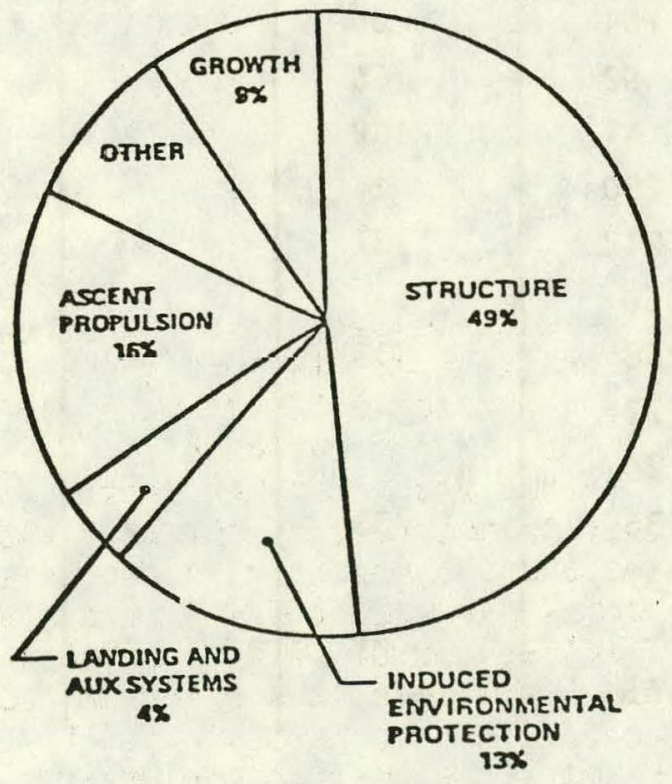

STRUCTURE

INDUCED ENVIRONR:ENTAL PROTECTION

LANDING AND AUX SYSTERAS

ASCENT PROPULSION

AUXILIARYPROPULSION

PRIME POWER

ELECTRICAL CONVERSION AND DISTRIRUTION

Mass (Mt)

182900

48300

15800

60800

8500

2500

4800

HYDRAULIC CONVEP.SION AND DISTRIBUTION

3600

SURFACE CONTROLS

AVIONICS

ECLSS AND PERSONNEL PROV

6800

2400

2800

GROITH

DRY MASS -

32000

PERSONPJEL AND PAYLOAD ACCOM:MODATIONS

373200
4100

RESIDUAL ANID RESERVES

14500

ENTTR IIS-FLIGHT LOSSES

LANDING MASS -

301800

START ENTRY BAASS - $\quad \lcm{395200}$

IN-FLIGHT LOSSES PRIOR TO ENTRY

INERT MASS - $\overline{435100}$

DRYMASS BREAKDOWN 


\begin{tabular}{|c|c|c|c|c|c|}
\hline VBS NO. & WBS ELEMENT & DDT\&E & TFU & AVU & O\&E \\
\hline 1.3 & SPACE TRANSPORTATION & & & & \\
\hline 1.3 .1 & CARGO LAUNCH VEHICLE & & & & \\
\hline 0.3 .1 .1 & VEHICLE & 11,202 & 1.748 & .595 & \\
\hline 1.3.1.2 & BOOSTER STAGE & 6,528 & 984 & 335 & \\
\hline 1.3.1.2.1 & STRUCTURES & 550 & 169 & & \\
\hline 1.3.1.2.2 & INDUCED ENVIRON. PROTEC. & 15 & 6 & & \\
\hline 1.3 .1 .2 .3 & LANDING \& AUXILIARY SYST. & 193 & 110 & & \\
\hline 1.3 .1 .2 .4 & ASSENT PROPULSION & 803 & 199 & & \\
\hline 1.3.1.2.5 & FLYBACK PROPULSION & 235 & 107 & & \\
\hline 1.3.1.2.6 & OTHER BOOSTER SYSTEMS & 156 & 134 & & \\
\hline 1.3.1.2.7 & BOOSTER SYSTEMS TEST & 3,294 & 0 & & \\
\hline 1.3.1.2.8 & BOOSTER GSE & 315 & 153 & & \\
\hline 1.3.1.2.9 & TOOLING & 397 & 0 & & \\
\hline 1.3.1.2.10 & SOFTWARE & 27 & 0 & & \\
\hline 1.3.1.2.il & PROG. INT. \& MCT. & 162 & 44 & & \\
\hline 1.3 .1 .2 .12 & GSE SUBSYSTEMS & 306 & 0 & & \\
\hline 1.3 .1 .2 .13 & ASSEMBLY AHD CHECKOUT & - & 61 & & \\
\hline 1.3 .1 .2 .14 & BOOSTER SE\&I & 75 & & & \\
\hline 1.3 .1 .3 & ORBITER STAGE & 4,674 & 764 & 260 & \\
\hline 1.3 .1 .3 .1 & STRUCTURES & 325 & 104 & & \\
\hline 1.3.1.3.2 & INDUCED ENVIRON. PROTEC. & 164 & 65 & & \\
\hline 1.3 .1 .3 .3 & LANDING \& AUX. SYSTEMS & 92 & 56 & & \\
\hline 1.3 .1 .3 .4 & ASSENT PROPULSION & 41 & 182 & & \\
\hline 1.3 .1 .3 .5 & AUXILIARY PROPULSION & 200 & 24 & & \\
\hline 1.3 .1 .3 .6 & OTHER ORBITER SYSTEMS & 272 & 137 & & \\
\hline 1.3.1.3.7 & WBS ELEMENT & 2,569 & - & & \\
\hline 1.3 .1 .3 .8 & ORBITER GBS & 258 & 119 & & \\
\hline 1.3 .1 .3 .9 & TOOLING & 273 & - & & \\
\hline 1.3.1.3.10 & SOFTWARE & 24 & & & \\
\hline 1.3.1.3.11 & PROG. INT. \& MGT. & 133 & 33 & & \\
\hline 1.3 .1 .3 .12 & GSE SUBSYSTEMS & 237 & - & & \\
\hline 1.3 .1 .3 .13 & ASSEMBLY \& CHECKOUT & - & 46 & & \\
\hline 1.3 .1 .3 .14 & SE\&I & 65 & - & & \\
\hline
\end{tabular}


HLLV - COST PER FLIGHT

HARDWARE:

$\frac{\$ 595 \mathrm{M} \text { PER VEHICLE }}{300 \text { FLIGHTS PER VEHICLE }}=\$ 1,980 \mathrm{~K}$

PROPELLANT:

$\begin{array}{lll}\mathrm{H}_{2} 346 \text { TONNES } \$ 1.53 / \mathrm{kg} & = & 530 \mathrm{~K} \\ 0_{2} 7,458 \text { TONNES } \$ .037 / \mathrm{kg} & = & 276 \mathrm{~K} \\ \mathrm{RPI} \quad 1,794 \text { TONNES } \$ .37 / \mathrm{kg} & = & 700 \mathrm{~K} \\ \mathrm{CH}_{4} 87 \text { TONNES } \$ .21 / \mathrm{kg} & = & 18 \mathrm{~K}\end{array}$

REPLENISHMENT AND REFURBISHMENT

STAGE 1

ASSENT ENGINES

$\$ 1,002 K$

AIRBREATHING ENGINES

$6 \mathrm{~K}$

ALL OTHER

$870 \mathrm{~K}$

STAGE 2

ASSENT ENGINES

$930 \mathrm{~K}$

MANEUVERING ENGINES

$6 \mathrm{~K}$

ALL OTHER

$780 \mathrm{~K}$

GROUND OPERATIONS

$628 \mathrm{~K}$

TOOL ING

$235 \mathrm{~K}$

MANPOWER

$2,138 k$

TOTAL COST PER FLIGHT .......\$10.1M 


\section{WBS $1: 3.2$ CARGO ORBIT TRANSFER YEHICLE}

Definition - The cargo orbit transfer vehicle is used to transport satellite components, maintenance hardware, and selected crew and base support supplies from LEO to GEO. This vehicle uses electric propulsion and is called the electric orbit transfer vehicle (EOTV).
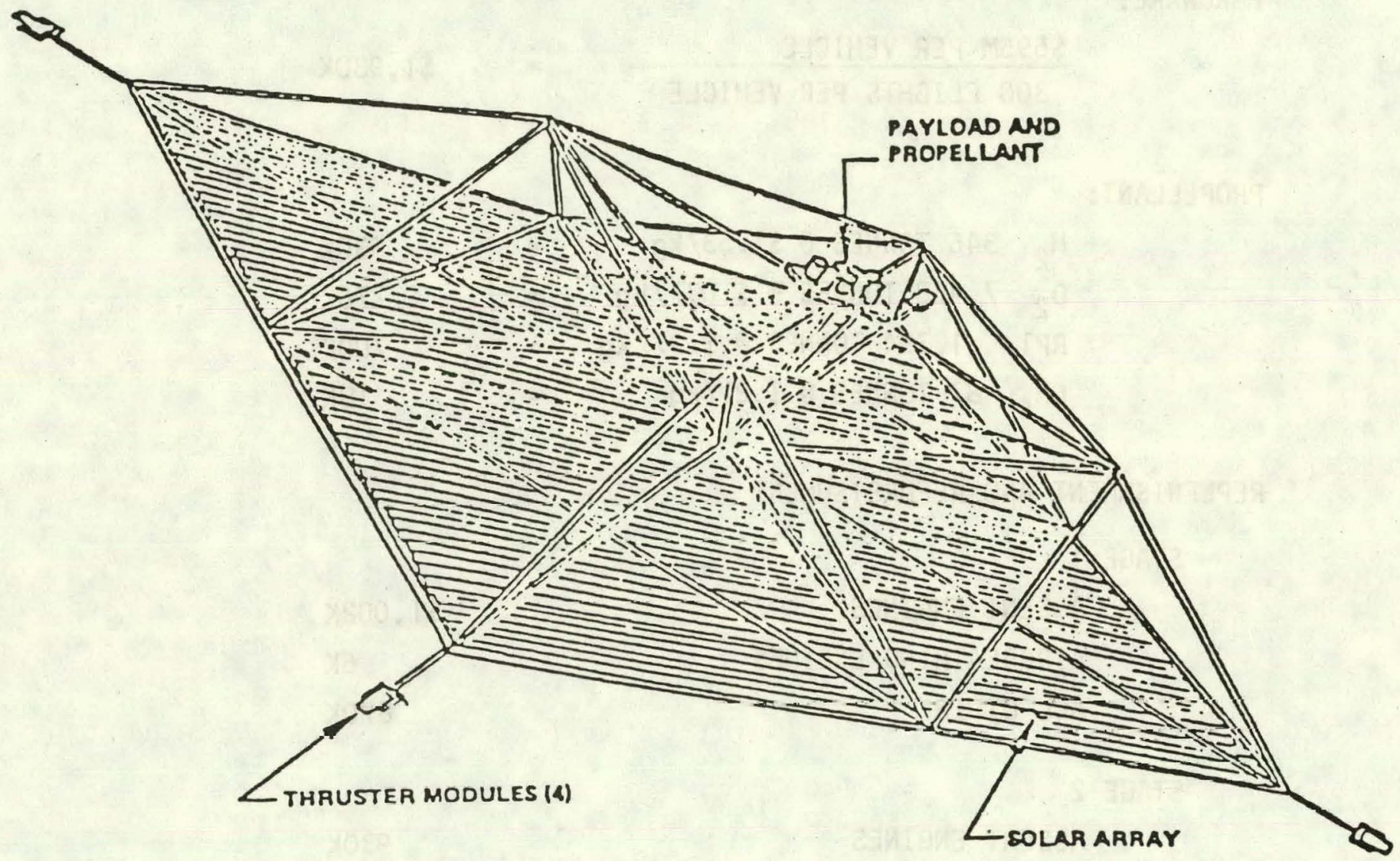

Design Description

The EOTV configuration for cargo transportation is shown above. The vehicle is sized to deliver 4,000 MT to GEO and return 200 MT from GEO, with an uptrip time of 180 days and a downtrip time of 40 days. Propulsion is provided by $1156-120 \mathrm{~cm}$ ion diameter thrusters with an Isp of 8000 seconds. The thrusters use an argon propellant and are powered by a $1 \mathrm{~km} \times 1.5 \mathrm{~km}$ silicon solar collector. Solid-state power processors are used to compensate for wide swings in power and voltage caused by accultation, radiation damage, and thermal effects. The vehicle is designed for 10 roundtrip flights and the payload size was chosen to be compatible with 10 HLLV flights. Additional detail may be found in 0180-25037-3, pages 278-293. 
Item

Solar Array - Silicon

Structure

Power Distribution'

Energy Storage
Mass kg.

780,000

122,000

42,000

7,000

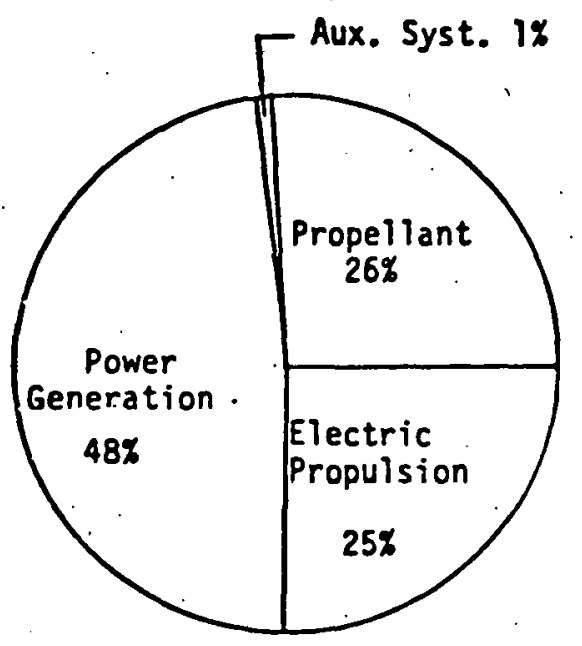

Power Generation \& Distribution Subtotal

951,000

Thrusters

79,000

Power Conditioning

219,000

Thermal Control

88,000

Structures and Mechanisms

61,000

Propellant Feed

49,000

\begin{tabular}{ll}
\hline Electric Propulsion Subtotal & 496,000 \\
\hline
\end{tabular}

Auxiliary Systems Subtotal

15,000

Total Dry Weight

$1,462,000$

Propellant

Argon

469,000

Hydrogen

6,600

Oxygen

39,400

Payload (Gross)

$4,000,000$

Total Start Burn Hass

$5,977,000$ 


\begin{tabular}{|c|c|c|c|c|c|}
\hline WBS NO. & WBS ELEMENT & DDT\&E & TFU & AVU & O\&E \\
\hline 1.3 .2 & $\begin{array}{l}\text { CARGO ORBITER TRANSFER } \\
\text { VEHICLF (OTV). }\end{array}$ & 2.247 & 2.126 & 283.6 & \\
\hline 1.3 .2 .1 & POWER GENERATION SYSTEIY & .4 & 917 & & \\
\hline 1.3 .2 .2 & POWER COLLECTION \& DIST. & 10.5 & 7 & & \\
\hline 1.3 .2 .3 & ELECTRIC PROPULSION SYST. & 89.1 & 777 & & . \\
\hline 1.3 .2 .4 & AVIONICS & 19.9 & 14 & & \\
\hline 1.3 .2 .5 & TOOLING & 858.5 & - & & \\
\hline 1.3 .2 .6 & SYSTEMS TEST & 1.164 .1 & - & & \\
\hline 1.3 .2 .7 & SE\&I & 12 & - & & \\
\hline $1.3,2.8$ & SOFTWARE & 18.3 & - & & \\
\hline 1.3 .2 .9 & GSE & 23.1 & 228 & & \\
\hline 1.3.2.10 & PROG. INT. \& MGT. & 51.3 & 75 & & \\
\hline 1.3 .2 .11 & ASSEMBLY \& CHECKOUT & - & 96 & 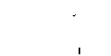 & \\
\hline 1.3 .2 .12 & SUSTAINING ENGINEERING & & 12 & & - \\
\hline
\end{tabular}


B-23

EOTV - PER FLIGHT I COST

HARDWARE:

$$
\frac{\text { AVERAGE VEHICLE COST }}{\text { FLIGHTS PER VEHICLE }}=\frac{283,600 \mathrm{~K}}{10}=\$ 28,400 \mathrm{~K}
$$

PROPELLANT:

$$
\begin{aligned}
& \text { ARGON } 494 \text { TONNES } \odot \$ 1 / \mathrm{kg} \\
& \mathrm{O}_{2}: 37.8 \text { TONNES } \$ \$ .037 / \mathrm{kg} \\
& \mathrm{H}_{2} 9.5 \text { TONNES } \$ 1.53 / \mathrm{kg}
\end{aligned}
$$

$\$ 494 K$

$1 \mathrm{~K}$

$14 K$

REFURBISHMENT :

$11,300 \mathrm{~K}$

PROGRAM SUPPORT

$500 \mathrm{~K}$

TOTAL COST PER FLIGHT. ........... $\$ 40,709 \mathrm{~K}$ 
WBS 1.3.3 PERSONNEL LAUNCH VEHICLE (PLV)

Definition - The PLV is a vehicle used to transport personnel and priority cargo to LEO.

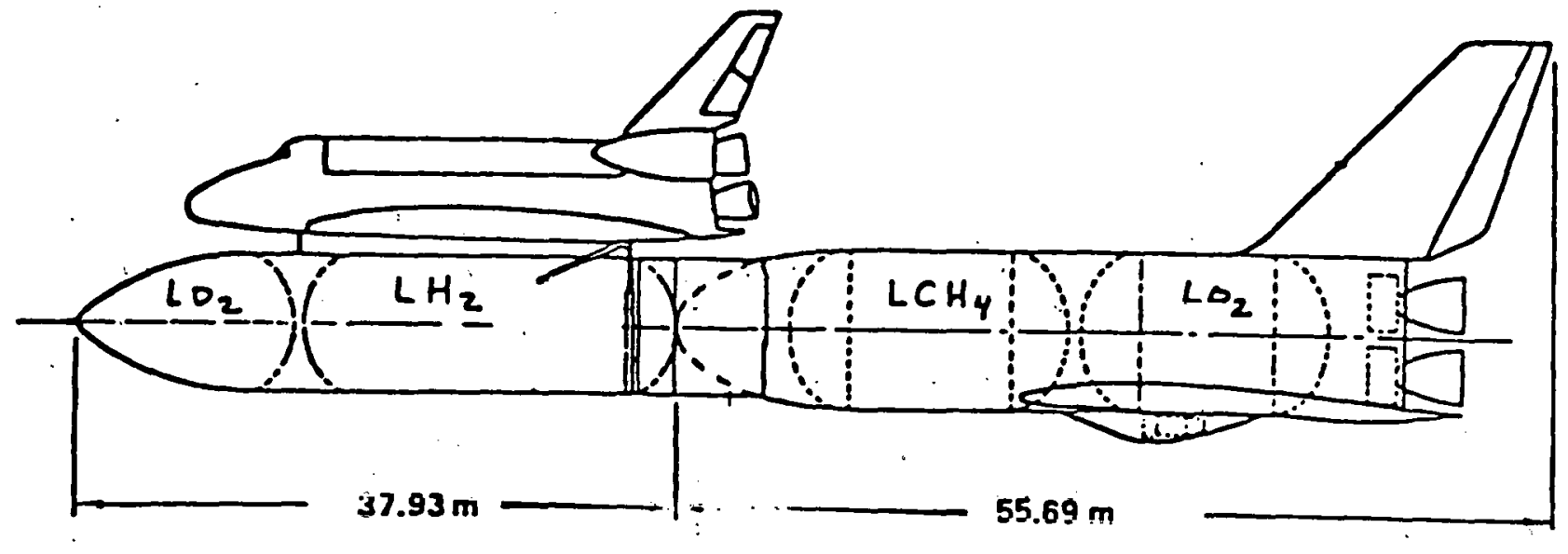

\section{Design Description}

The PLV is a drivitive of the space shuttle system. The vehicle consists of a winged liquid propellant flyback booster that uses four $\mathrm{O}_{2} / \mathrm{CH}_{4}$ engines similar to the HLLV booster engines, a smaller version of the shuttie tank and the space shuttle orbiter. The payload to LEO is 89 MT, compatible with the 80 man payload of the POTV. The vehicle has a design life of 200 flights. The choice of the space shuttle orbiter as part of the PLV minimizes the DUTI\&E costs and permits the average unit cost to be based on a known cost rather than an estimate. 


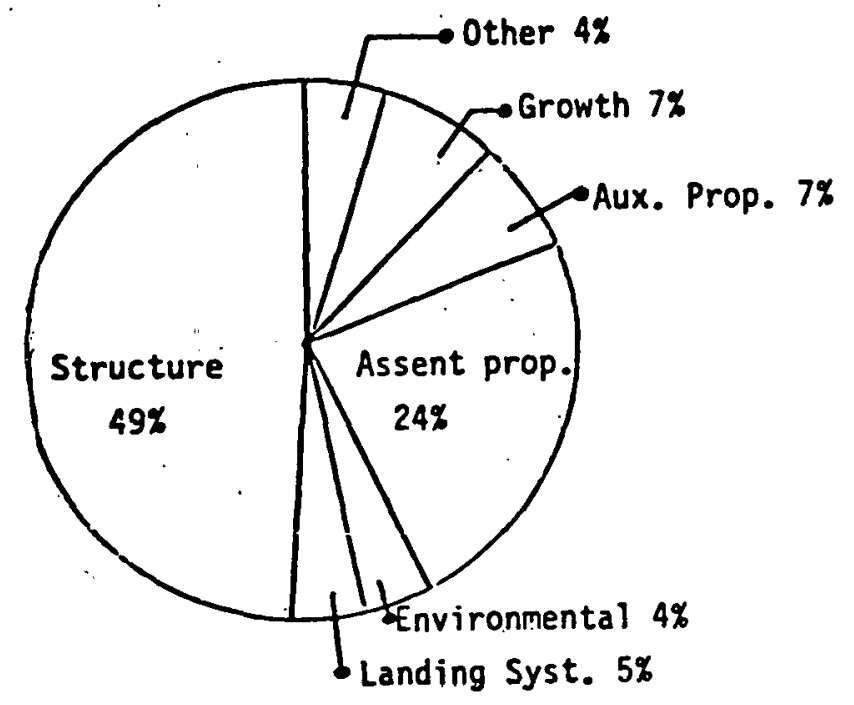

FLYBACK BOOSTER MASS SUMMARY

\section{Item}

\section{Wing}

Tail

Body

Induced Environ. Protection

Landing and Aux. Systems

Propulsion - Ascent

Propulsion - RCS

Propul sion - Flyback

Prime Power

Elec. Conv. and Distribution

Hyd. Conv. and Distribution

Surface Controls

Avionics

Environmental Control

Growth Allowance

Dry Mass

Residuals and Reserves Landing Mass

Flyback Fuel

Inflight Losses
KG

31,940

4,930

68,490

9,050

9,710

51,320

960

13,800

1,190

960

4,230

2,020

1,450

210

16,200

$(216,460)$

12,700

$(229,160)$

26,260

Inert Mass $\frac{3,900}{(259,320)}$

ET MASS SUMMARY

\begin{tabular}{lr} 
Element & \multicolumn{1}{c}{ KG } \\
\cline { 3 - 3 } Structures & 21,146 \\
Thermal Protection & 1,631 \\
Propuls son \& Mech. System & 1,710 \\
Electrical System & 66 \\
ORB Attachments & 1,492 \\
Change Uncertainty & 686 \\
$\quad$ ET Inert Mass & 26,731 \\
Unusables & 1,530 \\
$\quad$ ET Meco. Mass & 28,261
\end{tabular}




\begin{tabular}{|c|c|c|c|c|c|}
\hline MBS NO. & WBS ELEMENT & DDT\&E & TFU & AVU & O\&E \\
\hline 1.3 .3 & PERSONNEL LAUNCH VEHIC̣LE & 2.616 & 790 & 673 & \\
\hline 1.3.3.1 & BOOSTER ṠTAGE & 2.616 & 240. & 123 & \\
\hline 1.3.3.1.1 & STRUCTURES & - & - & & \\
\hline 1.3.3.1.2 & INDUCED ENVIRON. PROTEC. & - & - & & \\
\hline 1.3.3.1.3 & LANDING \& AUX. SYSTEMS & - & - & & \\
\hline 1.3.3.1.4 & ASSENT PROPULSION & - & - & & \\
\hline 1.3.3.1.5 & FLYYBACK PROPULSION & - & - & & \\
\hline 1.3.3.1.6 & OTHER BOOSTER SYSTEMS & 60 & 15 & r & \\
\hline 1.3.3.1.7 & PROGRAM INT. \& MGT. & 77 & 18 & & \\
\hline 1.3.3.2 & ORBITER STTAGE & - & 550 & 550 & \\
\hline 1.3.3.2.1 & STRUCTURES & & & & \\
\hline 1.3.3.2.2 & INDUCED ENVIRON. PROTECT. & & & & \\
\hline 1.3.3.2.3 & LANDING \& AUX. SYSTEMS & & & & i \\
\hline 1.3.3.2.4 & ASSENT PROPULSION & & & & \\
\hline 1.3.3.2.5 & OMS PROPULSION & & & & \\
\hline 1.3.3.2.6 & OTHER ORBITER SYSTEMS & & & & \\
\hline
\end{tabular}


PLV - COST PER FLIGHT

HARDWARE:

$\frac{\$ 670,000 \mathrm{~K} / \text { VHICLE }}{200 \mathrm{FLIGHTS} / \mathrm{VEHICLE}}=\quad \$ 3,350 \mathrm{~K}$
EXPENDABLE TANK $=3,200 \mathrm{~K}$

PROPELLANT:

$\begin{array}{llr}\mathrm{O}_{2} & 1685 \text { TONNES } \mathrm{C} \$ .037 / \mathrm{kg} & 62 \mathrm{~K} \\ \mathrm{CH}_{4} 432 \text { TONNES \& } \$ .39 \% \mathrm{~kg} & 169 \mathrm{~K} \\ \mathrm{H}_{2} 82 \text { TONNES } \mathrm{C} \$ 1.53 / \mathrm{kg} & 125 \mathrm{~K}\end{array}$

REFURBISHMENT AND REPLENISHMENT: $263 \mathrm{~K}$

GROUND OPERATIONS - $\quad 517 \mathrm{~K}$

TOOLING . 116K

MANPOWER 2,300K

PROGRAM SUPPORT 623K

TOTAL COST PER FLIGHT . .... \$10.7M 
WBS 1.3.4 PERSONNEL ORBITAL TRANSFER VEHICLE (POTV)

The Personnel Orbital Transfer Vehicle is a space transportation system designed to transport crews, priority crew supplies, and priority cargo from LEO to GEO. The POTV is also used to transfer crews from the GEO base to an SPS for maintenance.

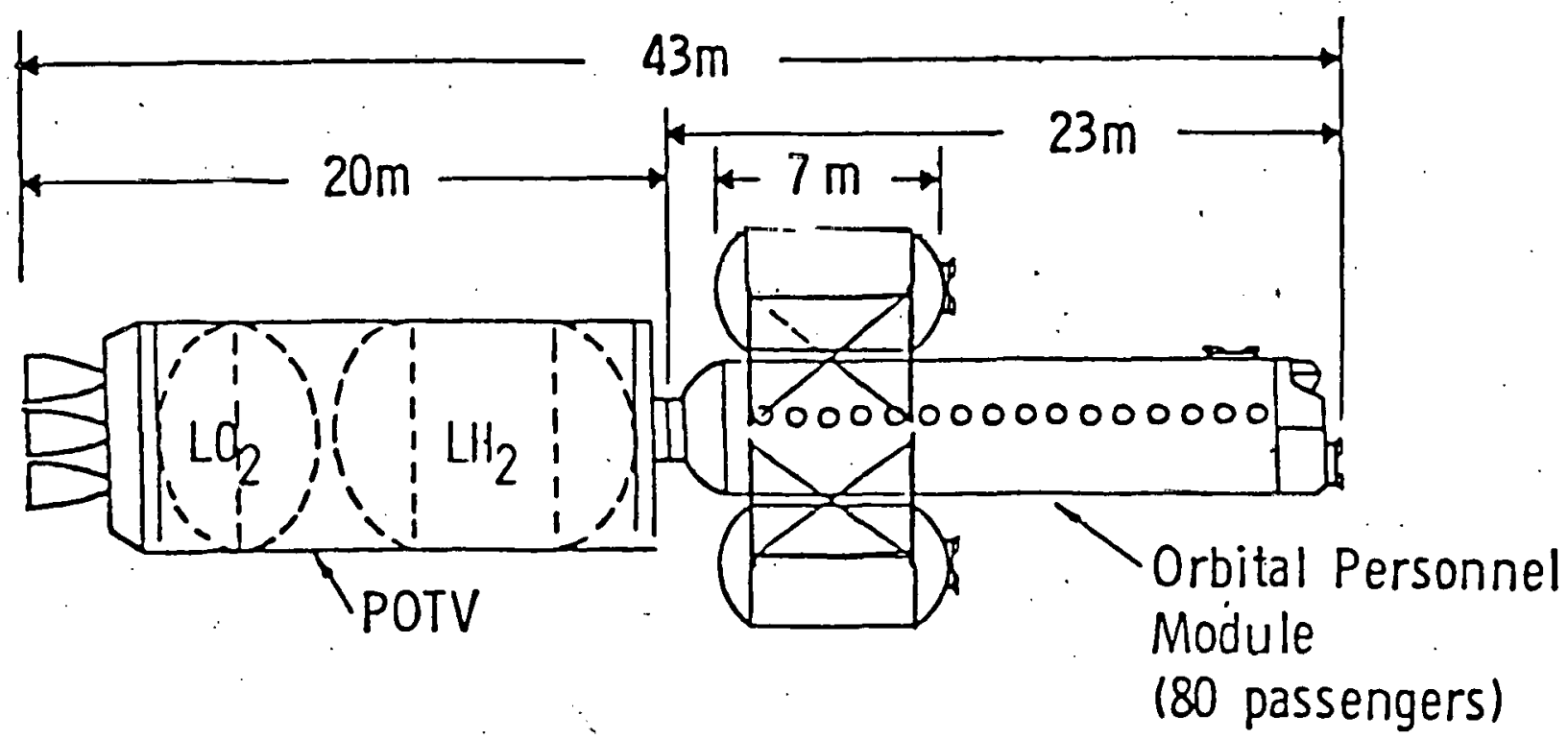

Design Description

The POTV is a single stage $\mathrm{LO}_{2} / \mathrm{LH}_{2}$ propelled vehirle which has the capability of transporting 9O MT of payluad from LEO to GEO with a turnaround time of 5 days. This includes transit time, refueling time, and crew rotation time. The payload is sufficient to deliver 80 GEO workmen and crew supplies for 6,600 man-days. The vehicle has a design life of 50 round-trip flights. Refuel ing is accomplished at GEO with propellant delivered by the EOTV. Five $88 \mathrm{KN}$ thrust staged combustion engines are used for main propulsion. These engines have an $1 \mathrm{sp}$ of 470 seconds. Auxiliary engines with an Isp of 375 seconds are used for attitude control and for low delta-V maneuvers and docking. Electric power is provided by space shuttle-type fuel cells. 
Item

Structure and Mechanisms

Ma in Propulsion

Auxiliary Propulsion

Avionics

Electric Power System

Thermal Control

Contingency (15\%)
$\operatorname{Mass}(\mathrm{kg})$

6,900

2,500

500

300

450

1,030

1,750

13,430

Payload.

90,000

Total Propellant and Fuel Cell Fuel

203,000

Total Start Burn Mass

216.5 MT

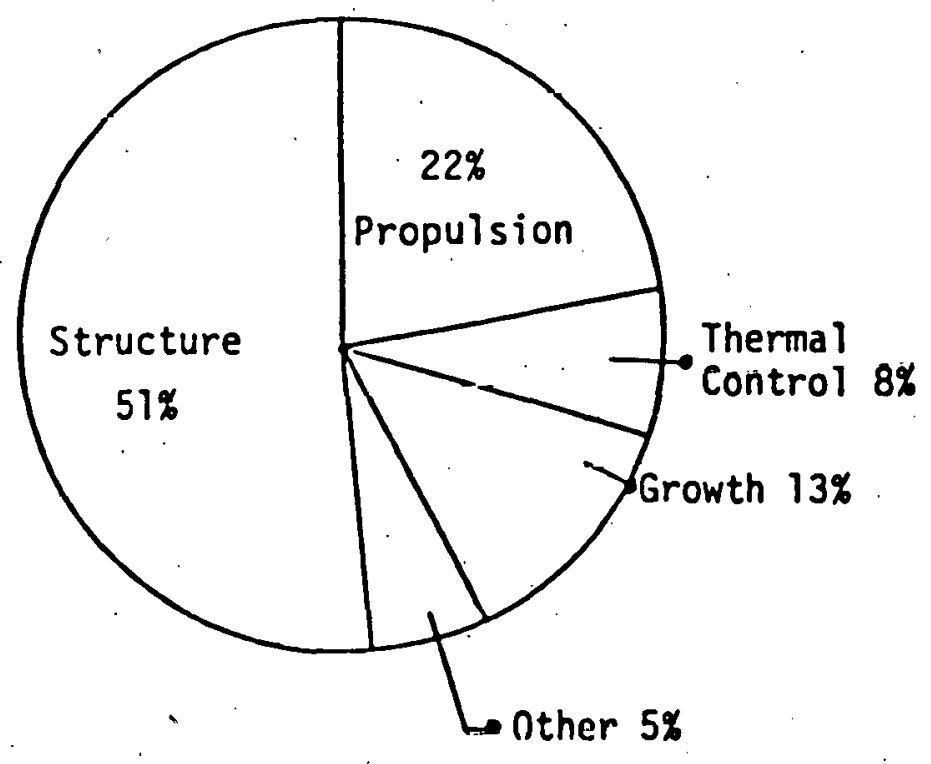




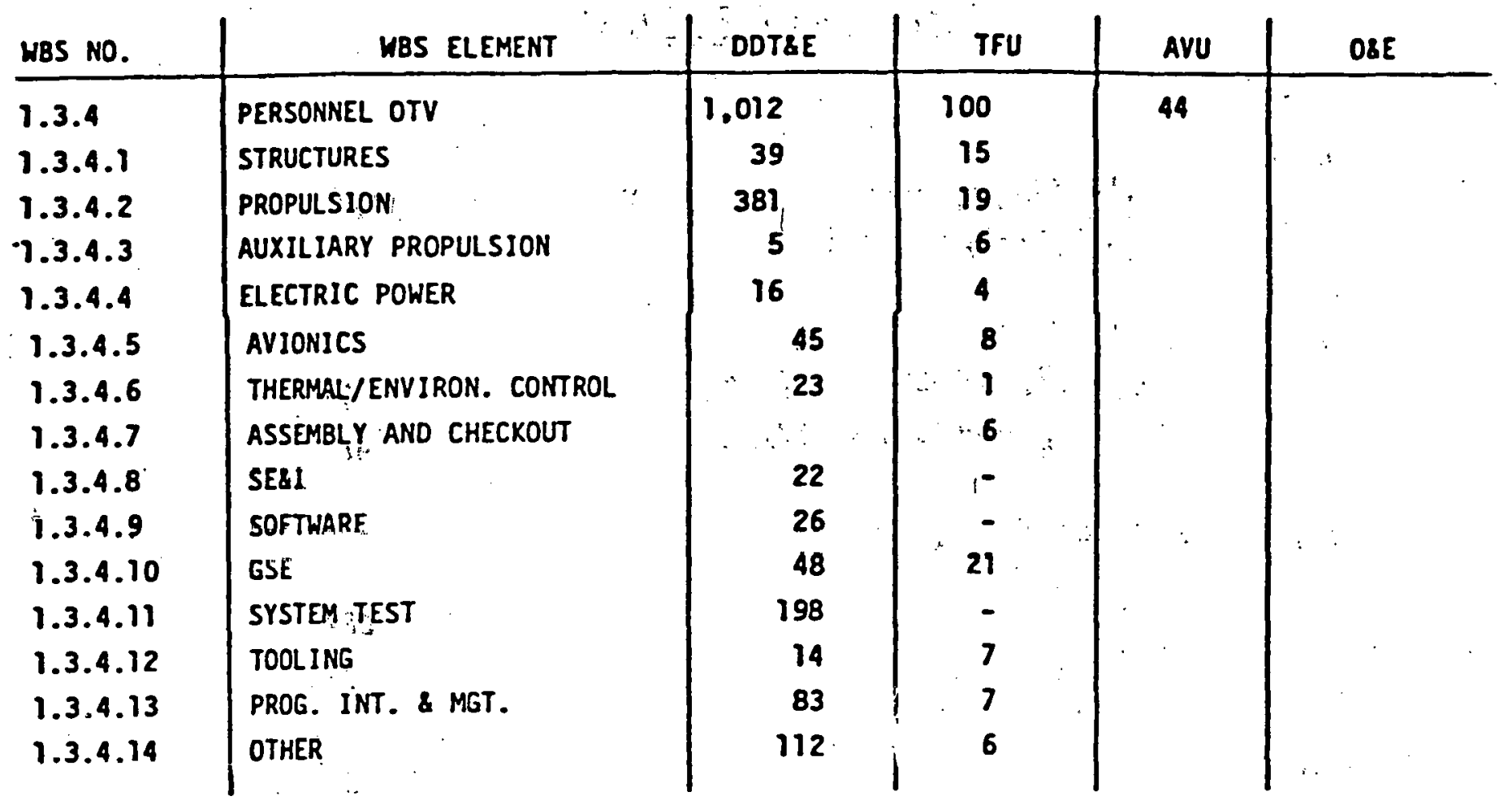




\section{POTV - COST PER FLIGHT}

\section{HARDWARE:}

$\$ 44,000 \mathrm{~K} /$ VEHICLE

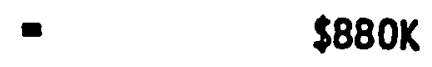

50 FLIGHTS/VEHICLE

PROPELLANT:

$\mathrm{O}_{2} \quad 179$ TONNES $\$ .037 / \mathrm{kg}$

$7 K$

$\mathrm{H}_{2}$ 32. TONNES \& $\$ 1.53 / \mathrm{kg}$

$48 K$

REFURBISHMENT AND REPLENISHMENT

ENGINES

OTHER

TOOLING

GROUND SUPPORT EQUIPMENT

MISCELLANEOUS
BKK

3K

$3 k$

$11 K$

$289 \mathrm{~K}$

TOTAL COST PER FLIGHT ........\$1,309K 
GROUND OPERATIONS AND SYSTEM MAINTENANCE

WBS

\subsection{7 \\ 1.3.7.1 \\ 1.3.7.1.1 \\ 1.3.7.1.2}

\subsubsection{2}

1.3.7.2.1

1.3.7.2.2

1.3.7.2.3

1.3.7.2.4

1.3.7.2.5

1.3.7.2.6

1.3.7.2.7

1.3.7.2.8

1.3.7.2.9

1.3.7.2.10

\subsubsection{3}

1.3.7.4

1.3.7.5
Ground Support Facllities

Launch Facllities

HLLV Launch Facilltles

PLV Launch Facllities

Recovery Facllitles

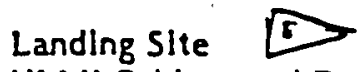

HLLV Orblter and Payload Processing Faclllty

HLLV. Booster Processing Facllity

Englne Maintenance Facllity

Hypergollc Maintenance Facllity

Passenger Offloading Facllity

PLV Booster Processing Facility

PLV Orblter Processing Facillty

Vertical Assembly Bullding

Moblle Launcher Platform

Fuel Facllitles E

Logistle Support 5

Operations

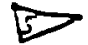

TOTAL ANNUAL

MAN-HOURS

OPERATIONS MAINTENANCE

$(5,174,832)$

DD

$(7,676,714)$

476,800

79,196

862,500

133,616

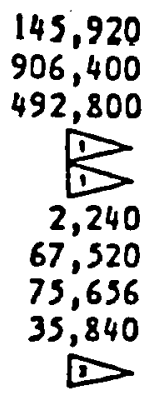

218,880

$1,359,600$

739,200

$\sum_{1}$

3,360

$101,280^{\circ}$

$1,134,984$

36,854

[2]

727,080

823,440

$1,314,000$

$1,971,000$

851,280

292,000

Included in 1.3.7.2.2 and 1.3.7.2.3

Included in 1.3.7.1.2

Total Annual Operatlons Man-Hours = 2,587 Man-Ye.ars

Total Annual Maintenance Man-Hours = 3,838 Man-Ycars

HLLV and PLV Man-Hours

each assume a portion of these items

HLLV Related. Man-Hours

HLLV Related Cost

PLV Related Man-Hours

PLV Related Cost

$4,710,500$
$\$ 0.188 \mathrm{~B}$
464,300
$\$ 0.018 \mathrm{~B}$

$6,075,700$

$\$ 0.243 B(\$ 40 /$

$1,601,000$

$\mathrm{MHr}$ )

$\$ 0.064 \mathrm{~B}(\$ 40 /$ 
DDT\&E

- Heavy Life Launch Vehicle.

$\$ 11,202$

- Cargo Orbit Transfer Vehicle

2,247

- Personnel Launch Vehicle

2,616

- Personnel Orbital Transfer Vehicle

1,012

Total Transportation DDT\&E

$\$ 17,077$

Average Transportation Cost per SPS
- HLLV
$\frac{\$ 10.1 \mathrm{~m} / \mathrm{FLT} \times 11,606 \mathrm{FLTS}}{60 \mathrm{SPS}}$
$=\$ 7,954 \mathrm{~m} / \mathrm{SPS}$
- EOTV
$\frac{\$ 40.7 \mathrm{~m} / \mathrm{FLT} \times 847 \text { FLTS }}{60}$
$=$
$575 \mathrm{~m} / \mathrm{SPS}$
- PLV
$\frac{\$ 10.7 \mathrm{~m} / \mathrm{FLT} \times 1458 \mathrm{FLTS}}{60 \mathrm{SPS}}$
$=$
$260 \mathrm{~m} / \mathrm{SPS}$
- POTV
$\frac{\$ 1.3 \mathrm{~m} / \mathrm{FLT} \times 587 \mathrm{FLTS}}{60 \mathrm{SPS}}$
$=$
$12.7 \mathrm{~m} / \mathrm{SPS}$
Total transportation cost per SPS
$\$ 2,802 \mathrm{~m} / \mathrm{SPS}$ 


\section{REFERENCES}

(1) "Satellite Power System Concept Development and Evaluation Program Reference System Report", U.S. Department of Energy and the National Aeronautics and Space Administration, DOE/ER-0023, (October, 1978).

(2) "Memorandum to NASA Headquarters Attn: RES-1/H. D. Calahan from EA4/Associate Director for Program Development/R. 0. Piland", EW4-79-212, Johnson Space Center, Houston, Texas, (November 14, 1979).

(3) Miller, R. H. and Akin, D. L. "Logistics Costs of Solar Power Satel-rites", IAF Paper 78-186, Space Systems Laboratory, Massachusetts Institute of Technology, Cambridge, Massachusetts, (September, 1978). A suminary of this information alsn has appeared in "Journal of Spacecraft" as a technical note.

(4) "Work B̄reakdown Structure: (1.3) Space Transprtation". Prei iminary Draft Subject to Revision, Johnson Space Center, Houston, Texas, (1979).

(5) "Statistical Abstract of the United States-1977", U.S. Department of Commerce, Bureau of the Census, (September, 1977).

(6) Haglund, et. al, "Solar Sail Technology Readiness Report", NASA Jet Propulsion Laboratory, (July 18, 1977).

(7) NASA "Pocket Statistics History", National Aeronautics and Space Administration, (January, 1976 and January, 1972).

(8). "Delta Spacecraft Design Restraints", McDonnel Douglas Astronautics Company, Huntington Beach, California, DAC 61687C, (May, 1979).

(9) Warmke, J. M., "The. Learning Curve and Its Application", BMI-NLVP-IM76-14, Battelle Columbus Laboratories, Columbus, Ohio (October 20, 1976).

(10) "Economic Data Document 1971" et. seq., BMI-NLVP-DD-3(71), Launch Vehicle and Propulsion Programs, Office of Space Science and Applications, National Aeronautics and Space Administration. [A limited distribution document] 
United States

\section{Department of Energy}

Washington, D.C. 20585
THIRD-CLASS MAIL

POSTAGE \& FEES PAID

U.S. DEPT. OF ENERGY

PERMIT NO. G 20

THIRD CLASS MA:-

Official Business

Penalty for Private Use, $\$ 300$ 